SF 259

.B27

CREAM RAISING

Copy 1

BY THE

CENTRIFUGAL

AND OTHER SYST.EMS

COMPARED AND EXPLĀINED

WITH A FULL DESCRIPTION OF THE PLANT REQUIRED AND HOW TO USE IT, ANI) A CHAPTER ON THE CONSTRUCTION OF ICE HOUSES, ROOMS AND CELLARS FOR COLD STORAGE

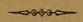

Illustrated with 55 engravings

$\rightarrow \infty$

BY S. M. BARE牟

Professor of Dairying Guelph Agricultural College, Ont.

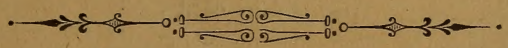

Printed at LE TRAVAILLEUR OfFice, WORCESTER MASS. 
WORK ON DAIRYING

$$
\text { S. N. BARRE }
$$

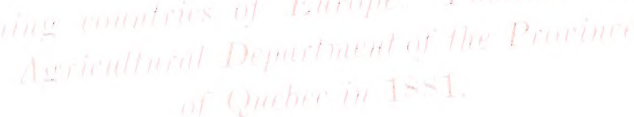

\section{CRTAII RAISTITG}

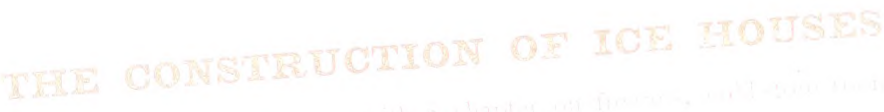

DSSAX ON BTMTER MATKRMG 



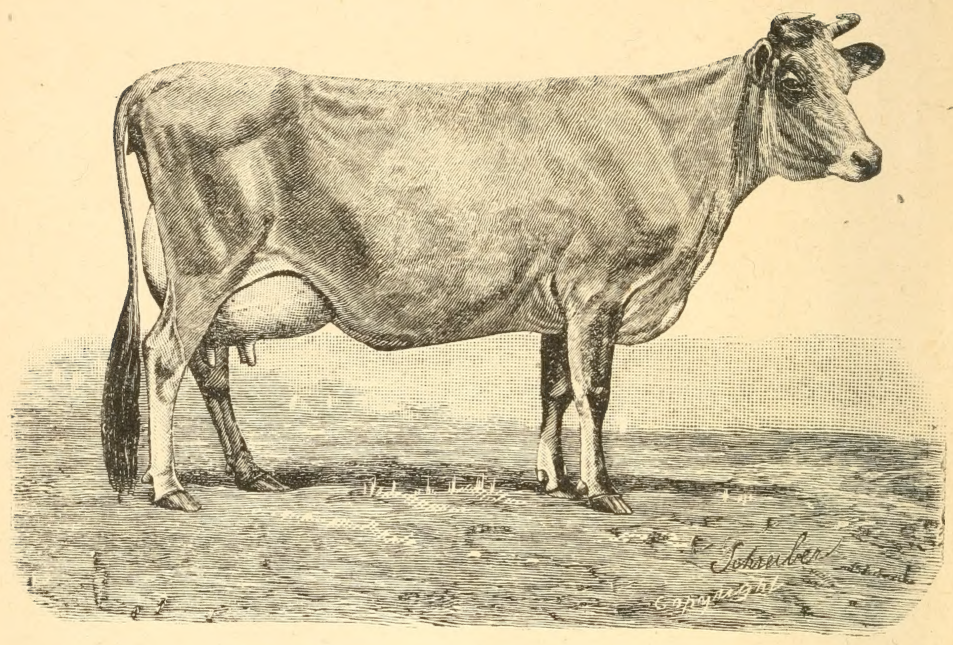

\section{MARY ANI,}

OF S'T. LAMBER'T.

This extraordinary Jers` $\mathrm{y}$ cow, owned by $\mathrm{Mr}$ V. E. Fuller, of Hamilton, Ontario, gave $36 \mathrm{lbs}$. and 12 ounces of butter in 7 days, and $867 \mathrm{lbs}$. and 14 ounces in 11 months and five days. 


\section{CREAM RAISING}

BY THE

\section{CENTRIFUGAL}

\section{AND OTHER SYSTEMS}

COMPARED AND EXPLAINED

WITH A FULL DESCRIPTION OF THE PLANT REQUIRED AND HOW TO USE IT, AND A CHAPTER ON THE CONSTRUCTION OF ICE HOUSES, ROOMS AND CELLARS FOR COLD STORAGE

Illustrated with 55 engravings

FY S. M. BAREF

Professor of Dairying Guelph Agriculluiral College, Ont.
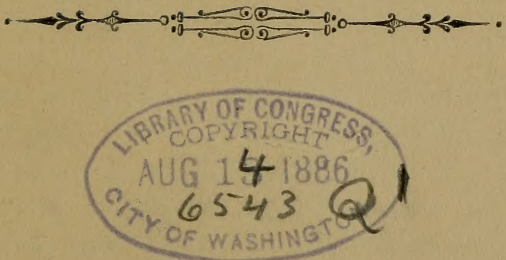

Printed at IE TRAVAILlEUR Office,

WORCESTER Mass.

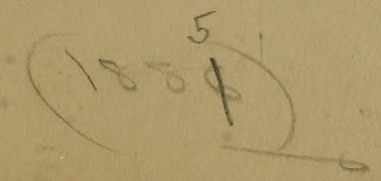


Entered according to Act of Congress in the year 1885, by Ferdinand Gagnon, in the office of the Librarian of Congress at Washington.

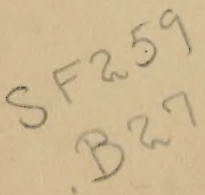




\section{INTRODUCTION.}

This pamphlet has been written to meet not only the requirements of dairy men, but also of the general public. For this reason we have been at considerable pains to make it as clear and comprehensive as possible.

There is no doubt that with the new and improved methods, coming into general use, the butter industry is destined to great development. Capitalists and dairy investors will find it to their advantage to have a book by means of which it is possible to form an accurate idea of the present state of the industry. From the numerous tables given in this work, it will be easy to determine the different yields of different methods, and ascertain which to use in given circumstances.

This work is divided into five parts.

The first part defines and classifies the different methods. It contains a description of the plent necessary for each, with instructions how to use it.-The second compares the different systems and contains remarks on their relative value.-The third is devoted to the centrifugal and contains a mass of practical information difficult to obtain elsewhere.-The fourth treats of what to do with the skim milk.-The fifth treats of the construction of ice houses, rooms, and cellars for cold storage and freezers, and of the storing and keeping of ice or snow.

We cannot conclude without offering our sincerethanks to Messrs. H. C. Petersen \& Co. of Copenhagen, J. D. Fredericksen of Littlefalls, N. Y., Henry Wade, Secretary of the Agricultural Bureau of Ontario, the Knickerbocker Ice Co. of Philadelphia and W. G. Walton of Hamilton, Ont. who have kindly placed the material collected by them at our disposal. 



\section{Cream Rasising by the Centrifiugal and other sygtems,}

\section{MILK.}

"Milk is a fluid in which float about numbers of globules : these consist of fat. When milk is suffered to remain at rest some hours, a large proportion of the fat globules collect at the surface into a layer of cream." (1)

\section{CREAM.}

The cream or butter globules come to the surface, because they are lighter than the watery fluid in which they float.

\section{HEAVY MILK.}

Heavy milk is milk in which the cream rises but very slowly, and in which a large proportion of the cream does not come to the surface at all. The cream from such milk is very thin, and there is no distinctly marked line between it and the skim milk. It is not to be wondered at, that such skim milk, does not look blue, there is often a larger quantity of cream mixed with it than has risen to the surface. In some cases as much as $750 / 0$ of the cream of heary milk remains in the skim milk.

Heavy milk is generally obtained from cows that have calved since a long time, or that are running dry through being in calf, or through other causes.

Milk always becomes "heary" though in a lesser degree, when it is aliowed to cool before setting.

\section{WHOLE MILK.}

This is milk from which the cream has not been cxtracted.

(1) Fowne's Elementary Chemistry. 


\section{SKIMMING.}

In every $100 \mathrm{lbs}$. of milk there is on average $3 \frac{3}{4} \mathrm{lbs}$. of butter fat. (1) The great art of skimming consists in being able to extract from the milk all the butter fat, or any proportion desired, and this without injuring its quality in the least.

\section{METHODS.}

Many different methods are recommended by dairymen, but all can be classified under two distinct heads: 1o. The natural; 2o. The mechanical.

\section{THE NATURAL PROCESS.}

This process consists in employing changes of temperature, to hasten and complete the separation of cream from milk. It is an admitted fact, that the cream rises while the temperature of the milk is falling.

The greater the fall of temperature, the greater the quantity of cream which rises.

The one point upon which dairymen are unanimous, is that milk should be set as soon as possible after the milking (that is when it is still at blood heat), and then cooled down. There is a difference of opinion as to the temperature to which it should be cooled, but the best practical butter makers agree, that it should be just short of the freezing point, 32o Fahrt.

\section{RULE.}

Set the milk as soon after milking as possible, and cool it down just short of $32^{\circ}$ Fahrt.

(1) We say butter fat designelly. If we were to say cream, it would be necessary to make a distinction between thick and thin cream. 


\section{7}

\section{REQUISITES OF THE NATURAI METHOD OF SKIMMING.}

The requisites of this method are:

1o. Milk ressels.

20. Refrigerating tanks.

3o. Ice, or ordinary spring or well water.

DESCRIPTION OF THESE REQUISITES.

1ST MILK VESSELS.

They are divided into two classes : shallow pans, and deep cans.

\section{SHALLOW PANS.}

The shallow pans, as the name indicates, are shallow vessels from 4 to 6 inches deep. They are made of any length and breadth to suit the requirements of the dairyman.

The newest of these are, in reality, double pans between which water is constantly allowed to flow.

\section{DEEP CANS.}

There are many good utensils of this form in the market, but we recommend a round or oval shaped deep can, such as can be had at a low price, at any tin shop, and upon which there is no royalty whatever to be paid. They are of different sizes. 
DIMENSIONS OF DEEP CANS GENERALLY USED.

OVAL SHAPED.

Table No. 1.

\begin{tabular}{|c|c|c|c|}
\hline Contents. & Height, & Length. & Width. \\
\hline $\begin{array}{l}40 \mathrm{lbs} . \\
50 \text { “" } \\
60 \text { “ } \\
65 \\
80 \text { “" }\end{array}$ & $\begin{array}{l}17 \text { inches. } \\
21 \text { " } \\
18 \text { " } \\
27 \\
20 \frac{1}{2} \text { " }\end{array}$ & $\begin{array}{l}16 \text { inches. } \\
15 \\
18 \frac{1}{2} \text { " "6 } \\
15 \frac{1}{2} \\
20\end{array}$ & $\begin{array}{l}6 \text { inches. } \\
5 \frac{1}{2} \text { " } \\
6 \frac{1}{2} \text { "6 } \\
7 \\
7\end{array}$ \\
\hline
\end{tabular}

I recommend for small dairies, 1st. the oval $40 \mathrm{lbs}$. can; 2nd the 50 lbs. 20 inches high by 8 inches diameter, round shaped. Both these cans are easily handled.

They should be made of strong material, have only one smoothly soldered seam in order to facilitate washing. The bottom of these cans rests on a perforated iron hoop, to allow the water or ice to penetrate underneath.

The oval can is the most effective. It offers a larger cooling surface. It is estimated that an oval can will cool $70 \mathrm{lbs}$. of milk, in the same time that a round can would take to cool only $50 \mathrm{lbs}$. 


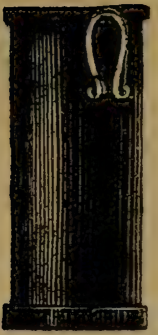

Fig. 1.-The deep round can.

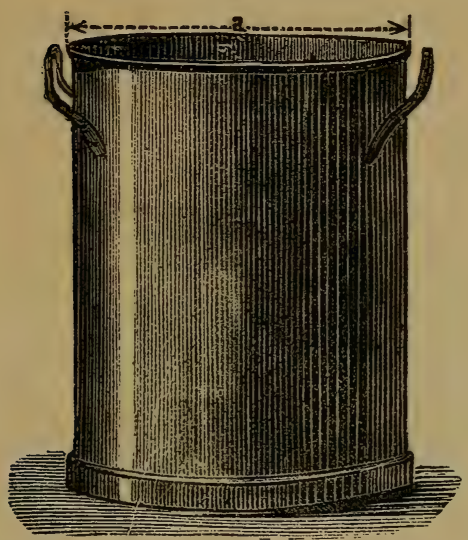

Fig. 2.-The deep oval can.

The deep can used in Denmark has neither covers nor taps. (1) Skimming from the bottom with a tap is not practised in Denmark. A can having no faucet or tap is easier to clean. A tap, placed in a position so as not to hinder the easy cleaning of the milk vessel, is not strictly objectionable.

(1) A cover in not objectionable when the manner of using it is properly understood. 
THE STRAINERS.

The strainers are of wire cloth, and made to fit the cans, (See figs. 3, 4 and 5.)

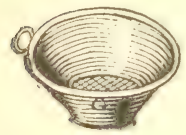

live. 3.

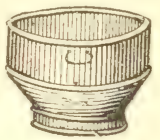

Fier.'s

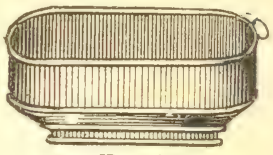

Fig. 5.

\section{REFRIGERATING 'TANKS.}

We give below a description with wood cuts, ol such tanks or refrigerators.

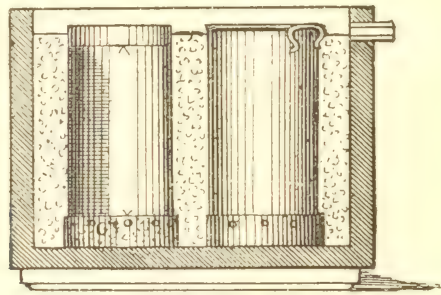

Fin. 6.

Fig. fi represents a sinal size conling tank containing milk cans set in ice.

1)IRECTIONS FOR MAKING COOLING TANKS.

Thes tankis may be made of wood with double sides, and 2 or 3 inches of space left between the sides, filled with chareal, rut straw, saw dust or chaff. Chareoal is th. best. If straw b used, it is necessary that the tank be watertight, or damp pronf, becanse if the water were to leak through, it would soon cause a disagreable smell. 
Otherwise make a water tight box. Bind and steady the angles with iron plates. Line with zinc or tin if convenient. If you do not line, a coat of rarnish or paint, should be given inside, as is done with brewer's vats. This precaution makes them easier to clean.

Tanks No. 7 and 8, could also be adapted to the use of running water, and are provided with inflow and outflow pipes, to allow a constant stream of water around the milk cans.

In the case of a tank for cooling milk to $33^{\circ}$ Fahrt. with water and ice, an outflow tap at the top and another at the bottom, to be used for cleaning purposes, are all that is necessary.

SIZE OF TANIKS.

The size of tanks should be adapted to the number and form of cans to be used.

The tank should be 4 inches (inside measure) higher than the cans used. It should be $4 \frac{1}{2}$ inches (inside measure) wider than the cans used; there should be a space of 5 inches between each can, and between the last two cans and the extremities of the tank.

\section{RULE.}

To find the height of a tank, add 4 inches to the height of the cans to be used. To find the width of a tank add $4 \frac{1}{2}$ inches to the width of the can. To find the length of the tank multiply the longest diameter of the can, by the number of cans which the tank is to contain, and to the product add 5 as many times, and one more, as the tank is to contain cans.

Supposing that six $40 \mathrm{lb}$. oval cans, are to be used. 
An oral can 17 inches high, 16 inches long and 6 inches wide, will hold $40 \mathrm{lbs}$. of milk.

$17+4=21$ inches = Height. of the tank.

$16+4 \frac{1}{2}=20 \frac{1}{2} "$ " $\quad$ Width : $\quad 36+(7 \times 5)=71$ inches length of tank.
$6 \times 6=36 \quad$ "
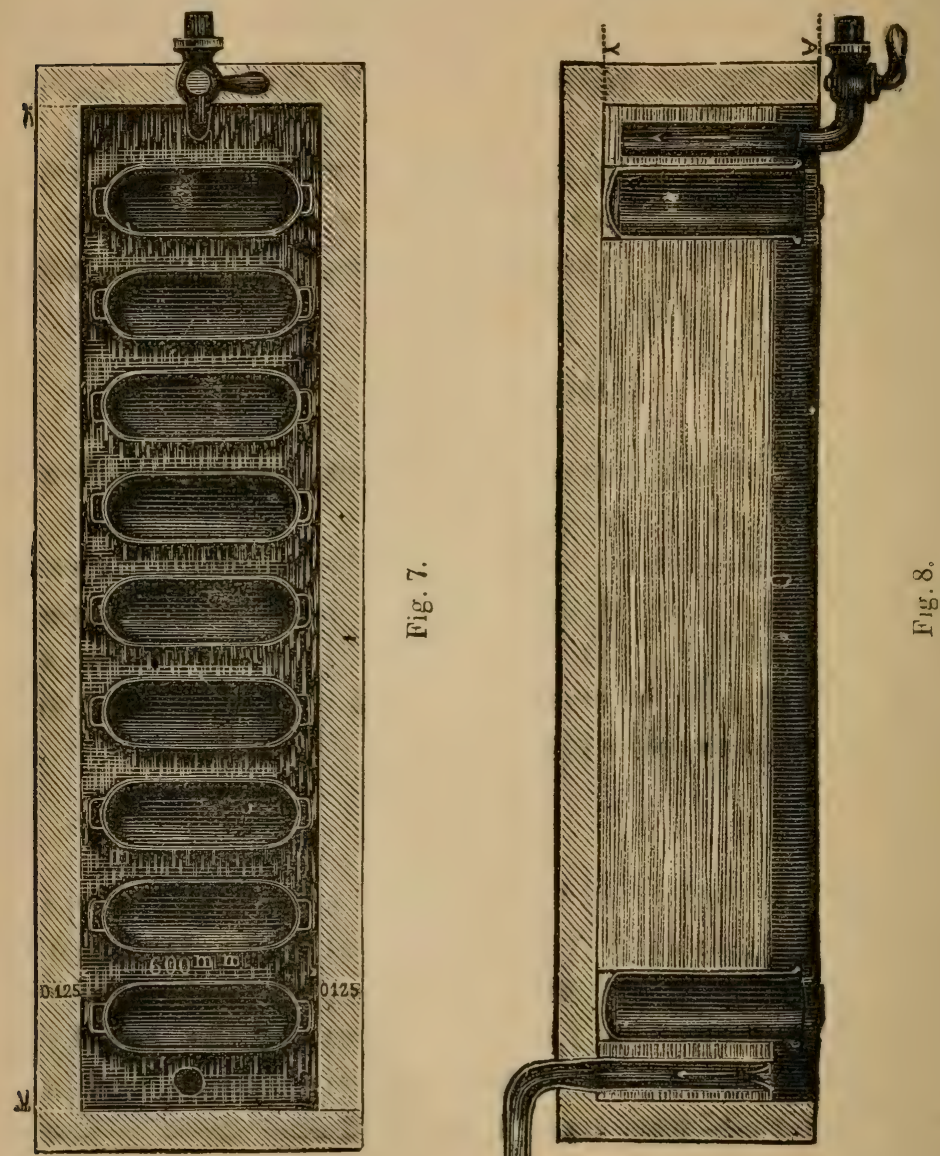

Fig. 7 represents a horizontal view of a tank containing milk cans. Fig. 8 represents a sectional view of same ta:k. 
The tanks may be corered or not. It depends on the room in which they are placed.

In a cool room where the air is pure and temperature uniform a cover is not strictly necessary.

Otherwise it would be advisable to use a corer over the tanks. In any case the use of a cover saves ice

\section{SKIMMERS.}

Skimming from the top, necessitates a specially made

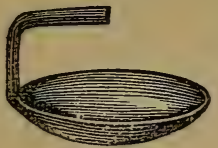

Fig. 9.

skimmer. The skimmers, are round or oval (see fig. 9). They are generally made of enameled iron.

\section{CREAMERS OF DIFFERENT DESCRIPTION.}

CABINET "OR BOX" CREAMERS

There is a great variety of cabinet or box creamers, all being modifications of the deep and shallow setting methods. They consist in general of cooling pails set in a box surrounded by water, some submerged, as in the Cooly plan, and others arranged so as to be surrounded with ice and water, or to hare ice at the top.

Amongst these we find the following:

\section{THE HARDIN.}

Mr. L. S. Hardin is probably the first man who used deep setting in the United States. In his method the 
cans aresetin a hox with lume in front like a cmpboard. It has a shelf on which the ice is placed over the milk,

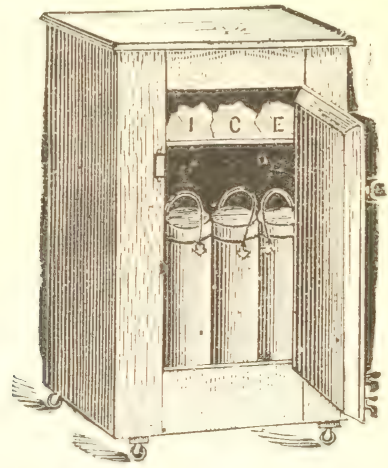

Fig. 10.-The Harlin Creamer.

and a sink on whith the "ans ane set, and which holds the water dripusing from the molted ice. The cooline medium is cold air. (see fig. 10.)

'JHE (OOIN (IAN.

The Cooly is a romm shaped caun with a corer projecting

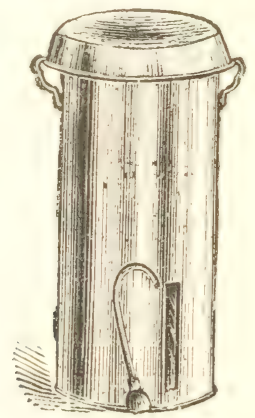

Fig. 11.-The Cooly Milk Can.

outwards, and so arrangerl that the whole may be placed under water. It has also at sperially constructed tap. 
This can is extensively used in the United States and Canada.

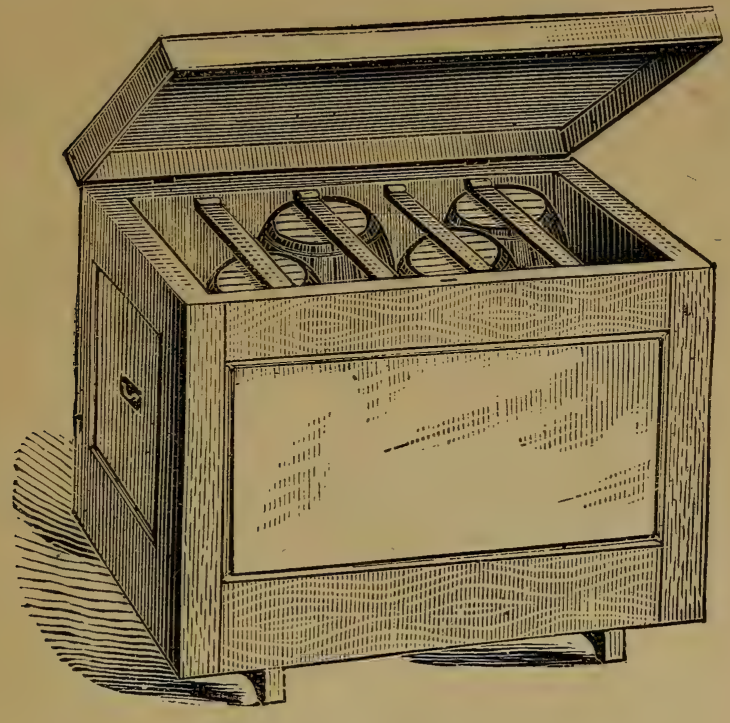

Fir. 12.-The Cooly Creamer.

THE FERGUSON:

Ferguson's Burean Creamer raises the cream on the shallow pan system. Ice is used on a rack in the upper part for the purpose of maintaining a uniform tempe. rature. The arrangement for drawing out the pans to skim is handy.

THE LITTISE GEM.

In this, the corer of each milk ressel is provided with an opening or rentilator.

Openings corresponding to those in the covers of the 
milk vesels are made in the cover of the hox, in order to allow the " animal odor" "to escape. (sue fig. 13.)

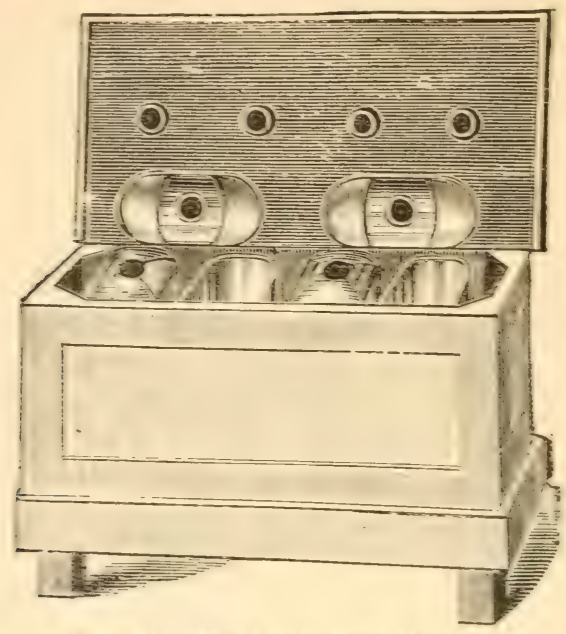

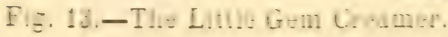

THE REILug:

It cmsists of a pan or tmok which is divided into two compartments an upper and a lower one. The lower

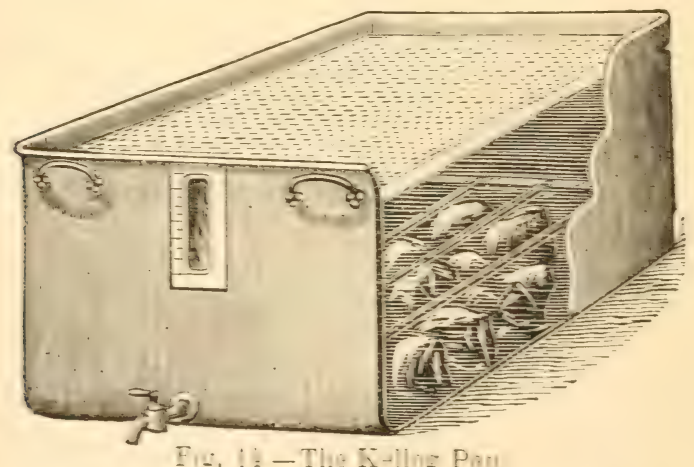

one is filled about one quarter of it: depth with pure 
clean ice. The upper is then filled with milk to the depth of 4 or 5 inches. The skim milk can be drawn by a tap at the bottom.

We also find the "Mosely and Stoddard Cabinet," the "Wooster perfection creamery," the "Excelsior creamer" "Dripp milk cooler and creamer," "Butler's Cabinet creamery," "Clark's Revolving pan" and many others.

The latest plan is to have the cans dropping or hanging into a lower chamber, thereby avoiding lifting and slopping.

\section{THE " HOME CREAMER."}

This is a novelty in construction. The milk is cooled by pumping cold air through it and this is effected in warm weather by drawing the air from a well through rubber pipes attached to the pump. The air tight compartment, where the milk is is then closed, and the air exhausted by the pump so that the cream is raised in vacuo.

\section{THE " MARQUIS PAN"}

This is another more recent apparatus for raising cream on the deep setting principle.

In its general appearance it is an oblong vat with rounded bottom, with a cylindrical tube of tin passing lengthwise from end to end through the middle. The cylinder is placed below the cream line. This cylinder has an inner cylinder and pipe for carrying off water. Cold water is forced by a pump through this cylinder and the refrigeration of the milk is of course rapid. This vat, or one similar to it in construction is used in a great number of creameries. 


\section{TIIE (REAM (}

The main teature of this syotem is that each farmer sets the milk. in ressels of miltorm size and shape, in his own dairy. It is skimmed by the cream gatherer, who is employed, and sent out daily by the creamery.

\section{VESSLLA REQUIRED TO SET THE MIRT.}

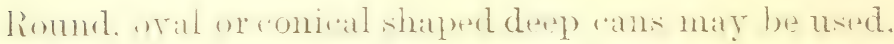
But firmers semeling creann 10 one ereamery shonld all hate resiole of sane size and form. In the side of the

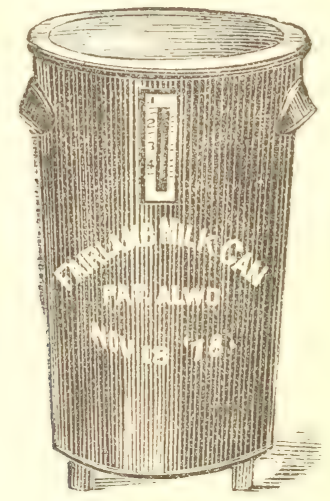

live. Ii,

(and two or three inches from the top, lis lixed a glass graduated seale. This seale graduated in inches and parts of in hese indieates the diriding line between the eream and the skim milk. and enables the cream gatherer to see at a chance the thickness of cream, and to measure the quantity to be credited to the acromut of each farmer. (See fig. 15.) 


\section{ICE BREAKERS.}

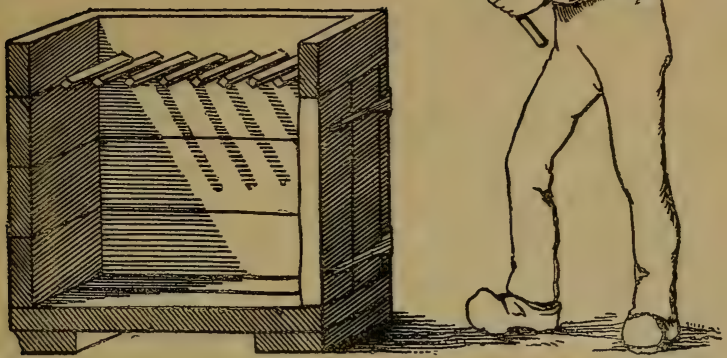

Fig. 16 -Section of box specially constructerl to break ice.

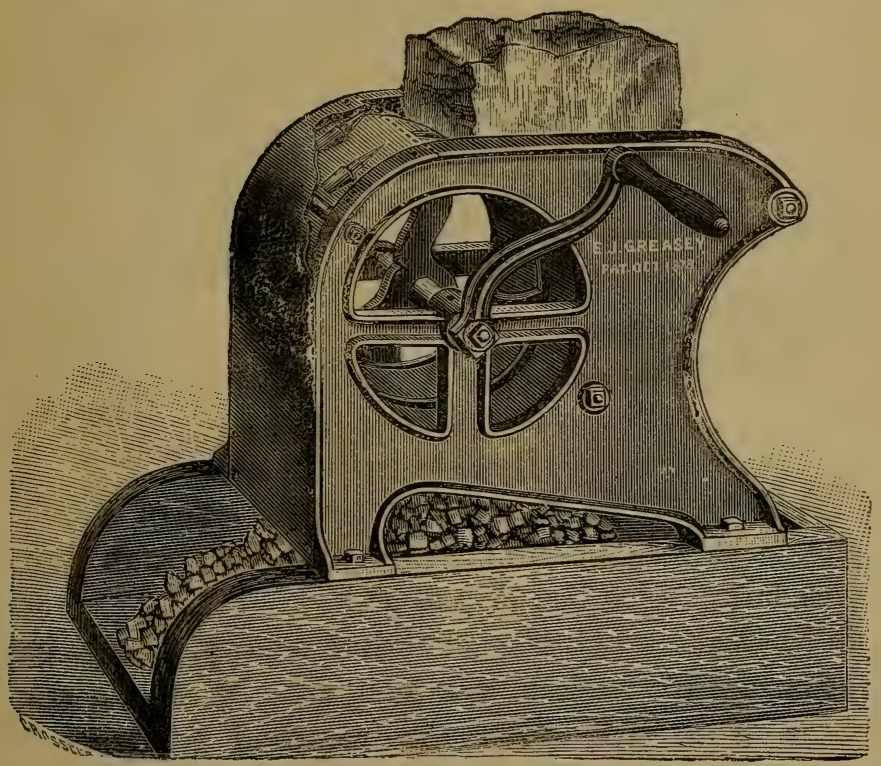

Fig. 17.-The Greasey hand Ice breaker. 


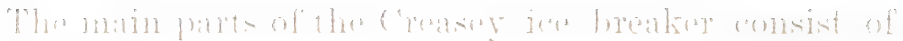

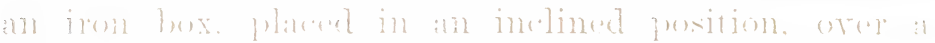

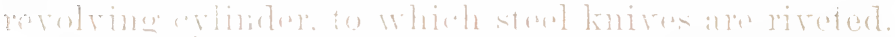

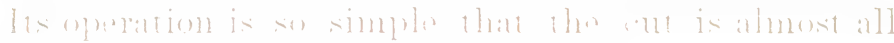

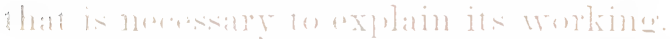

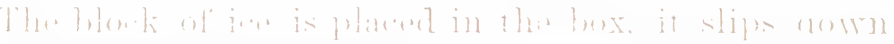

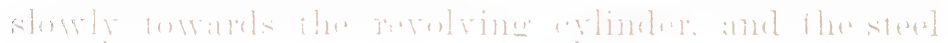

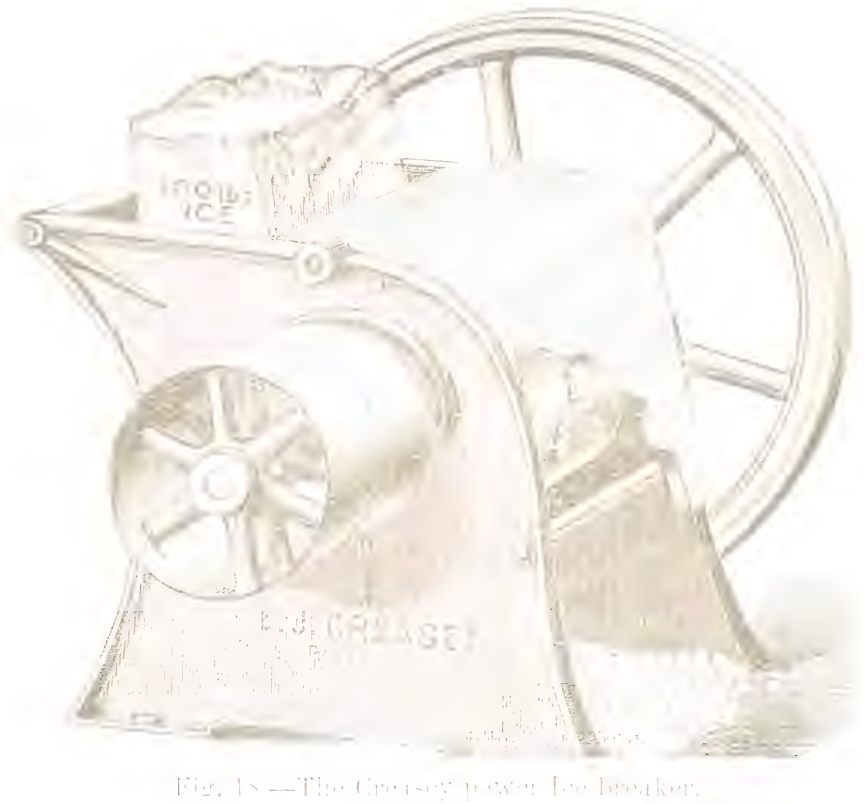

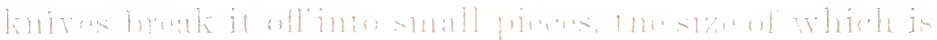

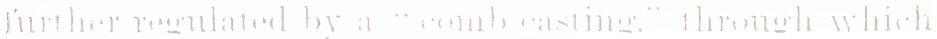

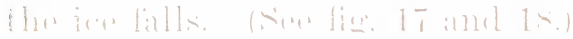

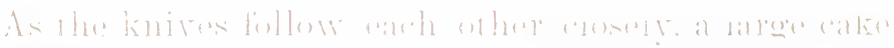

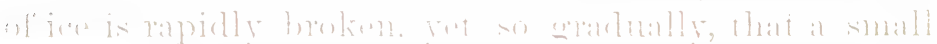

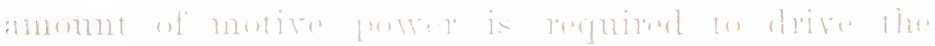
bireakere 


\section{DIFFERENT WAYS OF USING THE NATURAL} METHOD.

While dairymen agree as to the theory, that milk should be set at $98^{\circ}$ Fahrt. (or blood heat) and cooled down, they differ as to the vessels to be used, as to the cooling medium to be used, some taking ice, others water ; they also differ as to the length of time during which it is necessary to let the cream rise ; these differences, in the use of the natural method, are designated by different names.

Thus we have, the "Ice 10 hrs." plan. This means, that the milk was set in deep vessels and remained in ice during 10 hours.

Again there is the "Ice 34 hours" plan. This, indicates that the milk vessel was deep, the cooling medium was ice, but that the time instead of being 10 hours, was 34 hours. Another plan is the "Water at $50^{\circ}$ Fahrt. 34 hours". In this case the milk is also set in deep ressels, the cooling is done by means of water at $50^{\circ}$ Fahrt. and the time was 34 hours. There is also the "Shallow pan 34 hours " plan. In this, the milk is set in shallowpans, is cooled to $55^{\circ}$ Fahrt. and remains at that temperature 34 hours.

Still another plan is the "Churning of milk". This plan, consists as its name expresses in churning the whole milk.

\section{THE MECHANICAL PROCESS.}

The mechanical process consists, in depriving the milk of its cream by centrifugal force.

Centrifugal force is a force of nature, by which an 
object revolvin around a given enutr is continually trying to break away from that centre.

If the object. which is revolving, is a vessel containing

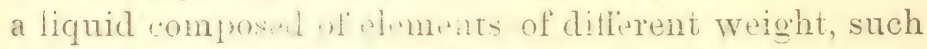
as milk, these elenencs will separate and arrange themselves atcording to their wight ; the heavier ones will be further from the centre, th: lighter ones nearer.

Milk as ahready "xplained, is a liquid containing elements of unequal widht, nanely cream and a watery liguid somewhat hravier ; therefore if milk is placed in a ressel which is male to rewhe, it is crident that the seram, the watry liquid, and any impurities the milk contains, wil! separate and form then listinet rings. The inpuritim l wing hariest will form the ontside one, the skim milk will fin the next. and the crenm being the lightest of all will be rowst to the centre. This is the principle apon whith all cutriligal separators are construted; the linkmes between thrm. are differences of detail.

W. shall now wive ents of sereral of them, with a complete and dotailen dineription of those which are generally used in America. 


\section{DESCRIPTION OF MILK SEPARATORS.}

The Burmeinster \& Wain Centrifugal Milk SepaRator, KNown as Danish Weston in the UNited States.

This Separator, whose action is continuous, consists of a hollow steel drum revolving on a vertical axis. This Separator differs from others in the manner of removing the cream and skim milk. Two curved metallic tubes (see fig, 19) are used which are screwed on and curved around the safety cap of the drum, without interfering with its working. These tubes draw up the cream and skim milk from their respective receptacles. They are pointed at the ends, and are inserted one, in the inside surface of the cream ring, and the other in that of the skim milk ring (see fig. 22). They are moved to and from the centre of the drum, thereby cream of any required thickness (from the consistency of butter almost, to the consistency of milk) can be obtained while the machine is working. The drum has attached to its inside, three vertical flanges extending 5 inches towards the centre. These flanges extend from the bottom, almost to the top. They serve a double purpose. 1st They prevent the milk from revolving independently of the drum. $2 \mathrm{~d}$ They serve to support the cream cover. The cream cover is a horizontal flat ring of metal which rests on these vertical flanges ; it does not touch the sides. Its use is to keep the cream and skim milk separate at the out flow. 


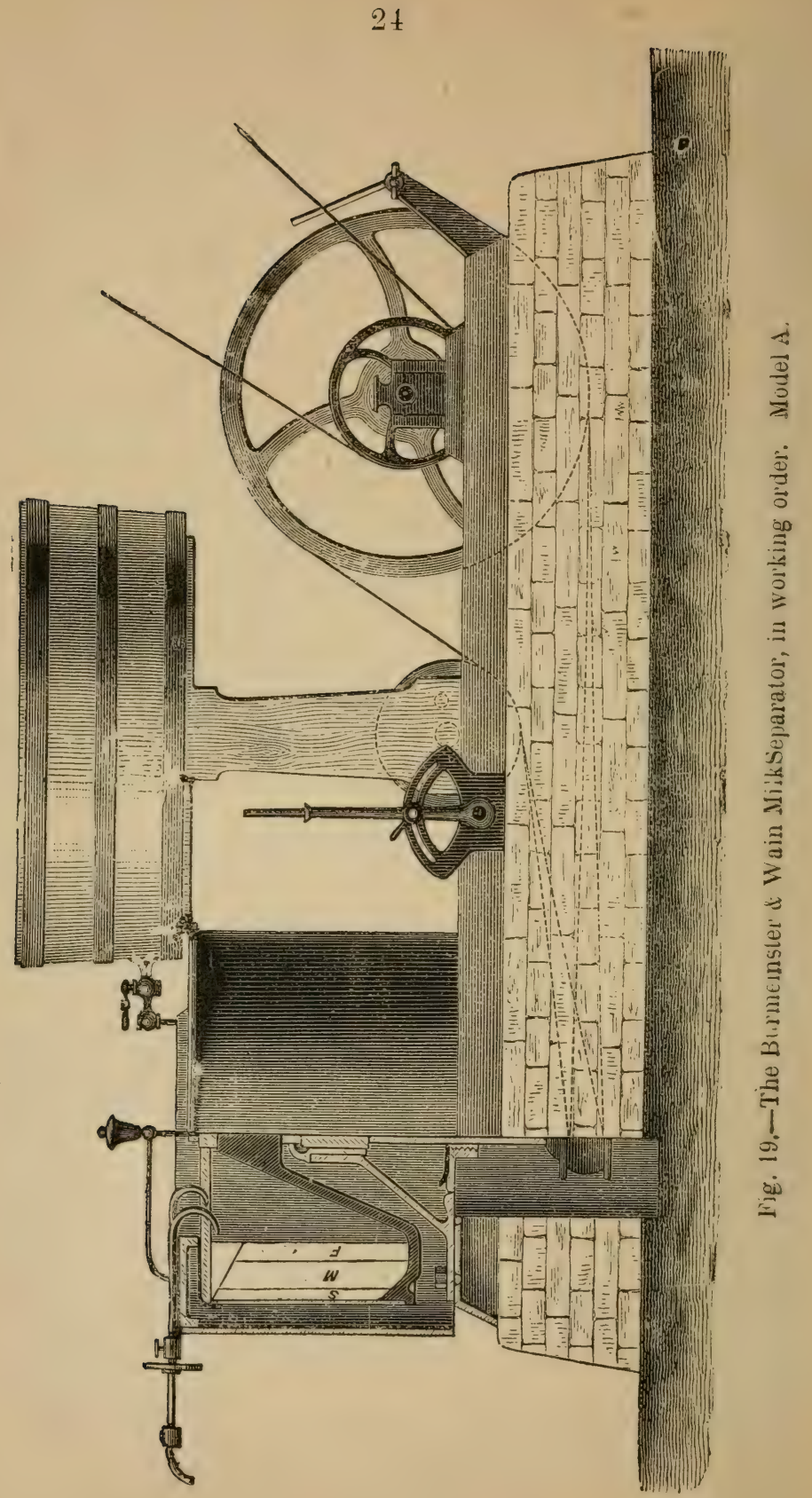


These machines are made of different sizes and capacities. According to Prof. Fjord's experiments, the A size can skim $1200 \mathrm{lbs}$ of milk per hour, with a speed of 1800 revolutions per minute. As the speed of this Separator has lately been increased to 2300 revolutions per minute, it is evident that it can now shim a much larger quan-

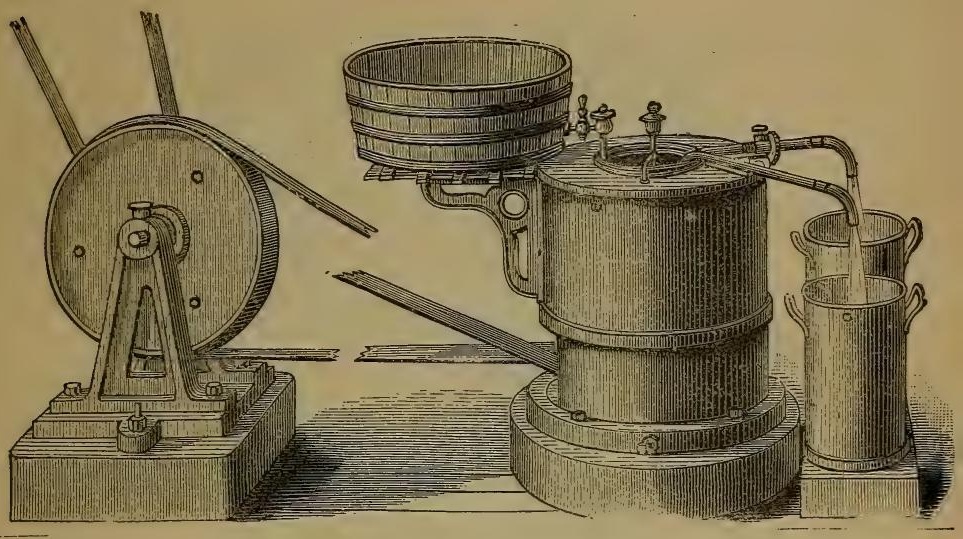

Fig. ?0.-The Burmeinster \& Wain Milk Separator in working order Model, AA

tity of milk than 1200 lbs per hour. (See Chapter on comparison between different separators).

The $B$ size is calculated to make 3000 revolutions per minute. According to the result of Prof. Fjord's experiments, it will skim, 700 lbs of milk per hour and leare $0.250 / 0$ (1) of butter fat in the skim milk.

The B size is built after the A.1. Model.

The latest improrements on this machine consist of a speed indicating apparatus, pipes for lifting fluid, d.cl, fig. 22, and a controlling fumnel showing the quantity of milk flowing into the machine. (see bb, fig. 22.)

(1) 4 ounces in the shim-nilk obtained from $100 \mathrm{lbs}$. of whole milk. 


\section{6}

The controlling funnel consists of a tin vessel 5 inches high, to which are attached two conical tubes, through which the milk enters the drum of the Separator. (See a, b, c, d. fig. 21 and b, b, fig. 22). By elevating or lowering two vertical cylindrical rods, placed $1 n$ the conical tubes

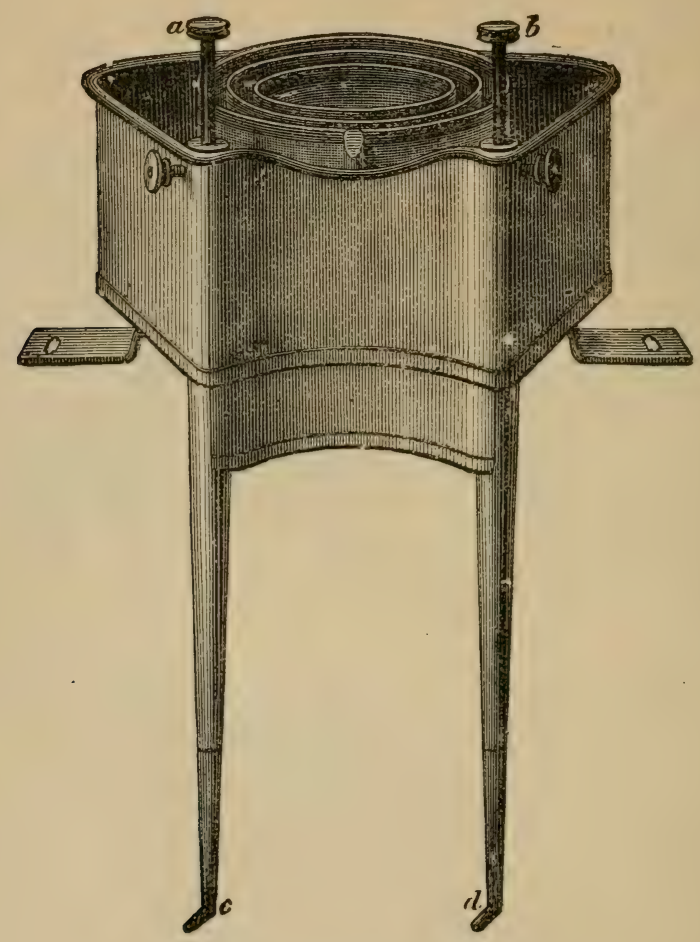

Fig. 21.-Controlling funnel.

the fiow of milk is increased or decreased at will. A graduated scale situated at the upper end of the vertical rods, indicates the quantity of milk flowing per hour into the machine. (see fig. 22). 
Fig. No. 22 represents a sectional view of the drum of the separator and also the milk regulator. It shows how . the skim milk, by means of an elevating tube may be raised by centrifugal force, as high as 8 feet or more, and

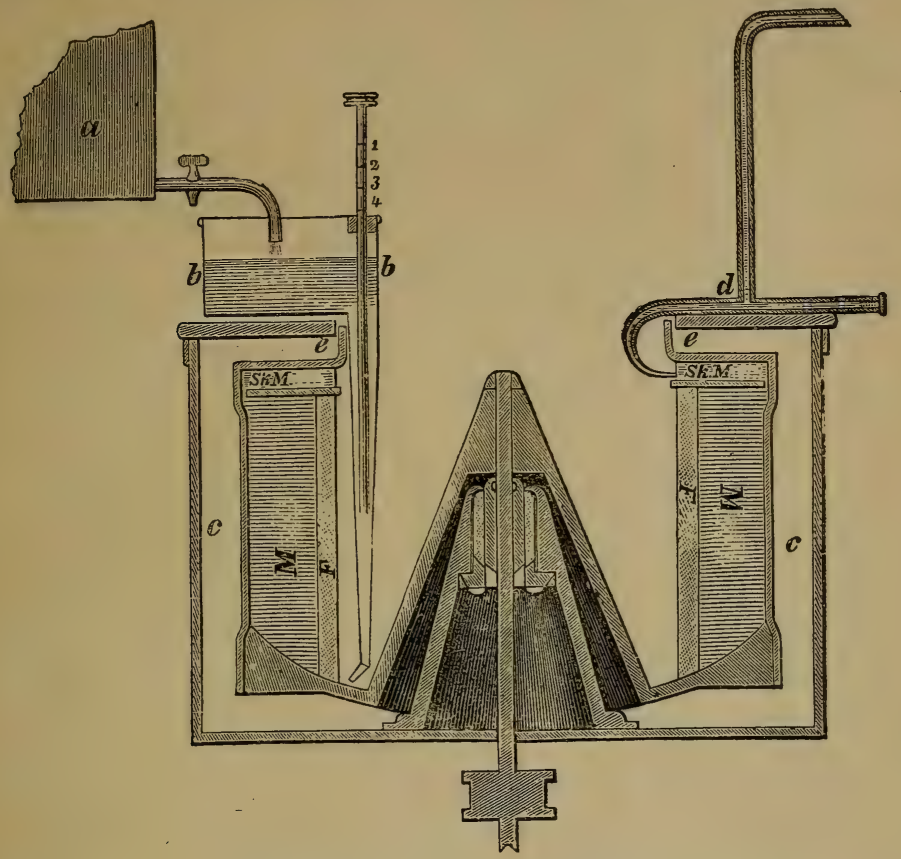

Fig. 22. - Section of the Separator.

a, Milk vat ; b, Ciontrolling funnel ; c, Sxfety Jacket ; F, Ciream ; SKM. Skim milk; d, Tube for removing the skim milk.

led into a cheese vat, reserroir, or to a great distance away from the factory or dairy, to a barn, piggery \&c. The cream may also be raised in a similar manner, and led into a cooler specially made for this purpose.

HOW THE MACHINE WORKS,

The new milk is placed in a milk vat (a. fig. 22) and 
flows through the controlling fumel (b. b. fig. 22) into a drun, which revolves rapidly; the centrifugal force thus generated, separates the different substanees according to their waght. The impurities being the heaviest, collect upon the sides of the drum. The skim milk next in weight collects next, and by a constant inflow of new milk, it gradually rises to the top, where it is stopped by the corer and forced into the onthow pipe, by a constant inflow as well as by centrifugal force.

The cream collects in a wall upon the immer surface of the sim milk, and flows in a constant stream throngh another tube similar to tube d. From the above deseription it will be seen that once started it works continuously untii the whole amount of milk is separated.

\section{TIIE SIIMMING OF THE FIRST AND TAST MILK}

CONTAINED IN THE SEPARATOR.

These operations require care and attention. With the bormeinster \& Wain separator they are dow in the following manner :

\section{FIRST CONTENTS.}

After filling the drum at lull, the machino is started slowly, and the milk is allowed on run ino the drum at the ordinary llow, until it reaches the shimming tubes.

The tubus must then be regulated in such a manner as traw defe cream. It must be rememberen that benl the mbes draw ofl' (ream at the begiming. But the

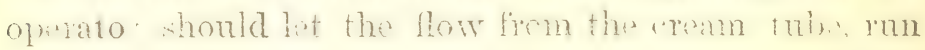
into the cream receiver, and the flow from the other 
tube (although it is cream and partially skimmed milk) run to the skim milk receiver.

The flow should now be considerably checked, and should remain so until one fifth (1) of the first contents has been drawn off. At this point the milk is allowed to enter the drum at the regular flow. The tubes are then regulated so that from 18 to 20 olo of the contents of the drum shall be drawn off in the shape of cream.

The machine is now in full operation.

\section{THE LAST CONTENTS.}

When the whole milk vat is empty, there remain but the last contents of the drum to be skimmed.

1st Partially unscrew the skim milk tube so as to check entirely the skim milk flow, and keep up the cream flow until the end of the operation. To displace the last contents, allow an intermittent inflow of skim milk. The quantity of skim milk necessary, is equal to one-fifth of what the drum is capable of containing while in operation (2). This operation takes from 10 to 15 minutes.

A great number of these separators are now in successful operation in different countries of the world. The Danish manufacturers being anable to supply the demand, they are now manufactured in the United States by the Philadelphia creamery supply Co. under the name of Danish Weston, and in Canada by Messrs. Garth \& Co., Montreal, under the name of Burmeinster \& Wain.

This Separator was introduced into Canada in the

(1) This one-fifth which is composed of cream and partially skimmed milk, should be thrown back into the whole milk vat, to be skimmed anew.

(2) The drum of the large size contains $130 \mathrm{lbs}$, of small size, 33 lbs. 
spring of the year 18.2, hy a publis spiriter centleman of Beauce, Mr H. J. J. Duchesnay

THE DE LAVAT, MILK SEPARATOR.

Fig. 24 wive an ontside virw of the mathine when in operation. The standard and bet-plate are in one

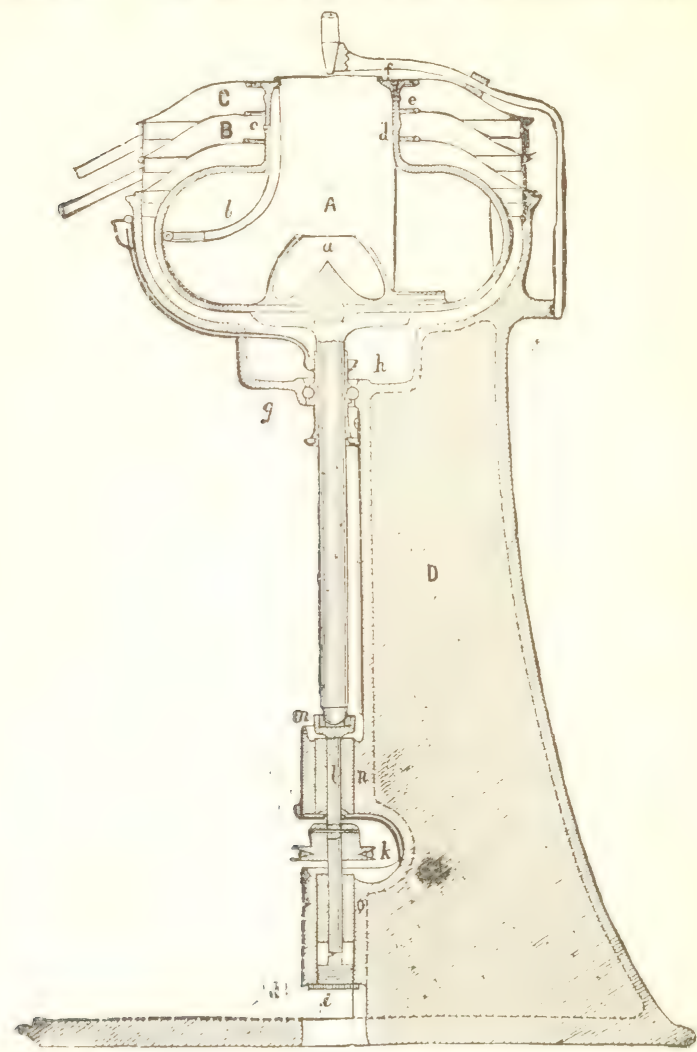

Fig. :3 - Sectional rinw of the I) Laval Separator.

piece, so that the whole can be at once attached to the floor of the dariry, or to the fimme of the intrinediate machinery. Its action is also continuous. 
31

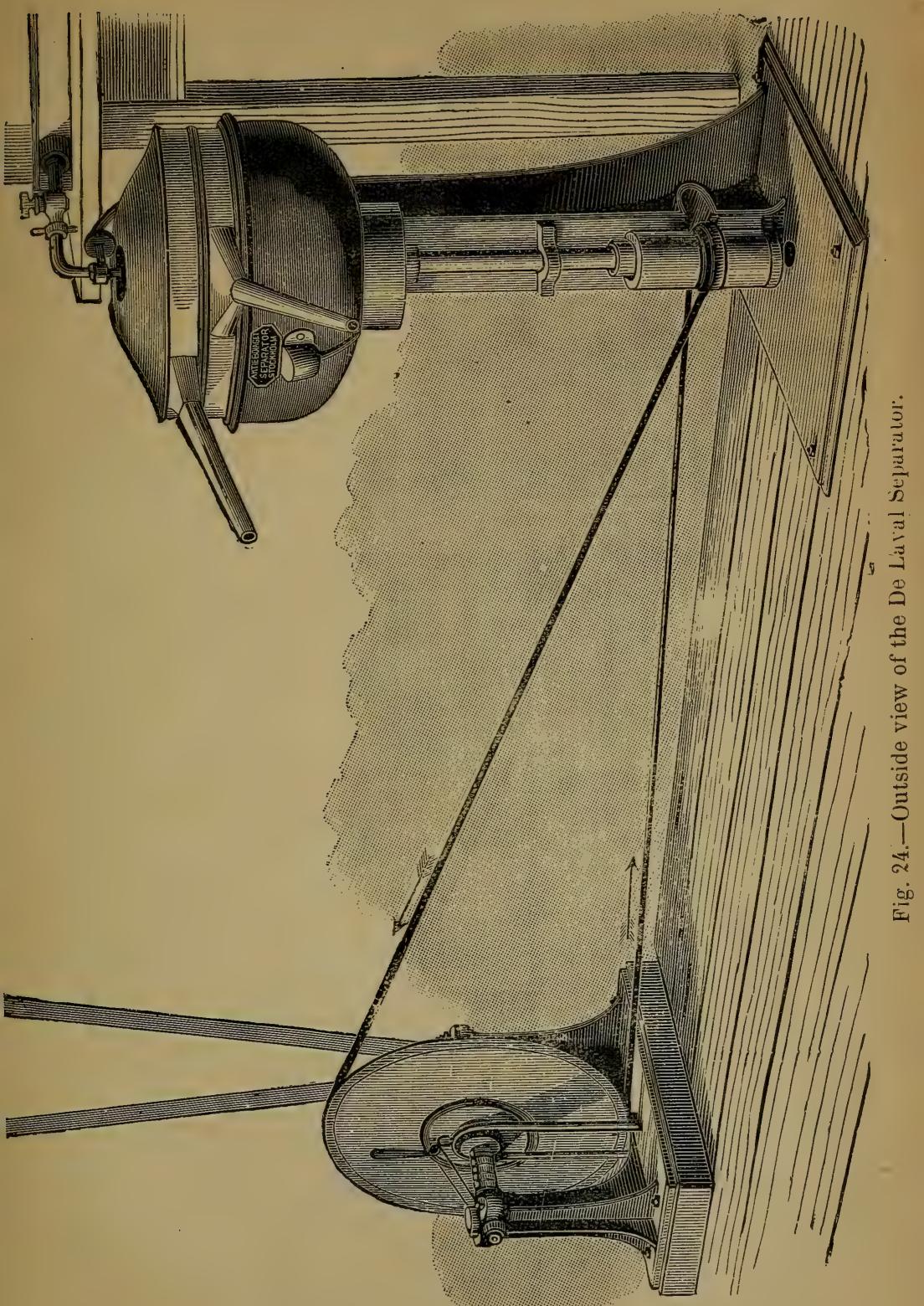




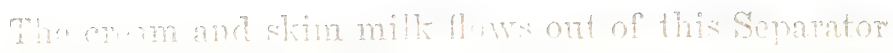

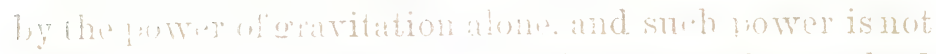

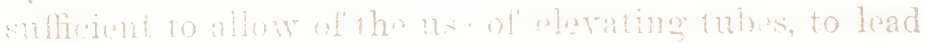

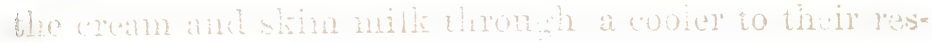
poctive pussuls.

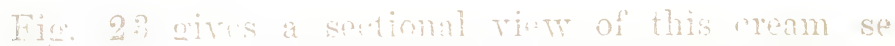

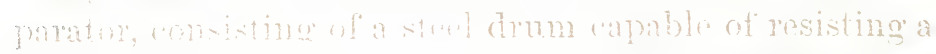

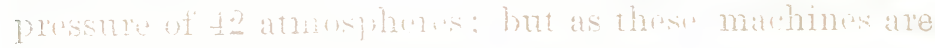

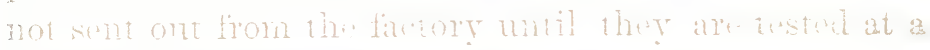
Jifesine of

The mathine is troplect in the following monner.

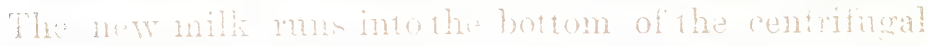

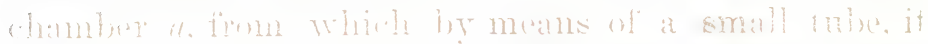

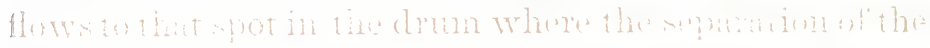

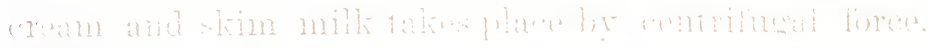

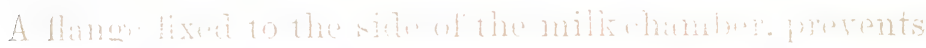

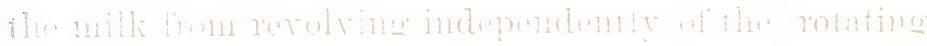

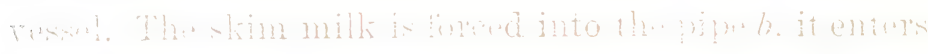

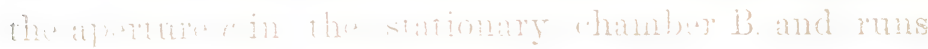

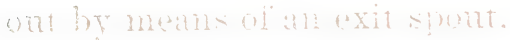

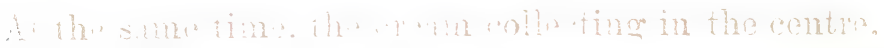

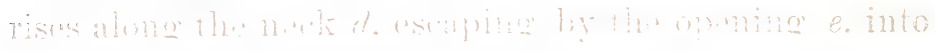

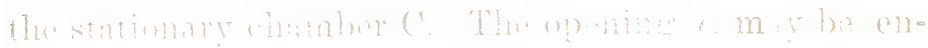

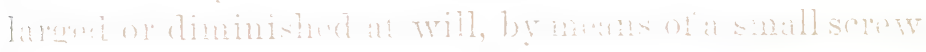

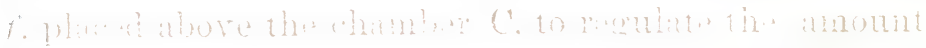

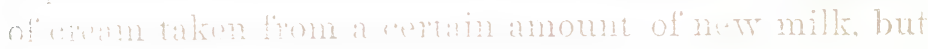

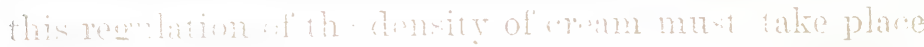

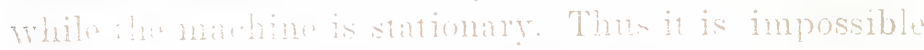

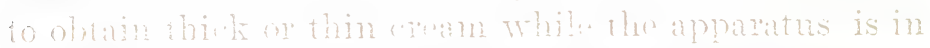

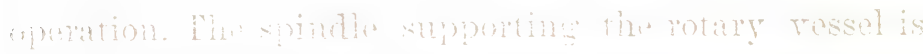

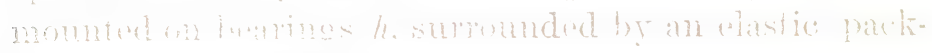

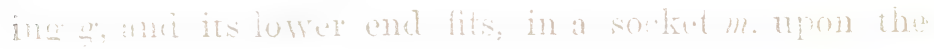


upper end of the shaft $l$, which is mounted on bearings, and is set into motion by a belt or band $k$.

The stand D supports the machine which requires no heavy foundation.

A small iubricating cup attached to the lower part of the spindle, gives through a pipe a constant supply of the oil required for lubricating the spindle,

The milk drum is driven at the rate of 6000 to 7000 revolutions per minute, and according to Prof. Fjord's experimental test, will skim from 600 to $700 \mathrm{lbs}$. of milk pei hour, and leare from 0.25 to 0.30 olo (1) of butter fat in the skim milk.

This separator made its first appearance in Canada. during the winter of 1884 . It is quoted at $\$ 260.00$.

THE LEFELDT MILK SEPARATOR.

A full description of this separator was given in my report to the Minister of Agriculture of the province of Quebec, in 1881. In the same year, it was tested by Prof. Fjord, and found to loose 0.85 o/o (2) of butter fat during erery hour of its working. This loss was caused by the suction of cream by air into the skim milk, The last contents of the drum could not be skimmed completely. We do not know whether these defects hare been remedied or not since.

(1) From 4 to $5 \frac{1}{2}$ ounces in the skim milk obtained from $100 \mathrm{lbs}$. of whole milk.

(2) This is $13 \frac{1}{2}$ ounces 
In this machine, the consistency of the cream cannot bir regulated while it is in operation. It must be stopped to do so.

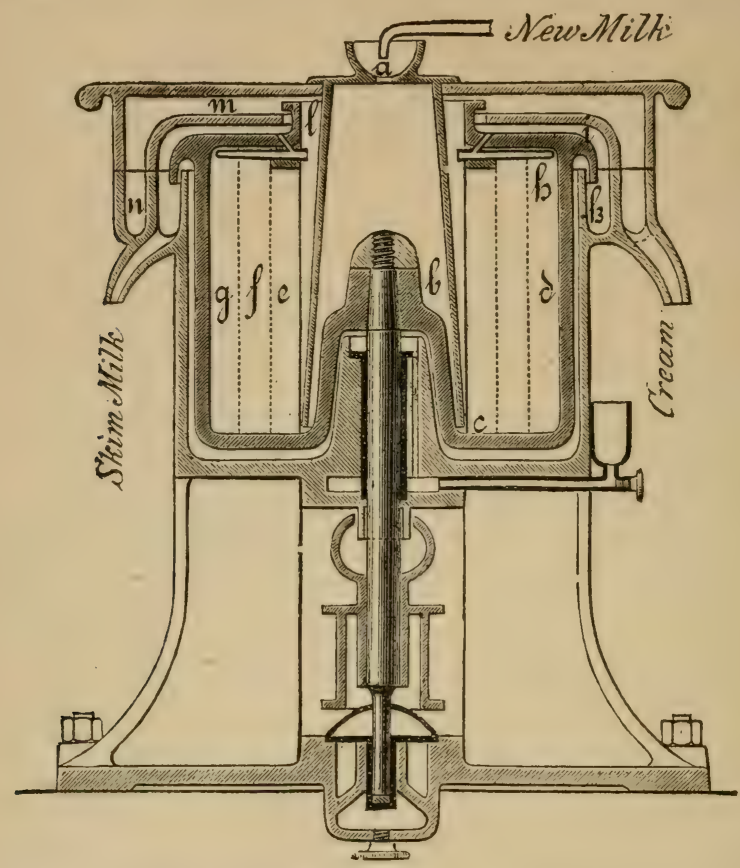

Fig. 25.-The Lefeldt Milk Separator. $e$, cream; $f$, milk in process of separation; $g$, skim milk.

1)r Fleischman quotes the price and eapacity of the Lefeldt separator as follows:

No 0. $330 \mathrm{lbs}$. of milk per hour, . . . \$125.00

$$
\begin{array}{rrrrrr}
\text { No } 1.550 & . & \text { " } 55 & . & 250.00 \\
\text { No 2. } 1100 & . & \text { " } & 375.00 \\
\text { No } 3.1650 & \text {. } 16 & \text { " } & & 500.00 \\
\text { No } 4.2250 & . & \text { " } & & . & 625.00
\end{array}
$$

Internediate motion. , , \$37.00 
The new model of the Lefeldt Separator, (fig. 26) has not to our knowledge been thoroughly tested, and we are unable to state exactly, what it can do.

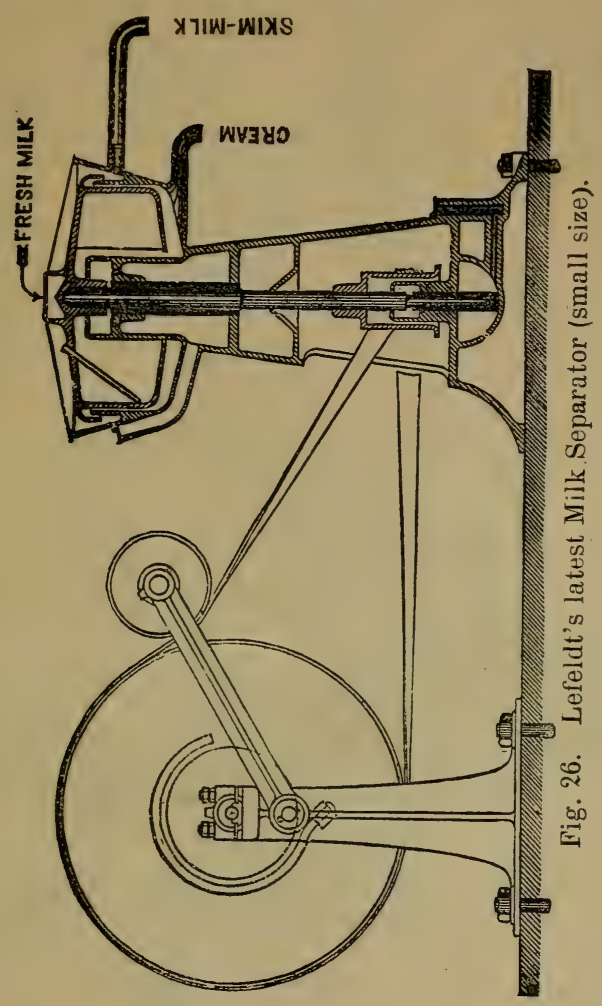

The capacity claimed for it is $600 \mathrm{lbs}$ per hour. Cost : \$22.5.

THE FESCA MILK SEPARATOR

This separator was also described in my report to the Minister of Agriculture, \&c., \&c.

In this Separator the skim milk only is continuously 
discharged during the operation, the cream remains in the drum. At the end of every hour the machine must be stopped and the cream emptied. For this reason it is

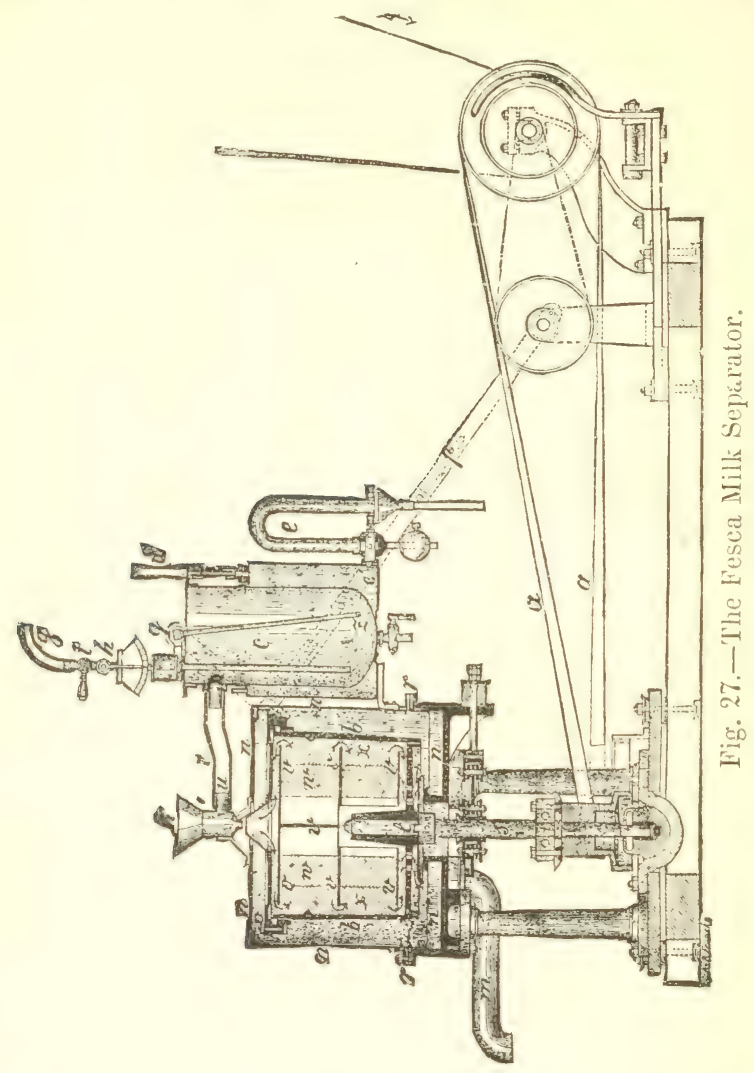

not to be rerommended. Mr Feswa has lately built a separator working continuous? y, hut it is not extensively used. This separator is built in Berlin, Germany.

$$
\text { THE NAKSKOV MITA SEPARATOR. }
$$

This small separator was exhihiod at Aalborg, Den- 
mark, in June 1883, but was considered too imperfect to compete with the Burmeinster \& W ain and De Laval, during the Vesterrig experimental trial and competition.

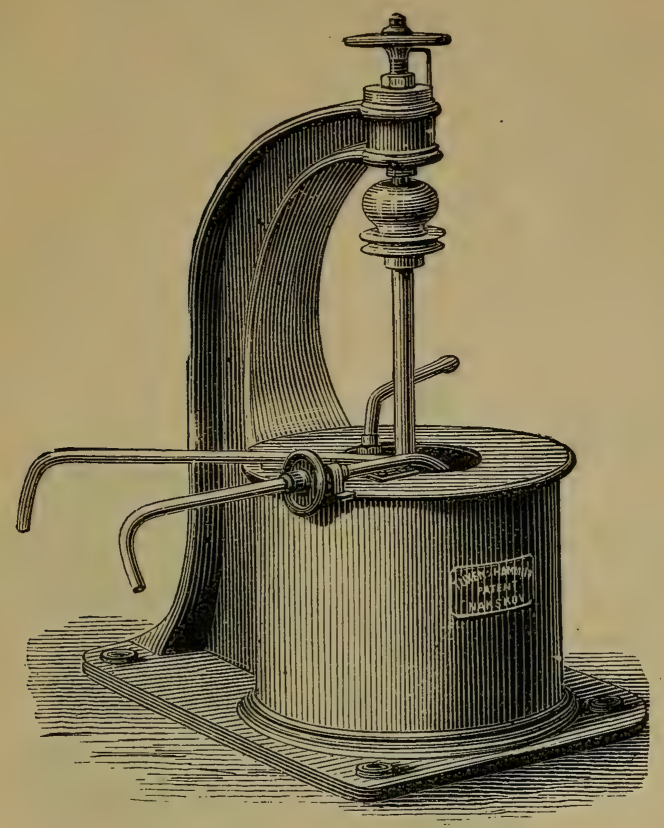

Figr 8.--The Nakskor Milk Separator.

Its defects were classified as follow's :

1st, The sprinkling of cream and skim milk.

$2 n d$. The suction of cream by air into the skim milk.

3rd. Difficulties in oiling the lower bearings.

We understand that some of these defects hare been remedied since. The capacity claimed for it is $500 \mathrm{lbs}$ of milk per hour.

This machine is made by Messrs. Tuxen \& Ham. merich, Nakskov, Denmark. 
THE HENRICH PETERSEN SHALE MACHINE.

This machine differs in its construction from those we have already described. Instead of a drum revolving on a rertical axis, we find one or two drums moring on a horizontal shaft.

In this separator, the skim milk is remored by moveable knives or shalers.

By the proper use of the shalers, thin or thick cream, may be obtained while the machine is in operation.

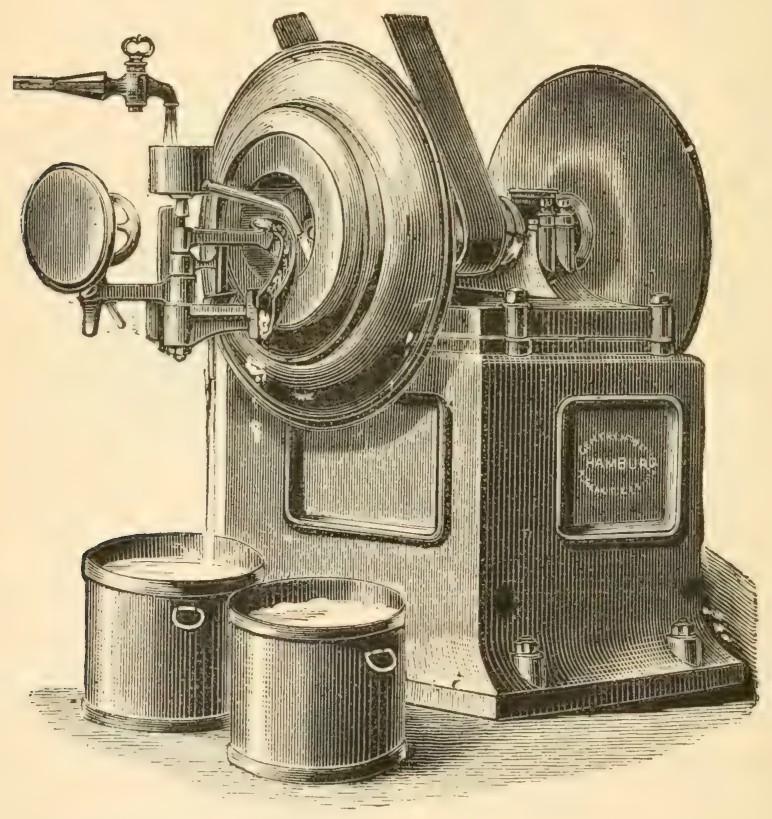

Fig. 29.-The Henrich Petersen shale Machine.

('rreat modifications have lately been made in the 1:Onstruction of the shalers of this machine. 


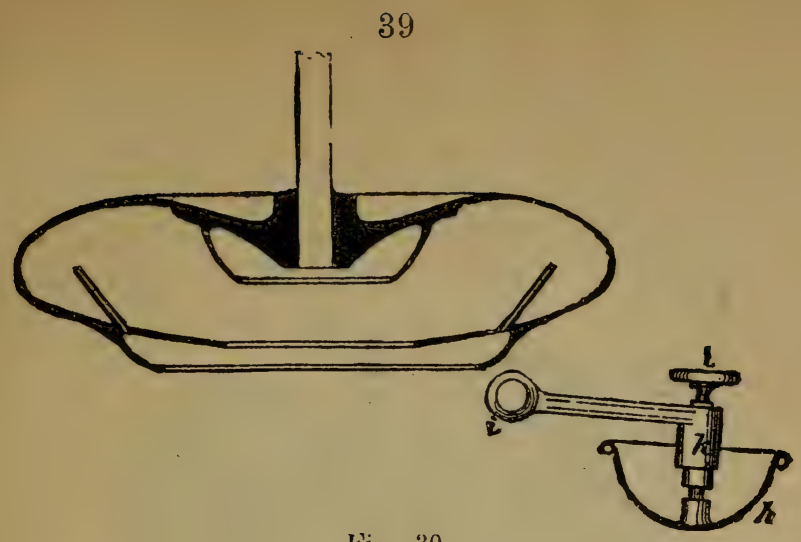

Fig. 30.

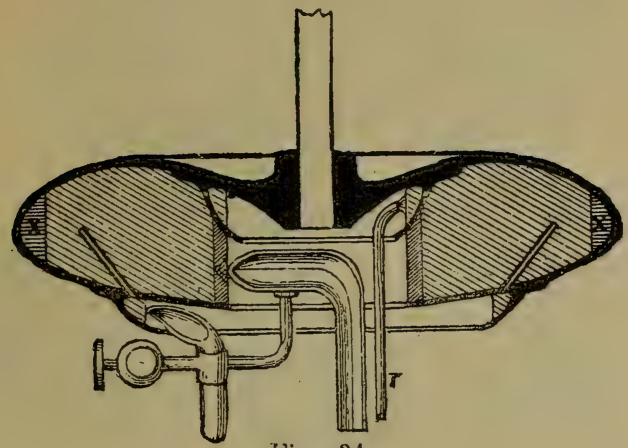

Fig. 31.

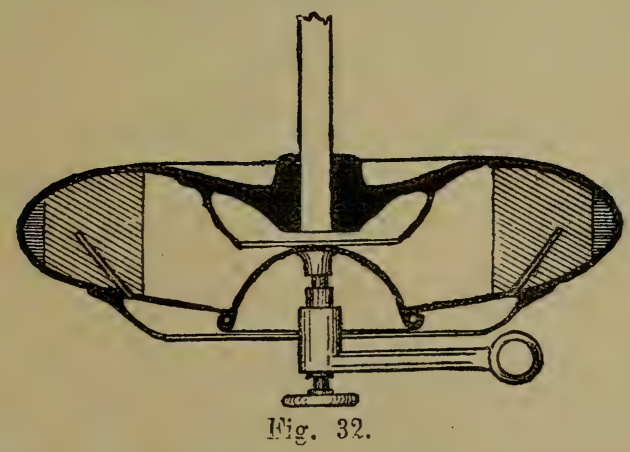

Cuts Nos. 30, 31 and 32, represent details of the shale machine. 
The new shaling tubes are arranged so as to remorr all the skim milk from the Arum, at the ente of the operatiom. This mathine is said to make from 1,000 to 1,100 revolutions per minute, and to repuire 1. 1.2 horse power. The capacity rlaimed for it is 1,000 lbs. of milk per

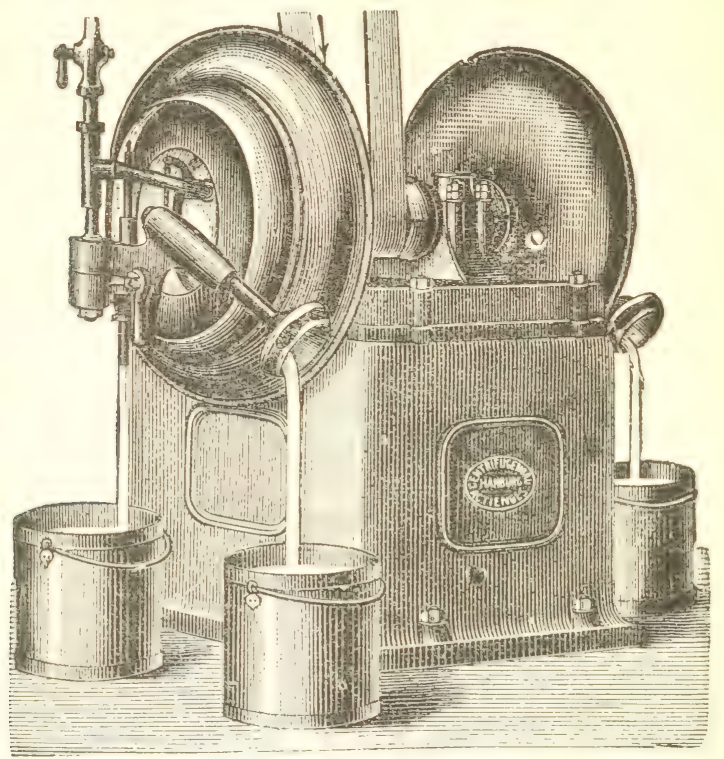

Fig. 33.-Petersen's Shale Centrifugal with new shaling tubes.

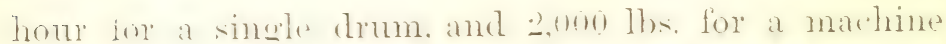
having two brums. This marhine is sold hy Mentrescht \& Co.. Hamburg, (remany. Price, \$825).

THE HERTIN PAPE MACHINE.

'This new mathine is makle with withere perpendicolar or horizontal drums. The cram and : kim milk insteat

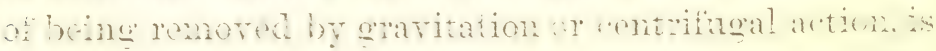
forced out of the drum br hrairostatic pressize. The 
outflow of cream and skim milk can be regulated during the operation by a suitable faucet.

Contrary to that of other separators, the drum is completely filled and closed air tight. From this machine, the cream and skim milk come out in quiet streams, without the foaming liable to occur, when the liquids are extracted by centrifugal forcé.

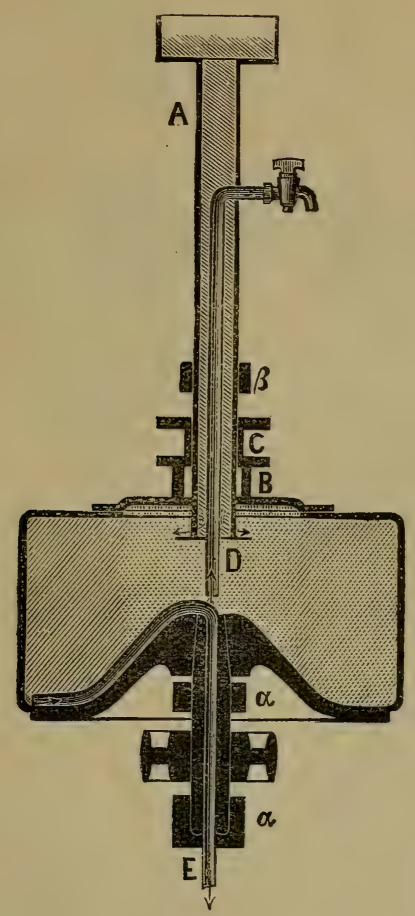

Fig. 34.

$A$, stationary pipe. $B$, cover rolating with the drum. $C$, rotating box in which the inlet pipe is tightly fitted. $D$, stationary outlet pipe for the cream. E, rotating pipe for the skim milk, $a a$, boxes on which the shatt is mounted. $B$, support for the inlet pipe. 
The air tight cover has to be fastened on the drum every time the machine is used.

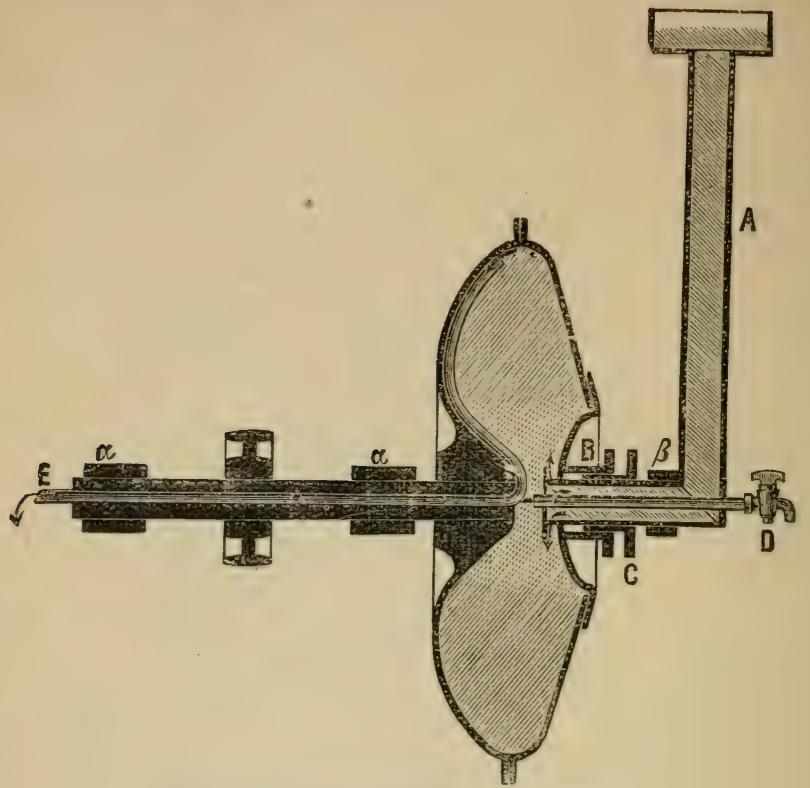

Fig 35 - The Horman Pape Machine.

THE AHLBORN MILK HEATER.

A rery useful apparatus for heating milk (when it is deemed adrisable to do so) was constructed by $\mathrm{Mr}$. Ahlborn, of Hildesheim, Germany. I have introduced it into Canada. It can be seen in operation at the SaintSebastien creamery, province of Qnebec.

This rery simple and useful apparatus consists of a copper box with an inclined and ribbed surface, something like a wash-board. A perforated spout is placed across this inclined surface at its highest extremity. The box is filled with water and heated by means of a steam coil ruming through it. The cold 
milk falls through a tap from the reception rat into the perforated spout, it is spread in a thin sheet over

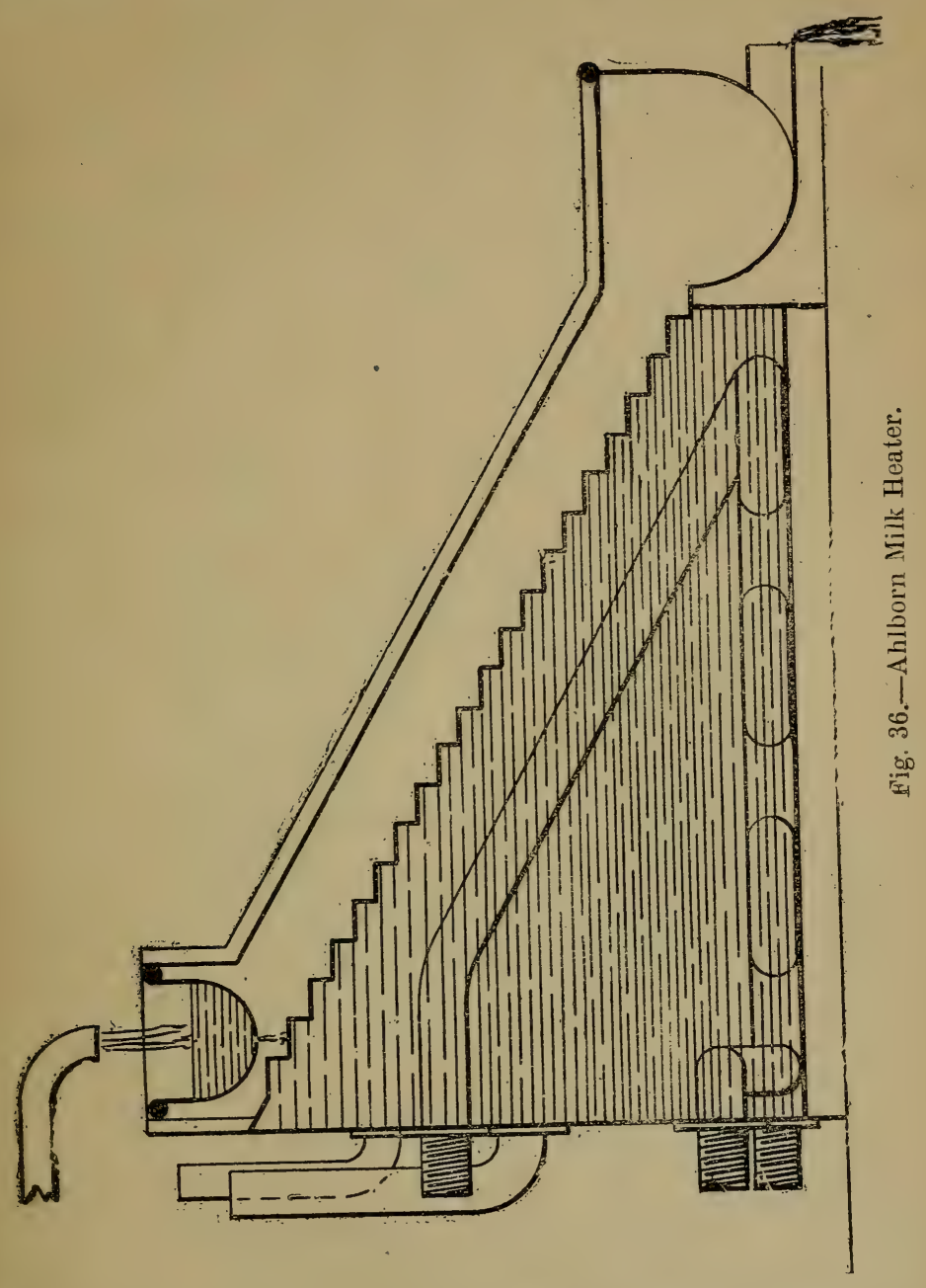

the inclined surface, and by the time it has reached the other extremity, it has acquired sufficient, heat to be led 


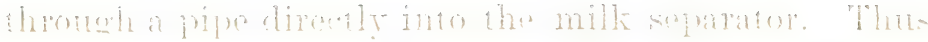

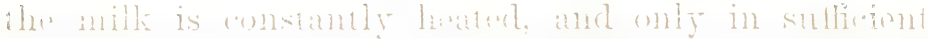

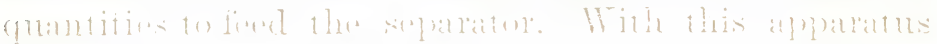

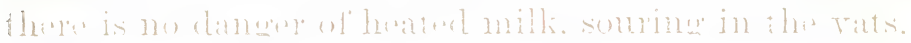

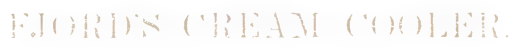

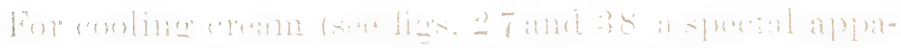

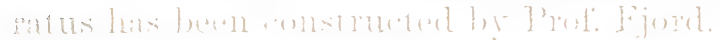

\section{1) Exirilirion}

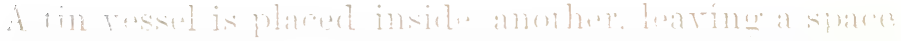

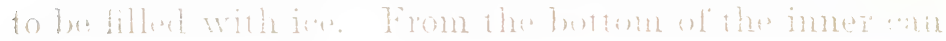

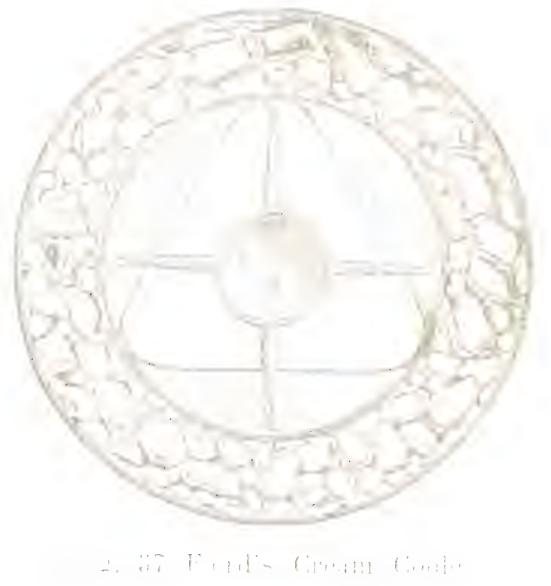

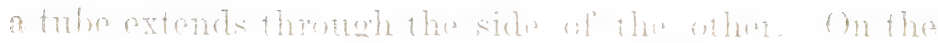

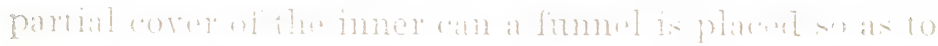

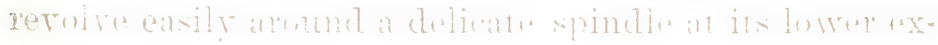
tension. (New in

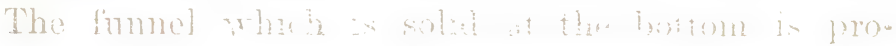


vided with four discharge pipes extending close to the cireumference of the can, and bent at the ends as shown in section, fig. 37. The cream drops from the skimming pipe of the separator, which, if necessary: may be extended above the machine (see fig. 22) into this

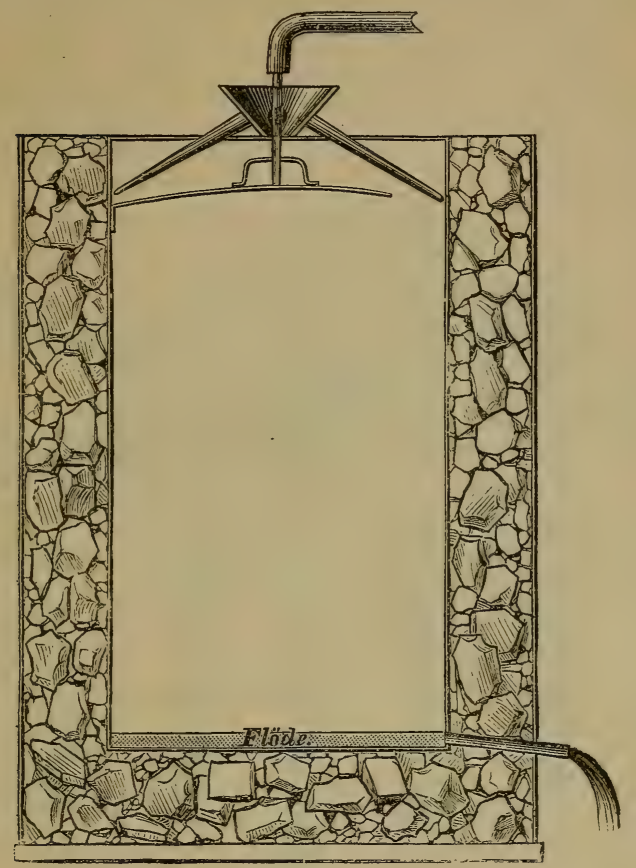

Fig. 38.-Fjord's Cream Cooler

fumnel, and flowing through the four tubes, it makes the funnel go round, distributing the cream around the sides of the can. Flowing down in a very thin sheet, along the wall of the can, it is cooled to a temperature below $50^{\circ}$ Fahrt. before reaching the bottom. A similar apparatus may be used for cooling the skim milk.. 
PROF. FJORD'S MILK CONTROLLER FOR TESTING MILK.

This instrument is destined to render great services to our cooperative dairies, for it can in a fer minutes show precisely the richness of from 12 to 24 samples of milk.

It consists of a scalloped disk of copper which can be made to revolve upon the spindle of a large size centrifu-

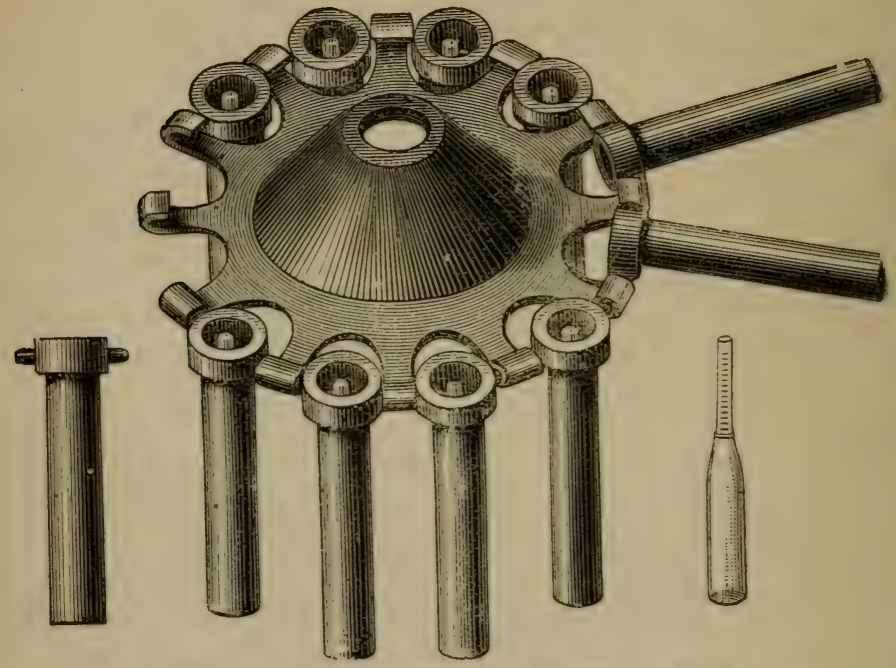

Fig. 39,-Fjord's Controller for testing milk.

gal, or on any other rapidly revolving vertical pivot. To this disk can be hooked from 2 to 24 copper tabes. In these tubes are placed graduated bottles holding samples of milk (see fig, 39) When at rest, these tubes assume a perpendicular position and hang down, hut when in motion they fly out and become horizontal, like the two at the right of fig. 39. 
Each bottle has on its neck a scale divided into mits and halves, from 0 to 12 to indicate at the end of the operation, the quantity of cream in the milk. These bottles are numbered so that they may be identified.

The separation takes place by centrifugal force in the milk bottles, the cream accumulating in the neck.

\section{MIODE OF OPERATION.}

The bottles are first half filled with the milk to ba tested, (a mark on the outside indicates the half). The remaining space is then filled up with hot water to the mark $\mathrm{O}$ in the neck, and the whole is heated up to $90^{\circ}$ Farht. When the milk has attained the required temperature the bottles are placed in the metal tubes, at the bottom of which rubber is placed to prerent breakage. The disk is then made to rerolve.

Mr Fjord estimates that 40,000 rerolutions are required to completely separate the crean. This apparatus should not be made to go fister then 1200 revolutions per minute.

RULE.

Allow for the time which the disk takes to reach the maximum speed one half the number of rerolutions per minute that is counted when it has attained the highest speed.

EXPLANATION.

For the first four minutes, while the machine is acquiring the required speed, we count 900 rerolutions per minute; this gives for these four ninutes 2400 revolutions. There now remain 40.000 revúutions, less 2400 to be made, equal to 37,600 . The mathine huring acquired 
its speed is thom monning it pon ropolutions a minutg Therefor. the number of indwe whin 87,600 will contain

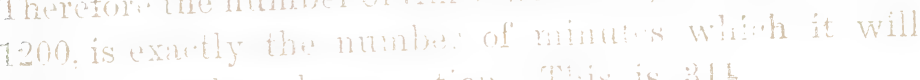

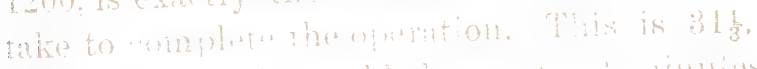

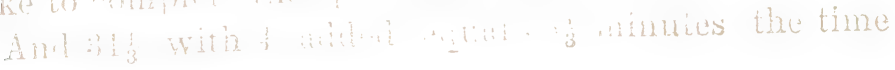
peytuitud. 


\section{Value of different systems of skimming,}

In Denmart where the importance of the dairy industry is well understood, the government keeps a staff of expert of great capacity, constantly employed in testing new systems, as they appear, in comparing them with the old and giving to the country at large the benefit of their experiments, and of the knowledge thus acquired. It is true that the country is obliged to expend a considerable sum of money for this purpose, but there is no doubt that it is a profitable investment; Danish larmers and dairymen don't invest in inventions and improrements, until they have ascertained their exact value from the government reports.

When the Cooly can first made its appearance in Denmark, and the claim was made that it could raise all the cream between milkings, or in 10 hours with water at $46^{\circ}$ or $50^{\circ}$ Fahrt., the Danish government ordered Prof. J. N. Fjord, the greatest living dairy expert, to investigate this claim and report on it.

When the centrifugal at first made its appearance, Prof. J. N. Fjord was commissioned to examine it, and to let the public know its value.

\section{COMPARISON OF THE COOLY WITH}

\section{OTHER SYSTEMS.}

We give below the result of the experiments then made, showing the comparative butter yield of the following systems : the "Centrifugal", the "Ice 12 høurs", the "Ice 24 hours", the "Water at $46^{\circ}$ Fahrt. 12 hours 
and 24 hours", the "Water at $40^{\circ}$ Fahrt. 12 hours alid 24 hours", and the "Cuoly".

The size of the Cooly can used in these experiments was equal to that of the ordinary deep can. Both the "Cooly" and the ordinary cans were placed in the same couling vessel, and left at the same temperature, the same length of time, so that all the conditions of shimming with the use of these diff rent methods were perfertly identical. The results are about similar to those obtained in preceding experinnents, and prove once more that THE LONER THE TEMPERATURE, THE LARGER THE YIELD.

TABLE No. ?

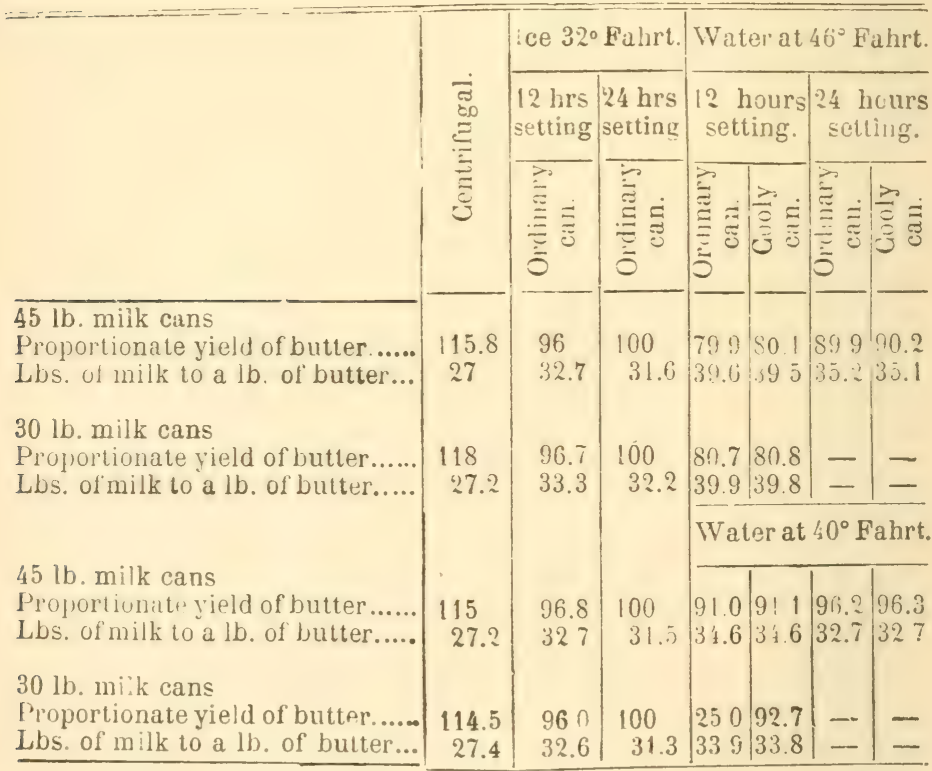

The milk from Danish cows is somewhat poorer than that froin Canadian cows. 
It is easy from this table to determine the value of these methods.

When from a certain quantity of whole milk the "Centrifugal" extracted 115.8 lbs. of butter, the "Ice 24 hours" extracted from the same quantity of whole milk of the same richness, 100 lbs.; and the "Ice 12 hours" extracted $96 \mathrm{lbs}$, and "Water" (according to the can used and the number of hours of setting) produced 79.9, 80.1 lbs. ; 89.9, 90.2 lbs.

It is thus seen that using the "Centrifngal" it takes $27 \mathrm{lbs}$. of whole milk to make $1 \mathrm{lb}$. of butter. Using "Ice 24 hours" it takes 31.6 ; "Ice 12 hours " requires 32.7 lbs. to make a lb. of butter, \&e.

Another series of experiments was made by Prof. Fjord at the experimental farm of Ourupp. The object of these experiments, which continued during 12 months, from April. 1881, to March, 1882, was to ascertain the relative butter yield of the following six systems :

"ICE, 10 HOURS;" "ICE, 34 HOURS;" "W ATER AT $50^{\circ}$ FAHRT, 34 HOURS;" "SHALLOW PANS 34 HOURS;" “CENTRIFUGAL;" “CHURNING OF MILK."

Each experimental day, 609 lbs. of milk were used, divided in the following manner: $50 \mathrm{lbs}$. for each trial by the "Ice," the " Cold water" and the "Pan" systems; $400 \mathrm{lbs}$. for the "Centrifugal," and 9 lbs. for the "Churning of milk," methods.

The milk was cooled to $33^{\circ}$ Fahrt by the "Ice system" By the "Cold water" system, setting in deep cans, the 
milk wras maintained at a mifom trmprature of bon Fahrt. The thinkness of the milk in the "Low pans" ran mp to two inchesand the milk was maintained at a tempesraturesulfently low, tolesp it perlet ty swet during 34 houls, eren in the hottest days ol wimmer.

Eath so 1b. experiment with the "Ice," "Cold water, and " Low pan "systms gave about 9 Ibs. of

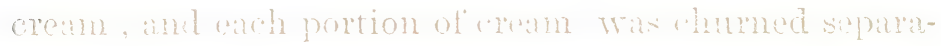

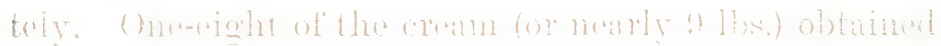

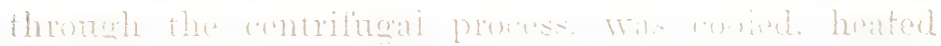

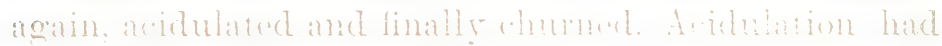

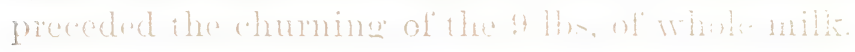

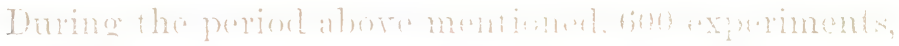

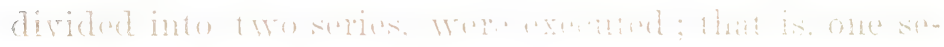

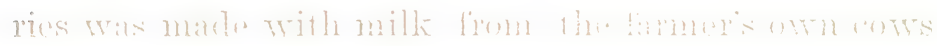

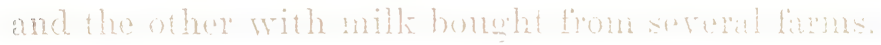

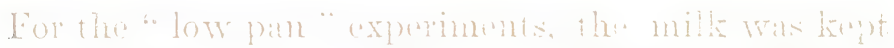

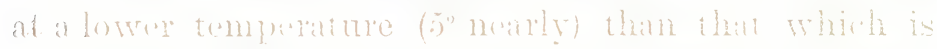

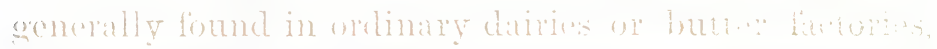

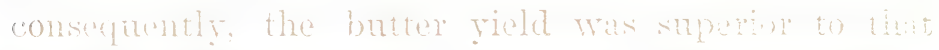

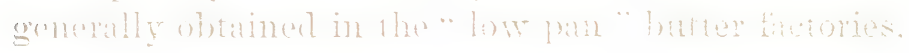

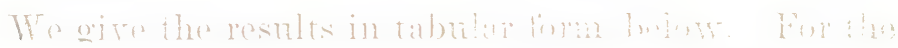

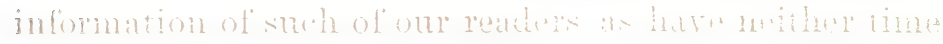
nor in lination to go orel the tables, we give the arerages in larger type.

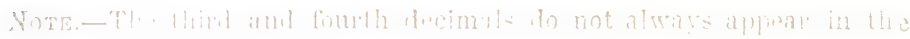

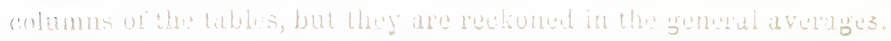




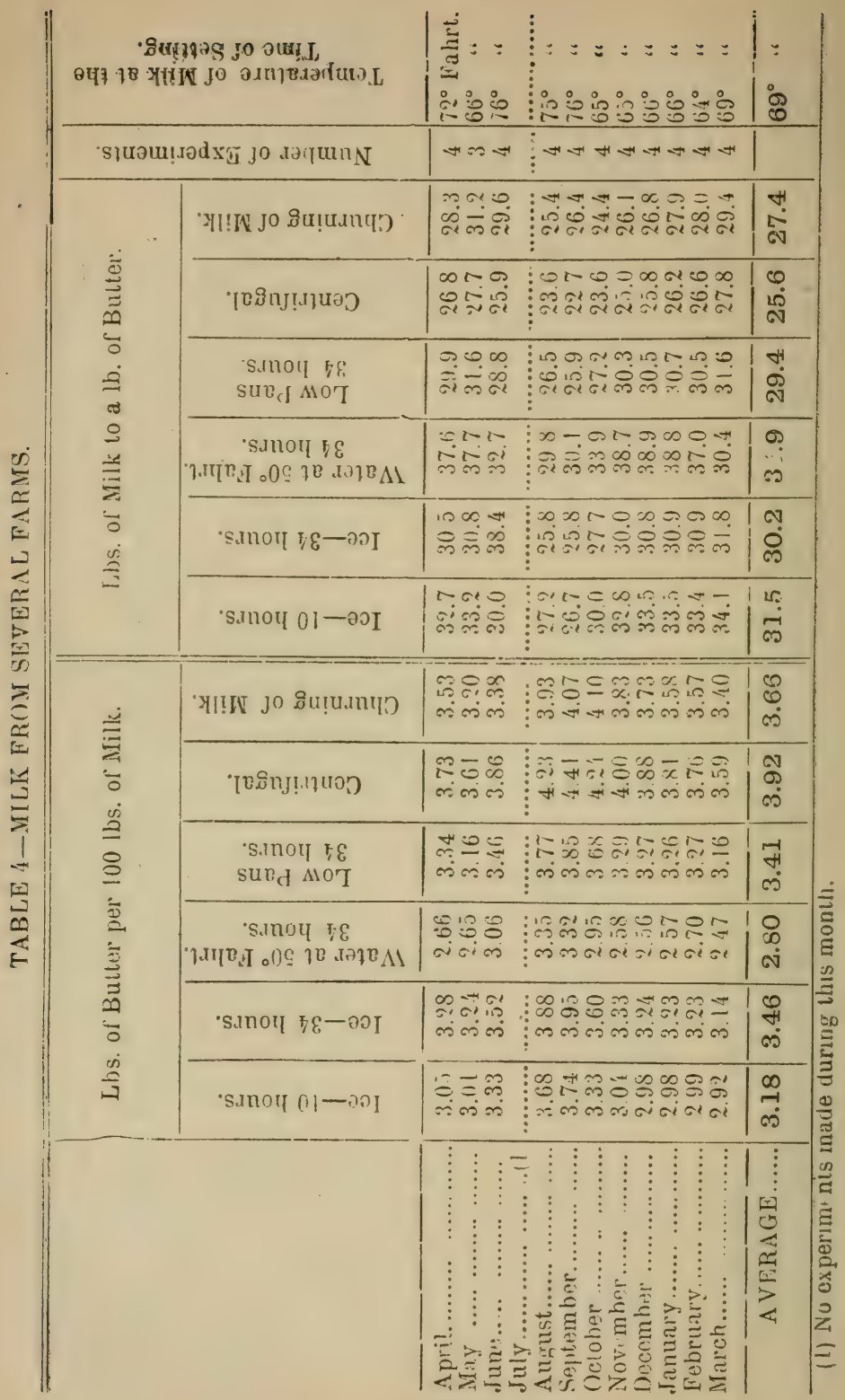




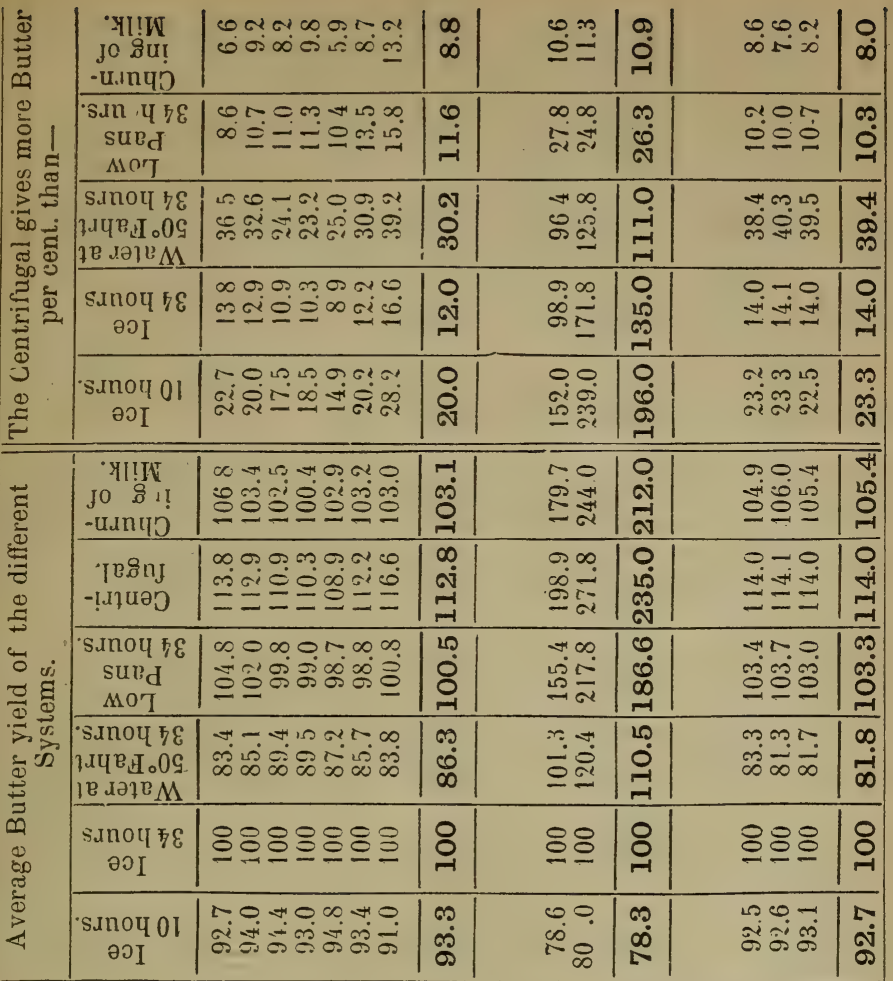

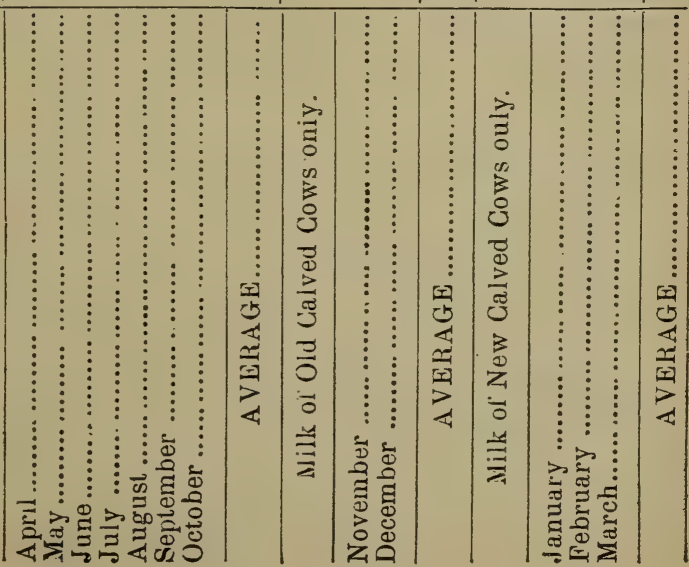


58

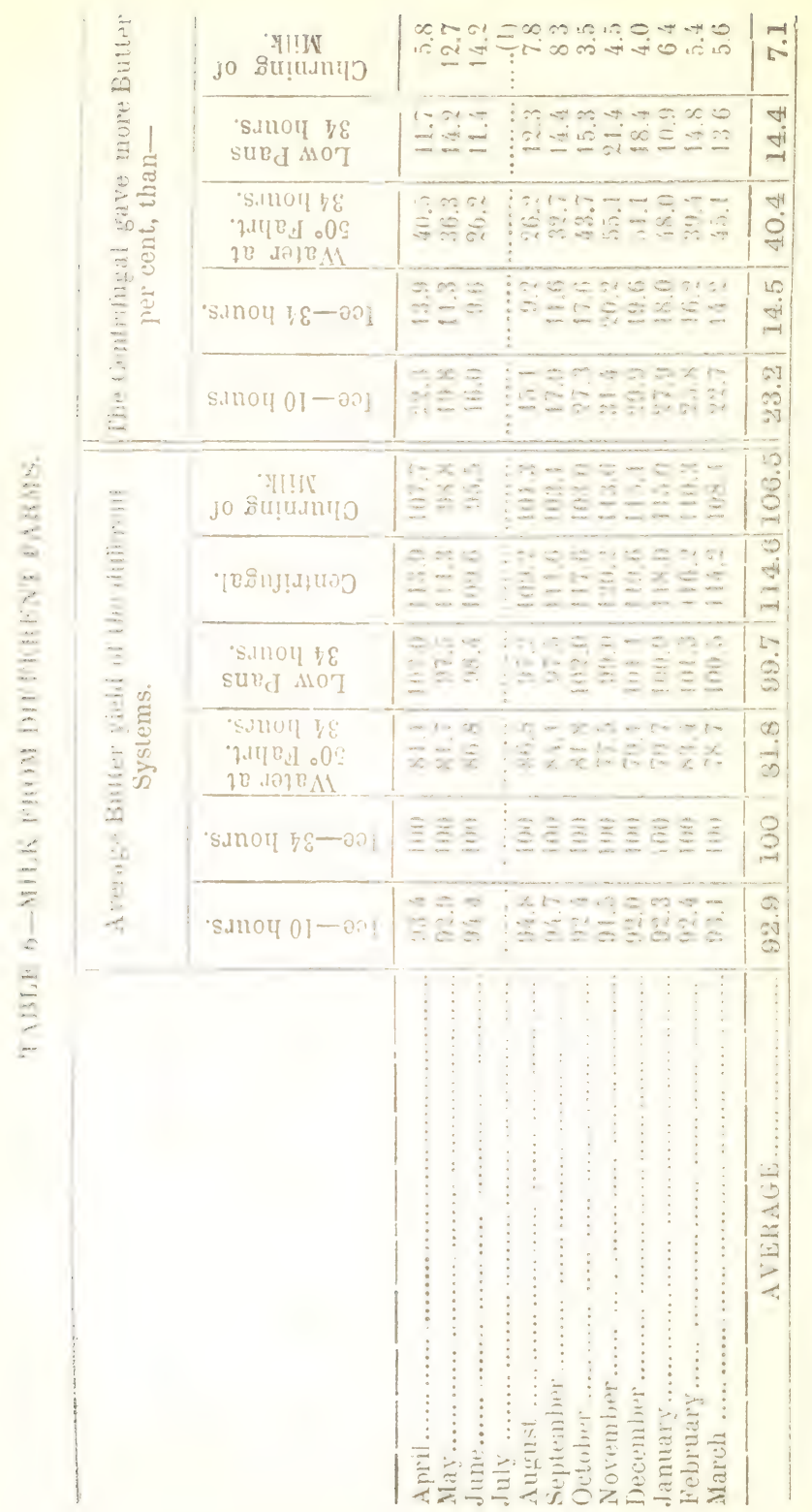


In table No. 5, the basis of comparison is "Ice 34 hours. "Thus the table is read in the following manner: taking April when "Ice" 34 hours gives $100 \mathrm{lbs}$. of butter, "Ice" 10 hours gives only $92.7 \mathrm{lbs}$., "Water at $50^{\circ}$ Fahrt. 34 hours" gives still less, $83.4 \mathrm{lbs}$; "Low pans 34 hours" give 104.8 lbs.; the "Centrifugal" gires 113.8.lbs.; the "Churning of milk" gives $106.8 \mathrm{lbs}$.

From these tables the following facts may be gather. ed :

1o. A method, which works well at one season, may not work well at another. Thus during the month of December (see table 3) by the "Ice 10 hours," it took $79.6 \mathrm{lbs}$. of milk to make $1 \mathrm{lb}$. of butter, while by the same method, during the month of August, it took but 27.6 lbs. All the conditions of skimming in both cases were perfectly identical. The difference was caused by "heavy milk."

20. The loss from heavy milk was less apparent in the milk obtained from several farms, than in that taken from the farmer's own cows, because in the first case the milk of old calved cows was mixed with that of newly calved cows; and old calved cows give comparatively little milk.

3o. Milk transported from other farms, shows an average loss of temperature of $14^{\circ}$ Fahrt, over that obtained on the farm. This loss of heat caused the butter yield to be $2 \frac{1}{2}$ per cent. less than that obtained from the milk of the farmer's own cows.

We give below an indicator diagram, showing the decrease or increase of the cream yielding power of milk during different months, with different methods of skimming : 


\section{TABLE X. . .}

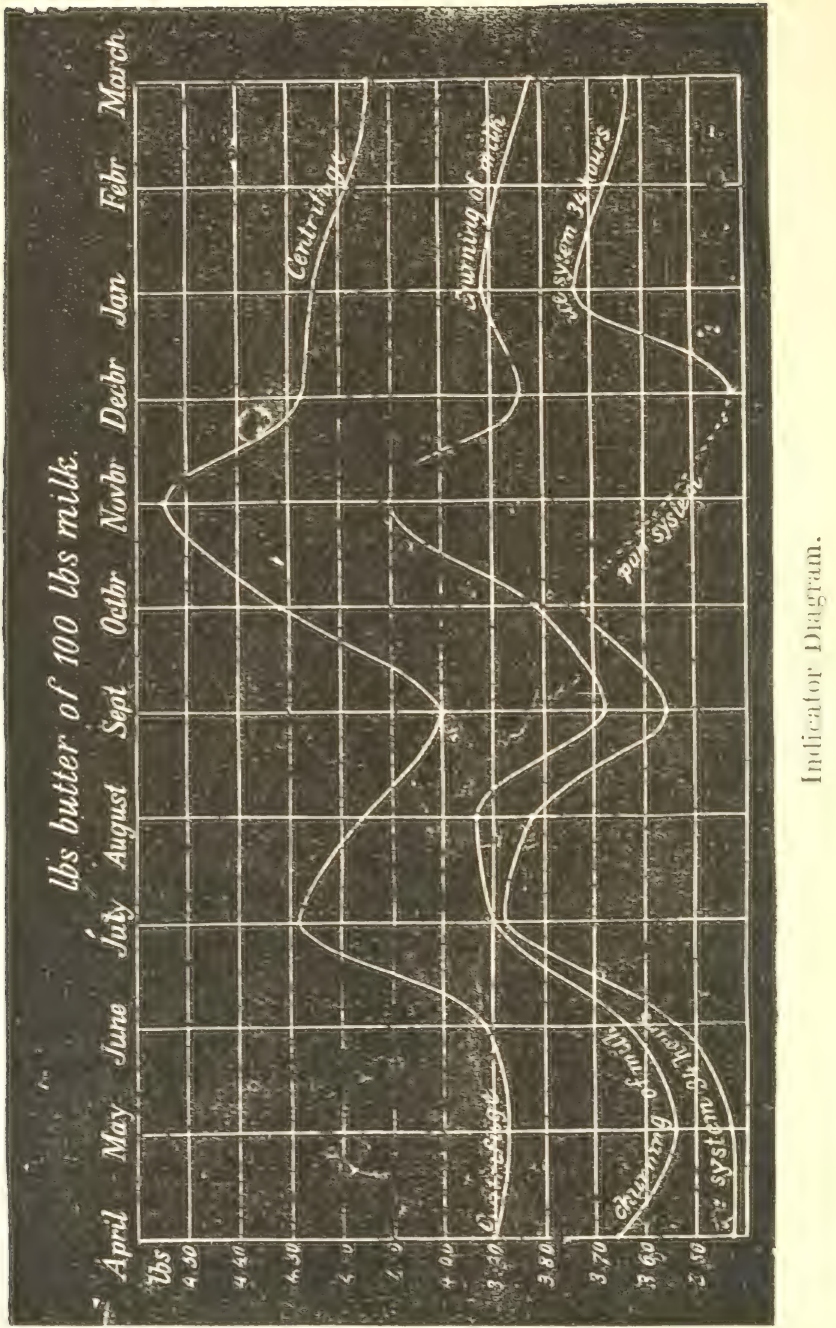

Thu ralue of the systems can here be seen at a glance First comes the "Centrifugal"; then the "Churning of 
milk," and afterwards the "Ice system " for a part of the vear.

During the months of October, November and December the "Ice" system being unable to raise a sufficient proportion of the cream, on account of the milk being "heavy," it was superseded by the "Low pan" system. This substitution is shown for these months by means of a dotted line; the months during which the "Ice" system was used being indicated by a full line.

From the above tables we take the following general results.

TABLe 8.

GENERAT, RESULTS.

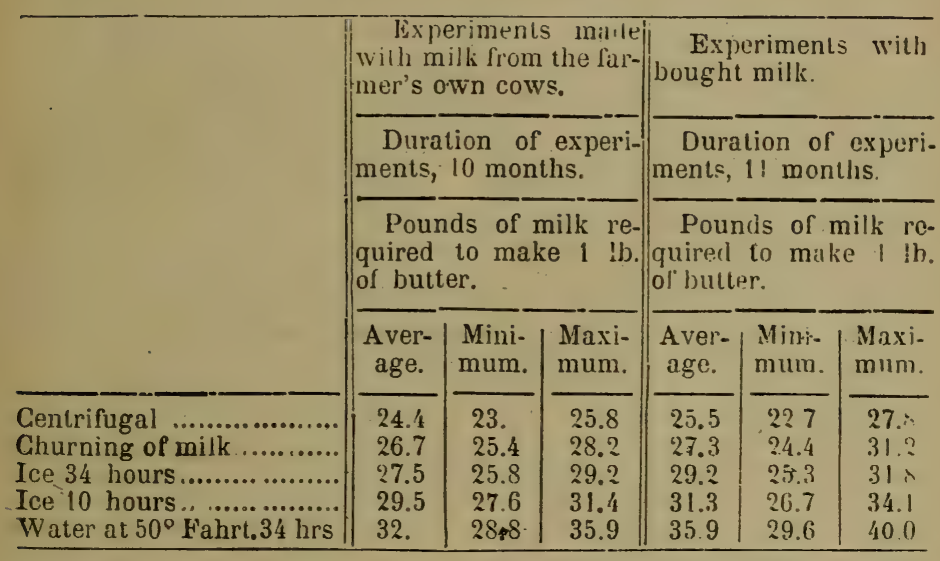

RESULT OF CHEMICAL ANALYSES OF " BUTTERMILK," "BUTTER" AND " sKIM MILK."

The "butter milk," "butter" and "skim milk" ob tained by the above methods of treating milk, wer next analysed by Prof. Storck, of the Stein experimenta Station, Denmark, in order to determine the quantity o: 
butter fat contained in arch of thein, and thus to ascertain if the dillinence in the butter riedd was due to the differences of efficieney of the sereral methols of treatmo milk, or if it could be partly attributed to the incomplete churning of the cream, or to th. ineffectual working of the butter in some cases.

\section{ANALYSIS OF THE "BUTTER MILK."}

The "butter mills" was then analy"d. and the result showe a remarkable unifornity in the quantities of butter fat contained in the different butter milks, obtained from milk of sam quality, but whith had been skimmed by different methods.

The butter milk derival from 10! liss. of whole inilk gave in no case a larger quantity of butter fat than $1 \frac{1}{2}$ munes. It was therefore evident that the difference in the butter yield conld not be atisibuted to a waste in the butter milk.

The difference in the hutter yield must then be attributed either to the presemes of an unmsual quantity of water or chensy instter in some of the butter, or to the superior alliency of som systems of skimming over others.

\section{ANAIYYSIS OF THE BUTTER.}

The results showed that the butter obtained from mik treated by different methods of slimming contained the sam. quantity of water, in erery case the quantity was $2 \frac{1}{2}$ ounces to a pound of butter.

ANALYSIS OF THE STIM MITK.

It wa- now plain, that the differences in the butter yied, mist be caused, bysune methods of skimming 
leaving in the skim milk a larger proportion of butter fat than others.

TABLE No: 9.

Chemical Analysis of the "Skim Milk."

PERCENTAGE OF BUTTER FAT IN THE SKIM MHLK.

\begin{tabular}{|c|c|c|c|c|c|}
\hline & \multicolumn{5}{|c|}{ Different Methods of Skimming. } \\
\hline & $\begin{array}{l}\stackrel{\infty}{\Xi} \\
\stackrel{0}{0} \\
1 \\
\stackrel{0}{0}\end{array}$ & 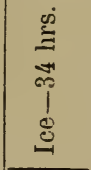 & 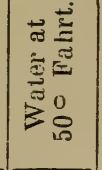 & 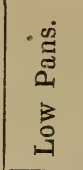 & 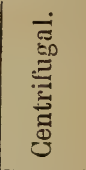 \\
\hline 1881. & ozs. & o2s. & ozs. & ozs. & ozs. \\
\hline June 7 th-Milk from the cows of a & & 8 & 112 & & \\
\hline $\begin{array}{l}\text { June } 8 \text { th-Milk from the cows of dif- } \\
\text { ferent farms }\end{array}$ & & & & & \\
\hline September $28 \mathrm{~h}$-Milk fiom a private & & 0 & & & $1 \frac{1}{2}$ \\
\hline $\begin{array}{l}\text { dairy } \\
\text { October } 4 \text { th-Milk from a private } \\
\text { dairy }\end{array}$ & & 9 & $\left|\begin{array}{ll}18 & 4 / 10\end{array}\right|$ & $8 \frac{1}{2}$ & $22 /$ \\
\hline dairy ......................................... & $173 / 25$ & 12 & $20 \frac{1}{3}$ & $9 \frac{3}{4}$ & $? \frac{1}{2}$ \\
\hline $\begin{array}{l}\text { different farms .......................... } \\
\text { November } 27 \text { th-Milk from the cows }\end{array}$ & $204 / 25$ & 15 & $: 25$ & $14 \frac{1}{2}$ & $4 \frac{1}{2}$ \\
\hline $\begin{array}{l}\text { of a private dairy } \ldots \ldots \ldots \ldots \ldots \ldots \ldots \\
\text { December } 16 \text { th-Milk from the cowe }\end{array}$ & & $16 \frac{1}{2}$ & & $16 \frac{1}{2}$ & $2 \frac{\pi}{8}$ \\
\hline of a private dairy ..................... & & $411 / 7$ & & 17 & $24 / 10$ \\
\hline Milk from newly-calved cows only: & & & & & \\
\hline 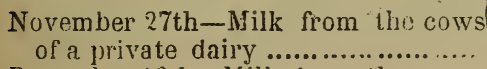 & & $93 / 25$ & & 7 & $1 \frac{3}{4}$ \\
\hline 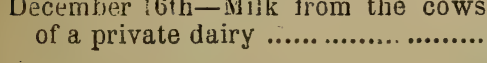 & & & & $6 \frac{7}{8}$ & \\
\hline $18 \delta 2$. & & & & & \\
\hline 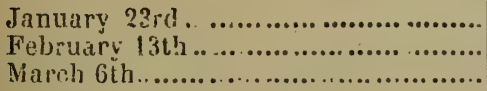 & $\begin{array}{l}13 \\
18 \\
11\end{array}$ & $\left|\begin{array}{cc}8 & 4 / 5 \\
12 & \\
7 & \frac{1}{2}\end{array}\right|$ & $\left|\begin{array}{ll}21 & \frac{1}{4} \\
12 & \frac{1}{4} \\
15 & \frac{1}{3}\end{array}\right|$ & $\mid \begin{array}{ll}5 & \frac{3}{4} \\
9 & \frac{1}{4} \\
5 & \frac{3}{4}\end{array}$ & $\begin{array}{ll}1 & 3 / 5 \\
1 & 3 / 5 \\
1 & \frac{3}{4}\end{array}$ \\
\hline
\end{tabular}

From this table, we see that the differences in the butter yield, are entirely due to some methods of skimming milk, being more efficient than others. 
Tha quintity of butter fat contained in milk from Danish enws varies from 3 to $4 \%$ of its waight. IW may adopt $3.50 \%$ as an average

WHAT THE DIFFERENT METHODS CAN DO AND SHOUIS DO.

Table No. $: 0$

\begin{tabular}{|c|c|c|c|c|c|}
\hline & \multicolumn{3}{|c|}{$\begin{array}{l}\text { What the methods } \\
\text { should do. }\end{array}$} & \multicolumn{2}{|c|}{$\begin{array}{l}\text { What they really do } \\
\text { in Denmark. }\end{array}$} \\
\hline Nethods. & & 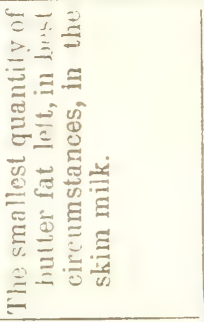 & 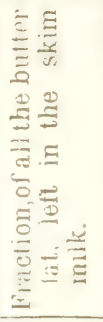 & 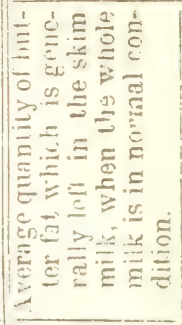 & 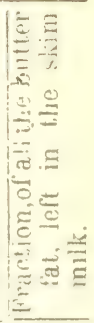 \\
\hline Ice $34 \mathrm{hrs} . . . . . . . . . . . .$. & $5 \quad 6 / 10$ & ozs. of bulter ... & $1 / 10$ & $\mid \begin{array}{c}1, z<\text { of butter } \\
\text { y } 92 / 100\end{array}$ & nearly \\
\hline Shallow-pans $34 \mathrm{hrs}$. & $6 \quad 4 / 10$ & “ & $1 / 9$ & $1088 / 100$ & $1 / 5$ \\
\hline Centrifugal ............ & $16 / 25$ & " & $1 / 87$ & $24 / 10$ & $1 / 23$ \\
\hline
\end{tabular}

Thus we can see at a glance, what the different mohods can do and shonld do, when used to their utmost capacity.

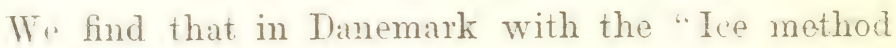
$3+$ hours," $\frac{1}{6}$ of all the butter fat is left in the skim milk, with the Shallow pans 34 hours, $\frac{1}{5}$ of the butter fat remains in the skim milk and, that the "Centrifugal" leaves about $\frac{1}{2 \frac{3}{3}}$.

This shows that the Danes find it advantageons to skim the milk very alosely. 


\section{CONCLUDING REMARKS ON THE DIFFERENT SYSTEMS (1). .}

10. Advantages and disadvantages.

2o. Appreciation of the quality of butter produced by each system.

3o. When and how to use them.

\section{THE SHALLOW PAN SYSTEM.}

ADVANTAGES.

10. When large pans are used, it requires less labor than the deep setting in cans, and the first cost of the plant is less than that of the centrifugal.

2o. It may be used with advantage in the treatment of heavy milk.

\section{DISADVANTAGES.}

In some countries where butter making is well understood and well practiced, the shallow pans are rapidly disappearing out of small private dairies, where ice can be had. They are also superseded by the centrifugal separator in large and cooperative dairies.

Good butter can be made from milk set in shallow pans, but this system offers the following disadvantages:

10. It requires very much time.

2o. " an abundance of running water.

3o. " " much space.

40. " a cool specially constructed and well aired room, and a uniform temperature.

(1) Shallow pans, deep setting in cold water, deep setting in ice, and the centrifugal systems, are now in use in Canada Deep setting in cold water ( 45 to $550 \mathrm{Fahr}$.) is most in use in our private dairies. 
5o. It exposes the milk to atmospheric changes, and to the ab-orption of impurities from the surrounding air.

60. In hot weather, crean from the shallow pans is apt in be chessy, and the quality of the butter generally lacks uniformity.

7o. The cream is apt to orer ripen.

80. During the heat of stummer even when milk ran be kept sweet during 34 hrs., this mode of skimming gives lus butter than deep setting in " Ine " 34 hrs.

9o. In hot weather it leares the skim milk in a bad condition.

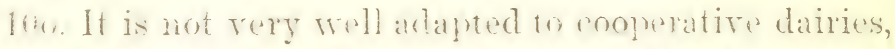
beatuse it reguires the transportation of milk twise a day.

The shallow pan system may be nesd with adrantage, in plates, where no other rooling medium than cold air or cold rumune water is to be had, and also in the treatment of heary mill.

\section{HOTV TO USE THE SHATIOW PANS.}

Milk should be set to the depth of from -12 to $t$ inches, ( $i)$ immediately after each milking. at a temperature of about 5.) Fahrt. (2) and kept sweet 315 hours before skimming. The best time lo skin is, when the milk is yet sweet. If the oprator desires to see if the cream has completely risen. he should make a streak with a spoon across the surlace. If this streak remains visible for a little while, aller it is made, the crean has finished rising.

(1) Accorrling to the temperature of the place where it is set, and the time of the milking periorl.

(2) If the temperature of the room is kept below $57^{0}$ the milk will ramain sweet 36 hours. If the temperature ranges from $57^{\circ}$ to $63^{\circ}$ the nilk will remain siveet from 30 to 24 hours. In any case it shoulal be skimmed belore acidulation takes place. 


\section{DEEP SETTING:}

ADVANTAGES OF DEEP SETTING.

10. It saves space.

20. It saves water.

3o. If proper means are taken it will keep milk free from atmospheric impurities.

DeEp SeTting IN WATER AT $50^{\circ}$ Fahrt.

According to the result of Prof. Fjord's experiments. deep setting at $50^{\circ}$ Fahrt. gave the poorest yield of any system of skimming. It gave something like 40 o 10 less butter than the centrifugal.

It may be used in small dairies, where the only cool. ing medium to be had is cold or spring water.

Milk should remain in the vessels at least 36 hours.

IMPORTANCE OF USING ICE WITH THE DEEP SETTINA SYSTEM.

In order to give the farmer a practical illustration of the advantage of using ice, in a country like this, where any quantity is furnished every winter by nature, let us give some figures in this connection.

According to Prof. Fjord's experiments and those of other dairy scientists, the ice syster, 34 hours gives from 11 to 17 per cent. more butter than cold water at $50^{\circ}$ Fahrt. 34 hours-average 14 per cent

Thus if we obtain $100 \mathrm{lbs}$. of butter out of $2500 \mathrm{lbs}$. of milk cooled to $33^{\circ}$ Fahrt., we will get only $86 \mathrm{lbs}$. out of the same quantity cooled to $50^{\circ}$ Fahrt. Loss $14 \mathrm{lbs}$. at $25 \mathrm{cts}$. : $\$ 3.50$.

Supposing that a farmer keeps 10 cows, and obtains 
firom them a yearly average of $3750 \mathrm{lbs}$. of milk, or about $150 \mathrm{lbs}$. of butter. The loss on $150 \mathrm{lbs}$. is equal to $\$ 5.25$ multiplied by 10 equal $\$ 52.50$.

Prof. Fiord calculates that to every $100 \mathrm{lbs}$. of rnilk 1 la lbs. of ice are required for erery degree of heat to be expelled. The guantity varies with the time the milik stands, the form of the milk can, the kind of refriuerator or cooling lank used, and also the temperature of the milk room.

Tobring 100 lbs of mill just short of freezing point with sngle sided tanks, with 24 hours setting; it would requires says Mr. Ifjord from 65 to 70 lbs. of ice a day arerage $67 \frac{x}{2}$ lbs. between May and September, and 42 lbs. during the remainder of the year. A cubic foot of of ice weighs about $45 \mathrm{lbs}$.

Thus to cool 3750 lbs. of milk (or about the milk of on? cow) to 320 Fahrt., it would require in summer $2531 \mathrm{lbs}$. or about $1 \frac{1}{1}$ tons of ice per cow, giving about L50 lbs. of butter (56 cubic feet of ice). (1)

From the figures given abore, any one can soe the adrantage of using ice.

\section{ADVANTAGES OF "DEEP SETTING" IN ICE.}

10. It gires a perfectly sweet cream.

20. It gires a product of uniform quali'y.

30. The best butter maknes of the world regard deep satting in ice, as one of the hat mans of obtaining the finest and longest keeping butter.

to. It keeps the skim nilk sweeter than any other system.

(1) 56 cubic feet of ice is a biock of aboni $3 \mathrm{ft} .10$ inches long, $3 \mathrm{ft}$. 10 inches wide, and 3 ft. 10 inches thick. 


\section{DISADVANTAGES.}

10. Towards the end of the milking period, when milk is leavy, it will not make a sufficient quantity of th: cream rise and the refore it must be discarded. (1)

Tha proper method of treating leavy milk, is by shailuw pans (small or large), or by the churning of whole milk, or still better by using a centrifugal separator.

20. Some people scem to think that the necessity of $\mathrm{r}_{\text {sing }}$ ice is a disadrantage, but it is nothing of the kind, the superior yield, more than makes up for any extra trouble.

We consider this the best system of milk setting for the average private dairy of Canada.

\section{HOW TO USE THIS SYSTEM.}

When milling use a covered milk pail provided with a strainer. (2)

Immediately after milking, while the milk is stil warm, strain it directly into the cans, and place the cans in the tank which has been previously half filled with cold water. Place a small temporary wooden cover over cach separnts, can. in order to prevent any ice from failing into the milk, while the oporator is shovel. ing it into the taink.

The ice should be broken to the size of large nuts, and enough of it should be used to fill the tank up, to

(1) It is not strictly necessary to discard the ressels provided, milk is set in them to a depth of 2 or 3 inches only, luring 3 i hours at $55^{\circ}$ Fahrt.

(2) There are several pails of this kinil in the market. A covered milk pail has a cover with a hole in it, through which a funnel provited with a strainer is run or otherwise fixed. 
about the level of the milk in the cans. After a little while, when the milk in cooling has melted, a small portion of the ice, the overflow tap of the tank is opened, a little water runs out, and the tank is filled up again with ice to the same height as before.

The covers are then taken off the cans, and the milk remains exposed to the action of pure cold air, which carries off the animal odor and other impurities of the milk. When covers are used (and they should be used in all dairies when the air cannot be kept perfectly pure, and when the conditions as regards cleanliness are not excellent), they should not be placed on the cans, until the temperature of the milk has reached the temperature of the dairy. If the cans a "e covered before this, the cowey odor will remain in the milk. If, on the contrary, they are left uncovered after this, the milk will absorb any bad smell, that there may be in the dairy.

The most economical plan is to leave the cans uncovered, but to cover the tanks. By this means, one corer does for all. This girus lass trouble, costs less, and takes less ice tran if the tanks are left uncovered.

With the deep setting, the cream is "thin," but let it not be supposed that this makes it more difficult to completely skim the milk, for the coating of cream is easily remored from the skim milk. Still care must be taken. The cream is taken off with the skimmer until the blue milk appears.

After some practice, a person can skim a can in one or two minutes. By skimming from the top of the can, one is sure of getting pure cream, which has not been mixed

(1) The water should be changed often enongh to kce, it perfeclly pure and odorless. 
with impurities, such as are often found round the sides and the bottom of the cans.

\section{CABINET CREAMERS, VATS, PANS, ETC.}

As regards the great variety of cabinet or box creamers, vats and pans, constructed on the deep and shallow setting plan, we may state that some of them are very handy devices, but as we do not know that they have been scientifically tested by disinterested parties, we are in no position to express an opinion as to their respective value.

\section{THE CREAM GATHERING SYSTEM.}

ADVANTAGES.

$1^{\circ}$ It is very economical, as it saves the drawing of milk to and from the creamery.

$2^{\circ}$ The creamery building need not be expensive.

$3^{\circ}$ The cream can be collected over a much larger territory, than it would be possible to carry the milk, if delivered at one factory.

The dairyman or farmer generally realizes considerably more than he would, were he to manufacture butter on the farm, and sell it on his own account.

\section{DISADVANTAGES.}

10. The cleanliness and temperature of 300 (and even more) dairies are not generally uniform. Again some dairies will use ice, while others will use water at varying degrees of temperature, as cooling mediums. Therefore the milk set in all these dairies is set in different conditions. This want of uniformity injures the quality and diminishes the quantity of the butter. 
20. In the best circumstances that is when all the farmers use ice water at $3: 30$ Farht., and the milk is set 34 hours, this system gives about 1 in per cent. less butt: than the centrifugal - (see table No. 6 of Prof. J. N Fjord's experiments, page 56).

30. Owng to the milk being set in different conditions as to temperature, \& $\cdot$, the cream $\rightarrow$ obtained raries very much in density, therefore it is rery diffirnlt to measure it accurately, and do justice to the patrons.

to. In the full of the year, when milk is herry, this system offitrs difficulties not generaliy understond.

As aiready explained in the article on "Heary nilk" (1) there is sometimes no distinctly marked line beiwen th: areim and skim milk, consequently its ineasurement would be a differity of th: most serious kind.

Again, according to the result of P'rol. Fjord's experiments (sete page 53 table No. 3i from 50 to 75 per cent. of the cream would reman m th" "herry " ralk if the deep setting were prentered in ; if the deep setting were superseded by hallow-pans, it would recuire two sets of ressels. It is true that his diffir nity can be overcome to a certain extelit by using the deep ans aren for "heavy" milk, setting milk in them only to the depth of four inche. In this ase it would be necessary to provide them with an extra gaugen nen the bottom.

The creangutering system may be used in thinly settled section, and sections wh're the herds are small.

\section{MANNER OF WORKING.}

Milk should be set in ice $393^{\circ}$ Fahrt. at least 24 homrs For details see page 67 , on deep setting in ice.

(1) This p"culiarity of milk is funnd on che fin'm to diay, and win the nexi to-morrow, \&c. 


\section{THE CHURNING OH' WHOLE MILK.}

\section{ADVANTAGES.}

10. The butter yield by this system is second only to that of the centrifugal.

2o. It may also be used with advantage in the treatment of heary milk.

\section{DISADVANTAGES.}

10. The churning of whole milk requires too much work to be of any practical value, where large quantities of milk are handled.

2o. The butter, from churned milk, contains a little more cheesy substance than that obtained by other systems.

\section{HOW TO CHURN THE WHOLE MILK.}

The milk should stand at a high temperature, until slightly sour (artificial means may be taken to produce this effect), and churned at about 68 Fahrt.

\section{THE CENTRIFUGAL SYSTEM.}

\section{ADVANTAGES.}

The centrifugal system offers the following adrantages :

10. It aLlows OF THE TRANSPORTATION OF MILK TO THE FACTORY, BUT ONCE A DAY. THUS HALF THE COST AND TROUBLE OF MILK TRANSPORTATION IS SAVED.

20. IT SAVES SPACE.

The space covered by a centrifugal is very small, not on an average more than 20 inches $x 6$ feet for the small sizes and $3 \frac{1}{2} \mathrm{ft} . \times 8$ for large sizes.

3o. It SAVES TIME. 
By this system 10,000 lbs. of milk will yield its cream in 4 or 5 hours. While by any other system, to yield considerably less cream it would require from 24 to 36 hours.

40. IT SAVES WATER AND ICE.

With this system, water is used only for washing butter, cleaning purposes and for the engine. It must be remembered that with this system only the cream is cooled, while with other systems, the whole mass of milk and cream has to be cooled. Instead of cooling 100 lbs. of milk the dairyman cools $20 \mathrm{lbs}$. of cream only.

5o. BY IT THE MILK IS SAVED FRON EXPOSURE TO IMPURE AIR, AND TO ATMONPHERIC CHANGES.

6o. It SAVES LABOR.

7o. It gives a perfectly sweet cream in large quantities, (two milkings can be skimmed at a time). This cream, uniformly fresh, can be soured to suit the taste of the butter maker.

80. It Gives a GReAter yLetid of Butter.

The latest experiments of $\mathrm{Mr}$ Fjord, show that the centrifugal system gave during 12 months, an arerage of 23 per cent. more butter than the "Ice 10 hours", 14 per cent. more than the "Ice 34 hours, 41 per ceni" more than the "Water at 50 Fahrt.", 14 per ceut. more than the "Pans $3 \frac{4}{4}$ hours" and 7 per cent. more than the "Churning of milk".

9o. IT GIVES A BETTER QUATITY OF BUTTER.

However carefully the milking and straining hare been done, the centrifugal extracts from the milk and cream, and consequently from the butter, a large amount of impurities, (1) which older methods could not remove.

(1) Often as much as 0.15 per cent. of the weight of new milk. 


\section{3}

Therefore, centrifugal butter is sweeter and purer. It has also a higher melting point, (1) consequently it ought to keep longer than the ordinary product.

10o. IT LEAVES THE SKIM MILK SWEET FOR THE CALVES AND SWINE.

\section{DISADVANTAGES.}

It requires more outlay for plant. When large centrifugal separators are used (or two small ones) and steam power is required, the running expenses are somewhat greater than with older methods.

The larger the dairy, the less expense comparatively speaking. For very large cooperative creameries, the running expenses are not greater than by other methods, (if we except the cream gathering system.)

Therefore, this system is the best adapted to large private, and to cooperative or public dairies.

For comparative value of all the systems see tables of averages, Nos. 5 and 6 , pages 55 and 56 .

(1) Melting point of centrifugal butter......... $98^{\circ}$ Fahrt.

" " - ordinary butter..... 94\% Fahrt.

Difference............ $4^{\circ}$. 


\title{
$7 \frac{1}{4}$
}

\section{Centrlfuga! Ullk Senarators,}

\author{
SPETD AND THFITI.
}

The capaoity of a centrifucal machine, is the largest quantity of mill: which it can skim per hour, lesving bat an extremeif small grantity of butter fat in the skim milk about $25 \%$ o, or four onnes in 100 of whole milihi.

Thus a tuarhine, of $700 \mathrm{lbs}$ copacity, is one which can skm -00 lbe, par hour, leving bat a minimum of fat in the shim rnilk.

The ompletenes of the shimuing depends:

10. On the speed.

20. On the inflow of milk.

An exsmple will illustrate our meaning. A' orahine is running at 3000 revolutions a minute, and at this rate of speed, is capable of completely shimming 450 lbs of milk per hour. If through any cause the sped dumi nishes. the milk will not be completely slmimmod. A part of the bater fat will be Lost in the skim mill. The greater the diminution of sped, the greater will bot the weste of butter fat in the skim milk.

The same los: wotald tak-pluce if instead of the speed diminsbung. the iuflow of milk should increase; if instead of $\frac{1}{2}$ in lhs.. the inflow should rise to fon or 700 lbe, there would remun a much larger fooportion of butter fat in the skim milt.

A series of experiments was rnade to find the relatton 
between speed and inflow. The following law was dis. corered :

The inflow should vary as the square of the speed.

When the number of rerolutions which a given cen. trifugal must make, to completely skim a certain quantity of milk, is known, the number of revolutions, which it should make to skim any other quantity, is found by the following rule:

Multiply the given number of pounds by the square (1) of the required speed, and divide the product by the square of the given speed.

\section{EXAMPLE.}

A dairyman having a centrifugal capable of skimming $450 \mathrm{lbs}$. of milk per hour, when rumning at a speed of 2,400 rerolutions per minute, desires to know how many lbs. he can skim when running at 3,000 revolutions per minute.

\section{SOLUTION.}

$$
\begin{aligned}
& \text { As } 2,400^{2}: 3,000^{2}: 450: \times \\
& 2,400^{2}=5,760,000 \\
& 3,0 ; 0^{2}=9,000,000 \\
& 5,760,000: 9,000,000: 450: \times \\
& \frac{9,000,000 \times 450}{5,760,000}=703 \mathrm{lbs} .
\end{aligned}
$$

In the above problem the giren number of pounds was 450 . The required speed was 3,000 . of which the

(1) The square of a number is obtainell by multiplying it by itself; thus the square of 3 is 9 , of 4 is 16 , of 5 is 25 , of 6 is 36 , etc. 


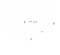


THE QUESTION OF SPEED IS OF GREAT IMPORTANCE.

For example, with a milk flow of $435 \mathrm{lbs}$. per hour, the small size Burmeinster \& Wain's separator left a minimum of 2 ounces of fat in the skim milk, but the quantity increased to $5 \frac{1}{4}$ ounces, when the speed of the machine fell from 2,410 to 2,287 revolutions per minute, and to a maximum of $6 \frac{1}{4}$ ounces, when the speed was still further reduced to 2,257 revolutions per minute.

When IS IT advisable to bUy a Centrifugat Milik Separator, and What size IS IT ADVISABLE TO BUY?

It is not, at present, advisable to buy a Centrifugal Separator for a dairy of less than twenty cows.

\section{SizE.}

The question of size depends on the quantity of milk to be skimmed and on the time which the dairyman can afford for this operation.

In large public dairies the time allowed for skimming should not exceed from four to six hours. In private dairies the work should be finished in from one to three hours.

It is desirable to have at least one large size Separator in every creamery of any importance. Prof. Fjord's control centrifugal for telling the amount of cream, in milk brought to the creamery, is adjustable to large Separators only. No well managed public creamery can do without this instrument.

Table showing the number and size of Separators necessary to skim a given quantity of milk. 
Creameries raving daily from
Number and size of Separator's necessary.
4 to 5,000 lbs. of milk

6 to 8,000 " "

9 to 12,000 " "
13 to 15,000 "6
16 to 20,000 "6

2 small Separators.

1 small and 1 large Separator.

2 large Separators.

3 " "

4 " 6

The lareses Separator will skim from 12 t; 1400 lhos per hour. The small Separator from 4 to 700 lbs.

If a muall -ramator will do the work in a reasonable time get a small one.

If a larew one will do. it is moprable not to try a laree one. but rather to buy tres small ones. For if one cets out of order. the second can be marle to do all the work while the first is bring rupaired. This rule does not apply to larese estahlishments ; it is better to harre treo or thee larew separators than four or six small ones. Te give below our reasons.

10. It takes lies power to drive two harge Separato:s than four small ones.

20. Four small siparators will require far more care in regulating the milk flow, than tuo large separators.

3o. Fonr mall separators will recuire far more care in regulating the speed, in looking after, in oiling, in cleaning, than two large Separators.

to. Four -mall suparators will cost more to buy to set nip. to k.p in weder. and to rum than two large Separators. 
5o. Four small Separators require more space than two large ones.

\section{ADVICE TO INTENDING PURCHASERS OF THE CENTRIFUGAL.}

Some one asks which Centrifugal to buy? We say buy a good one.

\section{Points of a good Centrifugal Separator.}

1o. A good Separator should be safe and strong, and its workmanship perfect.

2o. Its motion should be easy and steady.

3o. The foundation should be solid, and the revolving parts well protected.

4o. It should require but a moderate degree of power in proportion to the work done.

5o. It should be easy to take apart and to clean. There should be but few pieces to take apart.

6o. Its construction should be simple and plain, and the manner of working readily understood.

7o. It should be built so as to regulate the density of cream (getting thin or thick cream), while in operation.

80 . It should thoroughly skim the first and last milk contained in the drum.

9o. The separated liquids should be discharged in good condition.

10o. The machine should be cheap in the first cost, and cheap to put up. But the main point is that the machine be good, for a poor troublesome Separator, even cheap, will be more expensive in the long run, than a good one at a higher price. 


\section{DEFECTS TO BE GUARDED AGAINST IN}

\section{CENTRIFUGAL SEPARATORS.}

10. Liability to lose speed through any cause, shak ing for instance. (This is a very serious defect.)

2o. Sprinkling of milk and cream.

3o. Suction of cream by air into the skim milk.

4o. Loss of oil and heating, through imperfect means of oiling the bearings.

\section{POWER REQUIRED TO RUN CENTRIFUGAL}

\section{SEPARATORS.}

It is often supposed that centrifugal separators require much power to run them. This is a mistake. It takes less than three horse power to start the largest separators. Having reached full speed it requires much less power to keep it agoing. For this reason, several machines can be run by a power little greater than that which is necessary to start one or two large ones.

Of course, in this case, the machines are not all started together. The first is set going, and is got well underway before the second is started; when these two have reached the highest speed a third is set going, etc.

In dairies where two small separators are used the dairyman should provide 3 or 4 horse power. This is more than the power absolutely necessary, but it is always wise to have some spare power. In large creameries from 6 to 10 horse power is required. 


\section{REMARKS ON THE USE OF ANIMAL POWER IN RUNNING CENTRIFUGAL SEPARATORS.}

In using a horse to run a separator, it is well to remember that the strain on the animal depends :

1. On the speed of the separator. For example a horse could easily run a churn containing from 60 to $80 \mathrm{lbs}$. of cream and a small Burmeinster \& Wain separator, at a speed of about 2200 revolutions per minute, while the same horse would have all he could do to drive the same separator at a speed of 3000 revolutions per minute.

2o. On the time required to perform the day's work. Some farmers have milk for an hour daily. Others have milk enough for two or three hours, work. The less milk, the shorter is the time of the operation, and the more strain the horse could stand.

3o. On the kind of horse-gear used.

4o. On the speed at which the horse is made to go (1). In order to diminish the strain, use a larger pulley and decrease the speed of the horse. With a sweep power, the horse's pace should be regulated so as to cover less than three feet of ground per second.

Prof. Fjord's experiments with the small separator of Burmeinster \& Wain gave the following results :

With 2000 revolutions a minute and to skim from 2 to $300 \mathrm{lbs}$. per hour it requires $\frac{1}{2}$ horse power ;

(1) It must not be forgotten that the speed of the separator, and the speed of the horse are two different things. The horse may be and should be (if the work is to last a long time) traveling very slowly, while the machine is working very rapidly. 
With 24 no revolntions a minute and to skim from 3 to 400 lbs. per hour it requires $\frac{3}{4}$ horse power.

With 2300 revolutions a minute and to skim from 3 to $400 \mathrm{lbs}$. per hour it requires 1 horse power.

\section{TIMNGS TO BE REMEMBERED IN USING A MILK SEPARATOR.}

10. Start the machine slowly, skim the first and last contents aceording to directions given on page 28.

20. Let the speEd Be Const int. For this purpose, every centrifugal milk separator should be provided with: 1o A speed indicator atta hed to the spindle (1) so that the operator may ascertain the actual number of revolutions of the drum; 20 A belt strainer, to be used when the machine is losing sp sed.

30. Let the Inflew be Cunstant. For this purpose some means of controlling the inflow should be adoptad. Prof. Fjord is controllng funnel is the best moans we know of (see description, page 26).

40. WHEN THE SPEED DECREASES, DIMINISI THE INFLOW ; WHEN THE SPEED INUREASES INCREASE THE INFLOW. A decrease of $10 \%, 20 \%, 30 \%$ in the given speed of the Burmeinster \& Wain separater, must be attended by a decrease of $20 \%, 35 \%, 50 \%$ in th: milk inflow per hour. An increase of $10 \%, 20 \%, 30 \%$ in the speed must also be followed by an increase of $20 \%$, $40 \%, 70 \%$ in the quantity of milk worked per homr, if the same anount of butter is expected from a given quantity of mitr.

(1) We say spintle and nut the main shaft, advisadly, because the revolutions of the lather do not aresent accurately the rerviutions of the drum. 
5o. Srim THE MILK whILE WARM. If this be inconvenient, ths milik can be warmed to $88^{\circ}$ Fahrt. before skimming.

6o. For COLD MILK let the inflow be $\frac{1}{3}$ less than the inflow for warm milk. If a machine skims $300 \mathrm{lbs}$ of hot milk in an hour, it will skim $200 \mathrm{lbs}$ of cold milk in an equal time.

7o. Keep Working parts Very Well oIled. Use for this purpose the best lard oil or neat's foot.

80. CLEAN IMMEDIATELY after using.

\section{RELATIVE VALUE OF DIFFERENT CENTRI-} FUGAL SEPARATORS.

In determining the comparative value of rival Separators, it is necessary 1o. to determine what good skimming is; 20 . to ascertain how large a quantity of milk each Separator can skim when leaving a given quantity of butter fat in the skim milk; 3o. to see how long these can be run at their highest speed.

In Denmark the standard for average skimming by the Centrifugal is, to leave 0.15 of a pound of butter fat in the skim milk. (This is equal to a trifle less than $2 \frac{1}{2}$ ounces.) In Germany it is 0.35 . (This is equal to a trifle more than $5 \frac{1}{2}$ ounces.)

We believe that between 0.20 and 0.25 is the proper standard-that is to say between 3 and 4 ounces.

As some of our readers may think that there is not a great difference in the value of two machines, which. when skimming, the same quantity per hour leave, the one $2 \frac{1}{2}$ ounces [.15] and the ther $5 \frac{1}{2}$ nunces [.35] of butter fat in the skim milk, it is well to remark that in sorne cases, if the inflow into the rnachine which is lea- 
ving $2 \frac{1}{2}$ ounces were increased so as to leave $5 \frac{1}{2}$ ounces ; the inflow would be increased between 300 and $400 \mathrm{lbs}$. an hour.

This is a very important consideration and should not be lost sight of in buying:

We give below the result of a series of experiments made by Prof. J. N. Fjord to ascertain the exact capacity of the four undermentioned Separators in the following circumstances. [The Burmeinster \& Wain small and large sizes, the Neilsen \& Petersen and the De Laval Separators.)

1o. When each of the four Separators is extracting from the milk an equal quantity of cream of the same richness, [that is containing the same percentage of butter fat] and leaving the same quantity of fat in the skim milk.

20. When it is desired to leave a still larger proportion than 3 or 4 ounces of butter fat in a 100 lbs. of skim milk.

On page 85 we give the result of these experiments in table No. 13.

We see that during the period from April to July, and for the smaliest quantity of milk worked per hour, the differences between the "minimum" and the "maximum"(1) quantities of butter fat, left in the skim milk. amount to $1, \frac{8}{10}$ ozs. and to $\frac{9}{10}$ and $\frac{12}{2} \frac{2}{5}$ ozs. during the nonth of September.

This comparatively small difference shows the uniform reliability of the Centrifugal Milk Separator when properly used.

(1) The figures in the column of averages are not obtained from the figures of the minimum and maximum only, but from a whole series of experiments. 


\section{5}

TABLE No. 13.

Note. - In order to avoid large
fractions, we have prefixed to the
number of ounces the sign minus.
when the proper figure is a trifle
less than the given one. We have
used the sign plus when the proper
figure is a trifle more.

April and July 188\%.

A Burm. \& Wáin's centrifugal ismall size)

1. $290 \mathrm{lbs}$, of milk skimmed per hour

2. 435 lbs. do do do

B De Lavai's centrifugal....... ....

1. 300 lbs. of milk skimmed per hour

2. 450 ibs. do do do

C Nieisen \& Petersen's centrifugal

1. $49:$ ibs. of milk skimmed per hour

2. 810 lbs. do do do

D Burmeinster \& Wain's centrifugal (large size)

1. 870 lbs. of milk skimmeat per hour

\begin{tabular}{|c|c|c|c|c|c|}
\hline 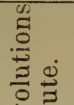 & $\begin{array}{l}\text { Percen } \\
\text { fat lef }\end{array}$ & $\begin{array}{l}\text { tage of } \\
\text { ft in the } \\
\text { milk. }\end{array}$ & $\begin{array}{l}\text { f butter } \\
\text { e skim }\end{array}$ & 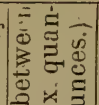 & $\frac{\infty}{a}$ \\
\hline 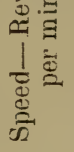 & 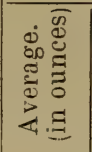 & 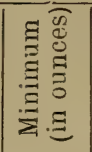 & 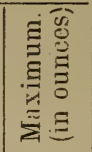 & 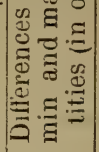 & $\mid \begin{array}{l}c \\
\vdots \\
\vdots \\
a \\
z \\
z\end{array}$ \\
\hline & & & & & \\
\hline 2410 & -2 & $-1 \frac{1}{2}$ & $-? \frac{1}{2}$ & +1 & 9 \\
\hline - & $3 \frac{1}{2}$ & $-2 \frac{1}{2}$ & $6 \frac{1}{4}$ & $3 \frac{3}{4}$ & 28 \\
\hline 6000 & $+2 \frac{7}{8}$ & $22 / 25$ & $3 \frac{1}{2}$ & $\mid 13 / 25$ & 5 \\
\hline- & 5 & $39 / 25$ & $-6 \frac{1}{4}$ & $289 / 100$ & 7 \\
\hline 1490 & $1 \frac{3}{4}$ & $+1 \frac{1}{4}$ & $22 / 25$ & $8 / 10$ & 10 \\
\hline - & $2 \frac{7}{8}$ & $214 / 25$ & $31 / 5$ & $16 / 25$ & 14 \\
\hline 1950 & $-2 \frac{1}{2}$ & $1 \frac{3}{4}$ & $-2 \frac{3}{4}$ & 1 & 4 \\
\hline 一 & $-4 \frac{1}{3}$ & $39 / 25$ & $6 \frac{3}{4}$ & $289 / 100$ & 8 \\
\hline 2410 & -2 & $1 \frac{3}{4}$ & -2 & $\frac{1}{4}$ & 8 \\
\hline "6 & 4 & $+3 \frac{1}{2}$ & $-4 \frac{1}{2}$ & 1 & 4. \\
\hline 66 & $614 / 25$ & $62 / 25$ & $+7 \frac{1}{2}$ & $121 / 50$ & 4 \\
\hline " & $119 / 25$ & $-10 \frac{1}{4}$ & $1: 16 / 25$ & $239 / 100$ & 4 \\
\hline 1800 & $-2 \frac{3}{4}$ & $214 / 25$ & $31 / 25$ & $12 / 25$ & 5 \\
\hline " & $111 / 5$ & $97 / 25$ & $1216 / 25$ & $39 / 25$ & 5 \\
\hline
\end{tabular}

2. $1280 \mathrm{lbs}$ do do do

September 1882

a Burmeinsler \& Wain's separator ismall size)

1. 290 ibs. of milk skimmed per hour

2. $435 \mathrm{lbs}$ do do do

3. 580 lbs. do do do

4. 720 lbs. do do do b Burmeinster \& Wain's milk separator (large size) hour

2. 1580 lbs. do do do
1. $780 \mathrm{lbs}$. of milk skimmed per

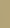


With a milk flow of 435 lls. per hour, the small size

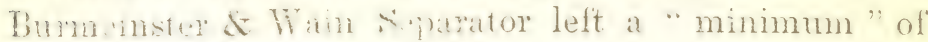
$2 \frac{1}{2}$ ozs. and a "maximum" of $6 \frac{1}{4}$ ozs. of butter fut in the skim milk.

With a milk dow of 1.220 1bs. per homr, the large

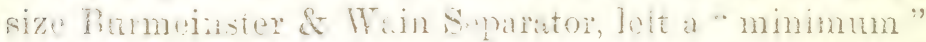
of $3 \frac{9}{25} 0 \% s$, and a "maximum " of $6 \frac{1}{4} 0 \%$. of butter fat in the slim milk.

With a milk how of 1.53011 s. per homr, the same size

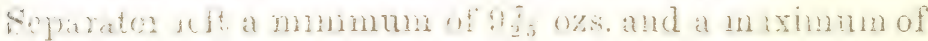
Ifis ous w whiler fat in the shim milk.

In arerae of the whols series of axperiments in the $1 \mathrm{~s}$ ase wan $: 12$ omes ; in the and $4 \frac{1}{3}$ onaces, and in the $31 d 11 \frac{1}{5}$ ounces.

Hrom a erporiments made fiom April to July, the Separators if clasifind acoording to efir.ien $y$, should be found in the following order:

TARIE NO.

FOR THE SMALLEST OUT NTITY OF MIL.F WVIRED PER HOUR.

\begin{tabular}{|c|c|c|c|c|}
\hline- & & & $\begin{array}{l}\text { Fract or a } 1\} \text {. } \\
\text { of butler at } \\
\text { loff in } 100 \text { ibs. } \\
\text { of skim milk. }\end{array}$ & In olinces. \\
\hline \multirow[t]{2}{*}{ 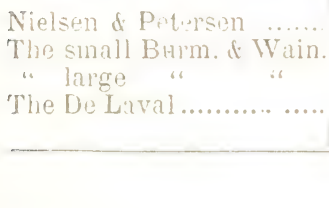 } & $\begin{array}{l}190 \\
2911 \\
870 \\
300\end{array}$ & 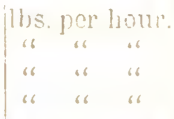 & $\begin{array}{l}0.11 \\
0.12 \\
0115 \\
0.18\end{array}$ & $\begin{array}{l}1 \frac{3}{4} \text { OzS. } \\
\text { Almost } 2 \text { ozs } \\
24 / 10 \text { OZS. } \\
2 \frac{7}{2} \text { OZS. }\end{array}$ \\
\hline & & Average......... & 0.14 & $22 / 15$ ozs \\
\hline
\end{tabular}


Table No. 14. Continued :-

FOR THE LARGEST QUANTITY OF MILK WORIKED PER HOUR.

\begin{tabular}{|c|c|c|c|c|}
\hline $\begin{array}{l}\text { Nielsen \& Potersen......... } \\
\text { The small Burm. \& Wain } \\
\text { " large “ } \\
\text { The De Laval ................. }\end{array}$ & $\begin{array}{r}810 \\
435 \\
1,280 \\
450\end{array}$ & 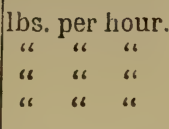 & $\begin{array}{l}0.18 \\
0.22 \\
0.27 \\
0.31\end{array}$ & $\begin{array}{lc}2 \frac{7}{8} & \text { ounces. } \\
3 \frac{1}{2} & \text { "6 } \\
4 \frac{7}{3} & \text { ،6 } \\
5 & .6\end{array}$ \\
\hline \multicolumn{3}{|c|}{ Average.......... } & 0.24 & $311 / 15$ \\
\hline
\end{tabular}

The average quantity of butter fat left in the skim milk amounts to $2 \frac{2}{T^{5}}$ ozs. in the case of the first four Separators on the list, and to $3 \frac{11}{15}$ ozs. in the case of the last four.

This last figure is nearly $75 \%$ larger than the first.

It is then safe to say, that an increase of $50 \%$ in the quantity of milk worked per hour, produces an increase of $75 \%$ in the amount of butter fat left in the skim milk,

This increase amounts to about $1 \frac{3}{5}$ ozs. of butter fat, and is equiralent to a decrease of $1_{3}$ ozs. in the yield of butter per 100 lbs. of milk, that is if the " smallest" quantity of milk worked per hour gives 4 lbs. of butter per 100 lbs. of milk, the "largest " quantity of millk worked per hour gives only $3.90 \mathrm{lbs}$. or 3 ibs. 14 ounces, and instead of $25 \mathrm{lbs}$. of milk to a lb. of butter, it would take $25 \frac{2}{3}$, or $\frac{2}{3}$ of a lb. more.

In a series of experiments made to test the relative value of the Nielsen \& Petersen and Lefeldt Centrifugal, it was found, that a loss of butter fat amounting to $13 \frac{1}{2}$ ounces took place for every hour the Lefeldt Centrifugal was worked. This loss was due to a certain amount of cream being drawn into the skim milk by air. This defect is known under the name of "Suction of cream ". 
We do not know whether this defect in the Lefeldt Separator has since been remedied.

POWER REQUIRED TO DRIVE THE BURMEINSTER AND WAIN AND DE LAVAL MILK SEPARATORS.

We now give, in tabular form the result of a series of experiments made by Prof. Fjord to determine the powrer necessary to drive the Burmeinster \& Wain and De Laval milk separators.

\section{DYNAMOMETER EXPERIMENTS.}

TABle No. 15.

These figures show the Separator's own consumption of power only.

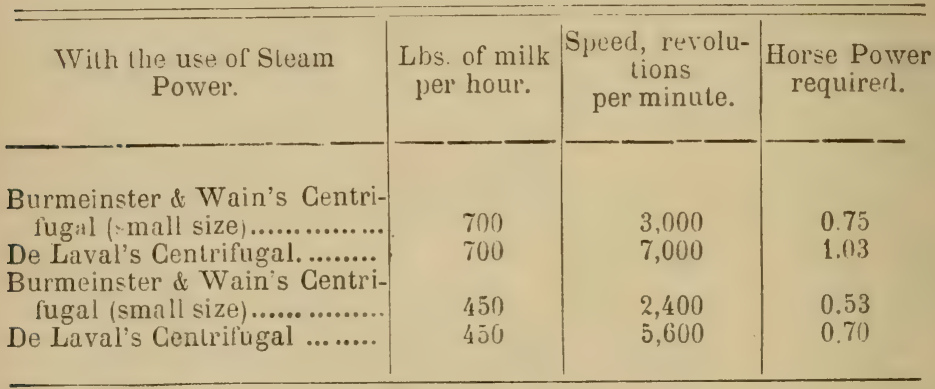

TABle No. 16.

This table shows the full consumption of motive power, horse power and gearing included.

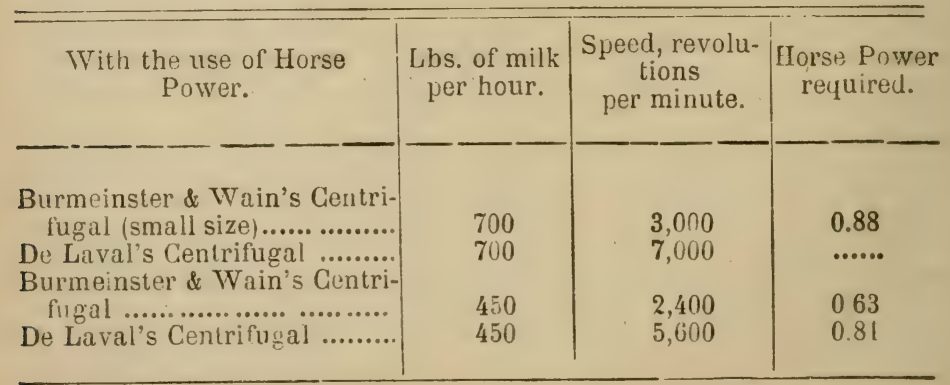


The experiment, with the De Laval machine, running at a speed of 7,000 revolutions per minute could not be carried out with a common horse, as it was unable to keep up the speed, the power required being calculated to be 1.20 horse power, -0.80 horse power is reckoned to represent the outside amount of work that we can expect from a horse, if the strain is to be kept up for some time.

Therefore, an inflow of $450 \mathrm{lbs}$. of milk per hour, and a speed of 5,600 revolutions per minute, must be taken as the maximum capacity of De Laral's separator, driven by horse power.

Experiments showing the reiative merits of the Burmeinster \& Wain and De Laval Milk Separators, as regards Speed, Consumption of power, Percentage of butter fat in skim milk, and inflow.

TABLE No. 17.

\begin{tabular}{|c|c|c|c|}
\hline $\begin{array}{l}\text { Same quantity of milk worked } \\
\text { per hour. }\end{array}$ & Unequal & $\begin{array}{l}\text { consumptic } \\
\text { power. }\end{array}$ & on of motive \\
\hline & Percentage & $\mathrm{e}$ of $\mathrm{Fat}$ in $\mathrm{tl}$ & he Skim Milk. \\
\hline & $\begin{array}{l}\text { In special } \\
\text { trial. }\end{array}$ & $\begin{array}{l}\text { In } 200 \mathrm{lbs} . \\
\text { of milk. }\end{array}$ & $\begin{array}{l}\text { In all the } \\
\text { milk skim'ed } \\
\text { in one hour. }\end{array}$ \\
\hline 1st Series, 450 lbs. per hour. & & & \\
\hline $\begin{array}{l}\text { A-Burmeinster \& Wain ....... Speed, } \\
2,400 ; \text { power, } 0.63 \mathrm{~h} . \mathrm{p} . \ldots . . \\
\text { B-Laval..speed, } 5,600 ; \text { power, } 0.8 \mathrm{i} .\end{array}$ & $\begin{array}{l}0.25 \\
0.23\end{array}$ & $\begin{array}{l}021 \\
0.23\end{array}$ & $\begin{array}{l}0.23 \\
0.33\end{array}$ \\
\hline 2nd Series, 700 ibs. per hour. & & & \\
\hline $\begin{array}{l}\text { A-Burmeinster \& Wain ....... Speed, } \\
3,000 ; \text { power, } 0.88 \ldots \ldots \ldots \ldots \ldots \ldots \ldots \\
\text { B-Laval..speed, } 7,000 ; \text { power, } 1.20\end{array}$ & $\begin{array}{l}030 \\
029\end{array}$ & $\begin{array}{l}0.22 \\
0.29\end{array}$ & $\begin{array}{l}0.28 \\
0.29\end{array}$ \\
\hline
\end{tabular}

In the "special trial " the De Laval had the advantage. In the trial "In 200 lbs.", the Burmeinster \& Wain had 
the advantage. In the trial "In all the milk in an hour", the results were the same.

The general result shows that De Laval's milk separator requires 29 per cent. more power than Burmeinster $\&$ Wain's in the first series, and 36 per cent. in the second series.

TABLE No. 18.

The same quantity of milk worked per hour.
Same consumption of motive power.

\begin{tabular}{|c|c|c|c|}
\hline & \multicolumn{3}{|c|}{ Percentage of Fat in the Skim Milk. } \\
\hline & $\begin{array}{l}\text { Special } \\
\text { trial. }\end{array}$ & $\begin{array}{l}\text { In about } \\
200 \text { lbs. of } \\
\text { milk. }\end{array}$ & $\begin{array}{l}\text { In all the } \\
\text { milk skim'ed } \\
\text { in one hour. }\end{array}$ \\
\hline 3rd Series, 450 lbs. per hour. & & & \\
\hline $\begin{array}{c}\text { A-Burmeinster \& Wain...... Speed, } \\
3,000 \text { revolutions; } 0.81 \text { horst }\end{array}$ & & & \\
\hline 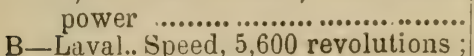 & 0.14 & 0.12 & 0.13 \\
\hline $\begin{array}{l}\text { B-Laval.. Speed, } 5,600 \text { revolutions } \\
0.81 \text { horse power..................... } \\
4 \text { th Series, } 600 \text { lbs. per hour. }\end{array}$ & 0.23 & 0.27 & 0.25 \\
\hline $\begin{array}{l}\text { A-Burmeinster \& Wain ..... Speed, } \\
2,950 \text { revolutions; } 0.83 \text { horse }\end{array}$ & & & \\
\hline power ................................ & 0.23 & 017 & 0.21 \\
\hline 0.83 horse power...................... & 0.38 & 0.36 & 0.37 \\
\hline
\end{tabular}

In this case Burmeinster \& Wain's milk Separator had the advantage all through. In the special trial, Laval's milk Separator leaves:

In the first series, $\frac{9}{14}$ or 64 per cent.; in the second series, $\frac{15}{2} \frac{5}{3}$ or 65 per cent, more fat in the skim milk than Burmeinster \& Wain's.

These differences correspond to $1 \frac{1}{2}$ and $2 \frac{1}{2}$ ozs. of fatty matter in $100 \mathrm{lbs}$. of skim milk, and show, in reckoning 


\section{1}

$25 \mathrm{lbs}$. of milk to a lb. of butter, that Burmeinster \& Wain's milk Separator gives from $2 \frac{1}{2}$ to $3 \frac{3}{4}$ per cent. more butter than De Laval's.

TABle No. $i 9$.

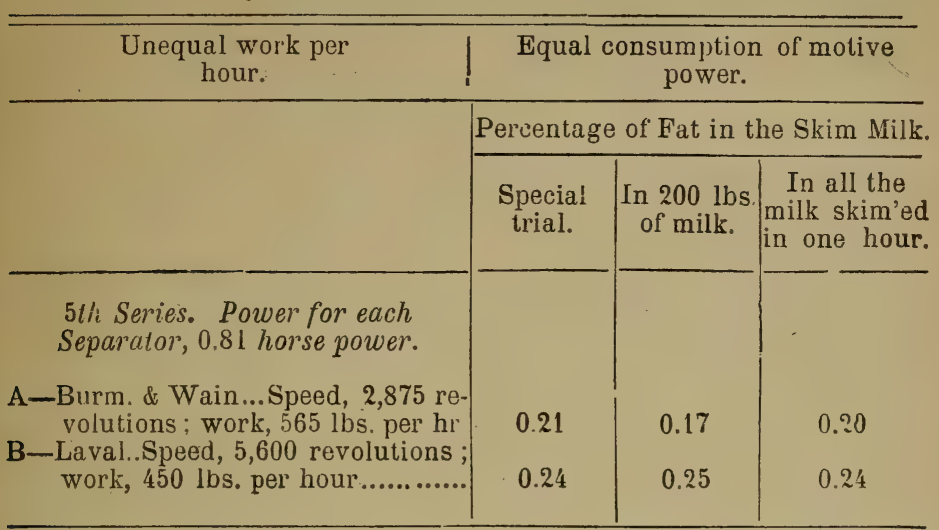

These last experiments clearly show that, with the same amount of motive power, the small milk separator of Burmeinster \& Wain can skim 115 lbs., or about 25 per cent. more milk than De Laval's, and leave much less fat in the skim milk. And with the same completeness of skimming and the same consumption of power, Prof. Fjord says, that Burmeinster \& Wain's separator can skim 150 lbs. or 33 per cent. more milk than De Laval's. Summing up, the result of the comparison may be shortly described as follows :-

1st. With the same completeness of skimming and the same quantity of milk worked per hour, De Laval's separator requires one-third more power.

2nd. With the same completeness of skimming and the same consumption of power, Burmeinster \& Wain's small (B) separator skims one-third more milk than De Laval's. 
3rd. With the same quantity of milk worked pe. hour and the same consumption of power, De Laval's leaves 64 to 65 per cent. more fat in the sinim rnilk.

The same report shows that Eurmeinster \& Wain's large size separator requires $1 \frac{1}{2}$ horse power.

\section{HOW TO SKIM HOT MILK.}

Milk fresh and warm from the cow, is in the best condition to yield its cream by centrifugal force. If it is allowed to cool, it lcses a part of its cream yielding power. If run cold into the Separator, other conditions being equal, a larger quantity of fat will be left in the skim milk.

Nevertheless, when milk has to be transported to a creamery it is impossible to aroid cooling it, because it is transported only once a day.

The loss caused by cooling the milk can be avoided by following carefully the following rule :

1. Aerate the evening's milk; 20 . Cool it to $60^{\circ}$ Fahrt., and keep it all night in cold water, 3o. Brng it on the following morning, with the morning's milk to the creamery. It is better to bring the two milkings in separate cans. At the creamery, weigh the inilk, cmpty it into a rat, mix it well in order to have it of miform richness, heat it up to about $88^{\circ}$ Fahrt., and pass it through the separator in this condition. The operator should cool the cream immediately on its discharge from the separator to $45^{\circ}$ Fahrt. (1).

(1) It must be borne in mind that the cream is cooled to counteract the injurious effect of heating the milk. Therefore the higher the milk has been heated the lower the cream must be cooled. For every degree higher than $88^{\circ} \mathrm{Fahrt}$. cool another degree below $45^{\circ} \mathrm{Fahrt.}$ 
Any neglert to cool the cream will be attended with various disadvantages. 10. The cream will contain an extra amount of cheesy matter, the effect of which is to injure the quality of the butter ; 20 . It will prevent the complete churning of the cream, thereby diminishing, the quantity of the butter.

\section{HOW TO SKIM COLD MILK TO THE}

BEST ADVANTAGE.

When the operator is not pressed for time, he can skim cold $r i^{\prime} k$ nearly as well as warm milk, by diminihsing the flow about $\frac{1}{3}$, or by increasing the speed proportionately.

We give below a table with experiments on this subject.

A quantity of evening milk amounting to $1350 \mathrm{lbs}$. having been well mixed, was divided into three equal parts of $450 \mathrm{lbs}$, one of which was skimmed immediately after milking, and the other two portions, being cooled to $52^{\circ}$ Farht., were kept orer night. The next morning, on portion was skimmed while cold, and the other after being previously heated to $104^{\circ}$ Farht.

We give the result of these experiments in table No. 20.

The milk skimmed immediately after milking gave $3.72 \mathrm{lbs}$. of butter, there remained in the skim milk, three and one fifth ounces of butter fat.

The milk skimmed, after having been cooled and heated, gave but 3,51 lbs. of butter and, singular to say, the same amount three and a fifth ounces of butter fat remained in the skim milk. It should have left $6 \frac{1}{2}$ ounces. But it was discovered that the portion of fat which 


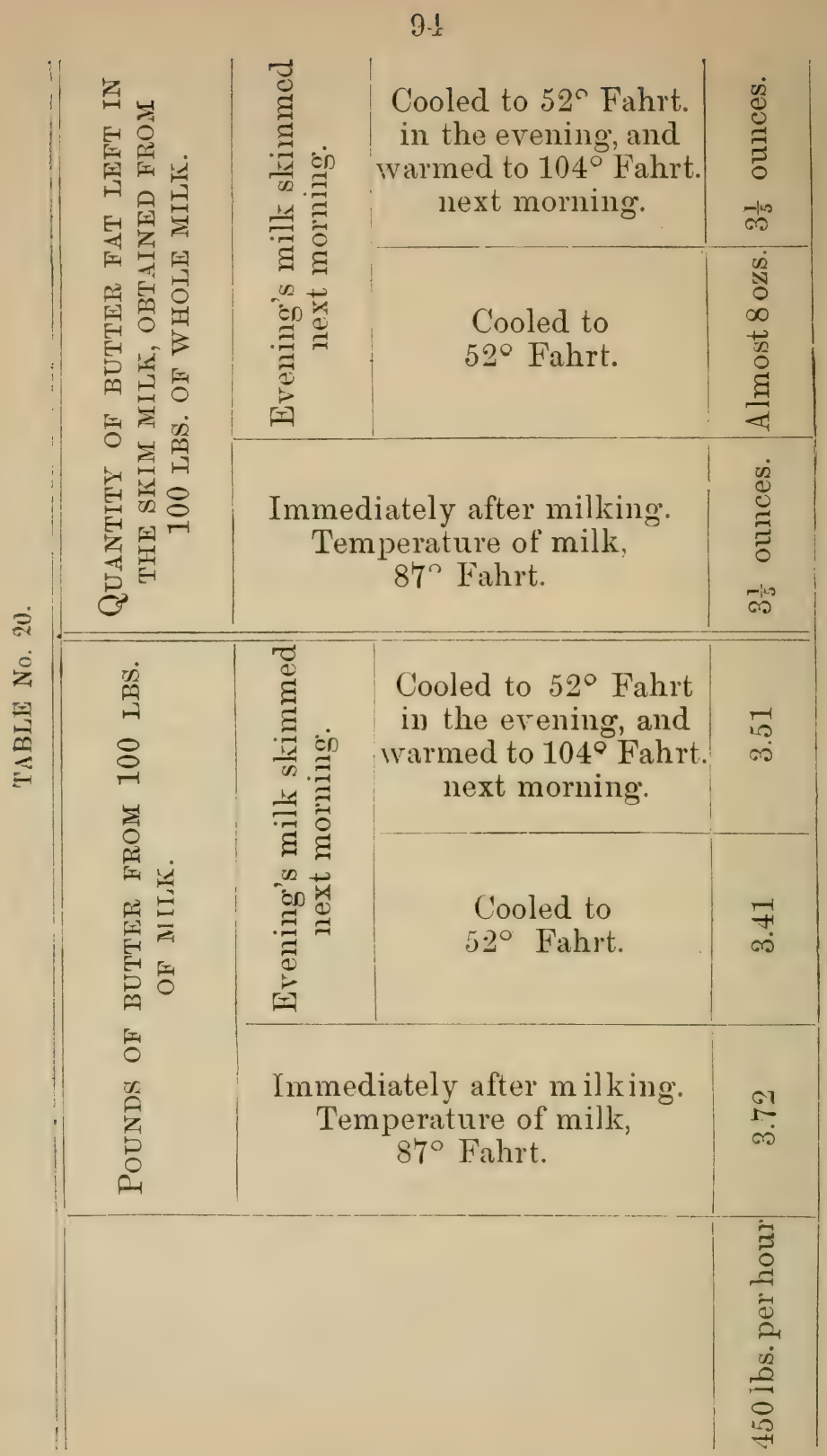




\section{5}

could not be accounted for, $3 \frac{1}{3}$ ounces, had been lost in churning. It was found in the butter milk. This loss was due to the cream not having been cooled as it left the machine

In another series of experiments, where the cream was immediately cooled, there was no loss in the churning, and the heated milk gave as good a yield as the milk skimmed immediately after milking. 


\section{What to do with the skim milk,}

In places where large creameries are established, the question naturally arises what to do with the skim milk. The answer to this question must vary to a certain extent with the locality.

In this country I do not think it is advisable to convert the skim milk into skim cheese, at least at present, because :

10. The demand for skim cheese is yet very limited.

20. The methods for making skim cheese are not generally understood in this country.

3o. The making of skim cheese, as generally made in the United States and Canada, is liable to destroy the splendid reputation of Canadian cheese on foreign markets. (1)

We think, the best thing to do with the skim milk, is to use it as food for calves and swine. We give below our reasons.

1o. We import large quantities of po.k.

20. There is a large demand for pork and beef in Europe.

3o. The using of the skim milk in this manner has for result to restore to the soil, in the shape of manure, a part of the fertilizing substances, which had been drawn therefrom.

(1) We do not find anything objectionable in skim-cheese, if it is made and sold as such. In Holland and other European countries it bears a special form, by which it is easily distingui shed. 



\section{The Construction of Ice Houses,}

The information contained in this chapter has been compiled from the best foreign and American authorities, and from our own experience; and we have no doubt, it will prove of some interest to dairymen and farmers.

\section{GENERAL PRINCIPLES.}

Water freezes at a temperature slightly below $32^{\circ}$ Fahrt. Ice melts at a temperature ever so little above $32^{\circ}$ Fahrt.

The three enemies of ice are water, heat and moisture. Water and moisture are more destructive of ice than ordinary atmospheric heat; at least when the ice is protected from the direct rays of the sun.

In building an ice house, therefore. the ice must be protected from these three things.

Moisture generally comes from the bottom of an ice house, and heat from the sides and the top.

Moisture in an ice house may be produced by two causes: by the atmosphere and by some defect in thbottom of the building.

That which is caused by the atmosphere must be car ried off by properly constructed ventilators; that which comes from the foundation, must be carried off by guod drainage.

\section{SIZE OF AN ICE HOUSE.}

For dairy use it will of course depend on the quantity of milk, cream and butter handled daily.

We can give no special rule, but the following figures 
may guide farmers and dairymen, as to the size of the buildings required for their special wants.

In an ice house, where the ice is packed closely, ice men generally allow about 45 lbs of ice for every cubic foot of space, or 45 cubic feet to the ton. Where the ice is loosely packed, they allow about $40 \mathrm{lbs}$ of ice for every cubic foot of space, or about 50 cubic fect to the ton.

Table showing, in "ubic feet, the ruantity of ice reguired for setting milk $2 t$ hours. in single sided tanks, accordiag as the ice is closely or loosely packed.

\begin{tabular}{|c|c|c|c|c|c|c|c|}
\hline & \multicolumn{4}{|c|}{ From May to November or 180 days. } \\
\hline & & & & \multicolumn{2}{|c|}{$\begin{array}{l}\text { Ice elosely packiel } \\
\text { or at } 45 \text { cubic loet } \\
\text { to the ton, about } \\
45 \text { ibs to the cubic } \\
\text { fool. }\end{array}$} & \multicolumn{2}{|c|}{$\begin{array}{l}\text { Ic loosely packed } \\
\text { or at } 50 \text { cubic feet } \\
\text { to the ton, about } \\
40 \text { ths to the cubic } \\
\text { foot. }\end{array}$} \\
\hline & & & & $\begin{array}{l}\text { Cubic } \\
\text { feet }\end{array}$ & Tons & $\begin{array}{c}\text { Cubie } \\
\text { fert }\end{array}$ & Tons \\
\hline $100 \mathrm{lb}$ & i & cre & per day & $2 \pi 0$ & 6 & 300 & 6 \\
\hline $200 "$ " & " & & is & 540 & 12 & 6ono & 12 \\
\hline 300 " & " & "s & 66 & 810 & 18 & 900 & 18 \\
\hline 400 " & " & "6 & " & 1080 & 24 & 1200 & 24 \\
\hline 500 " & " & " & 16 & 1350 & 30 & 1500 & 30 \\
\hline 600 " & a & “ & "، & $\mid 6: \geqslant 11$ & 36 & |xin| & 36 \\
\hline 700 " & "6 & 66 & "6 & 1890 & 42 & 2100 & 42 \\
\hline 800 " & "6 & " & "6 & $? 160$ & 48 & 240 & 48 \\
\hline 900 ، & 6 & " & " & 2430 & 54 & 2700 & 54 \\
\hline $1000^{\prime \prime}$ & " & " & " & 2700 & 60 & 3000 & 60 \\
\hline $2000^{6}$ & "6 & 6 & " & 5400 & 120 & 6000 & 120 \\
\hline
\end{tabular}

In ortur to find ont the storing capacity of an ice house multiply the length, width and height together, the result is the capacity in cubic feet. By dividing the number of cubic feet by 4.5 or 50 , the apracity in tons is obtained. Thus a house 10 feet long. 10 faet wide and 12 feet high $=1200$ abic feet. This divided by 45 or 


\section{1}

50 according as the ice is closely or loosely packed gives $26 \frac{2}{3}$ or 24 tons.

Other things being equal, the higher an ice house is built, the better the ice keeps.

We give below a few figures on the dimensions of ice houses.

We do not advise to build an ice house smaller than $8 \times 8,10$ feet high, inside measurement.

Storing capacity of ice houses of different sizes.

\begin{tabular}{c|c|c}
\hline \multicolumn{2}{l}{$\begin{array}{c}\text { Length, width, height, } \\
\text { in feet. }\end{array}$} & \multicolumn{2}{|c}{ Capacity in cubic feet and tons. } \\
\cline { 2 - 3 } & Cubic feet. & Tons. \\
\hline $10 \times 10 \times 10$ & 1000 & 22 \\
$12 \times 12 \times 13$ & 1872 & $41 \frac{1}{2}$ \\
$12 \times 15 \times 15$ & 2700 & 77 \\
$12 \times 18 \times 16$ & 3456 & 142 \\
$20 \times 20 \times 16$ & 6400 & \\
\hline
\end{tabular}

SHRINKAGE.

In deciding the question of size one important thing must be considered, that is the waste known as shrinkage.

The larger the ice house, the less waste in proportion. In a well constructed ice house of 165 tons capacity or 7500 cubic feet, the waste should not be greater than 15. per cent, or 25 tons.

In one whose capacity is only 28 tons or 1250 cubic feet, the waste should not exceed 25 per cent. or 7 tons.

In building an ice house, build it rather too large than too small. 
The house should stand, as much as possible, by itself, in a high, airy, and sumny position (1) because such a site requires but little drainage. When such a position is not to be had. and when the soil is not of a sandy, gravelly or otherwise porous nature, the drainage should receire the builder's most careful attention. On porous soil, an outside ditch is all that is necessary.

Loamy and heary land should be thoroughly under. drained. In the case of small houses, these drains should be round the outside of the buildings. In large ice houses, and when the land is very wet, it is sometimes necessary to carry the drains under the buildings.

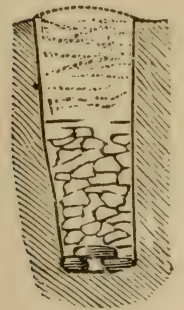

Fig. 40.

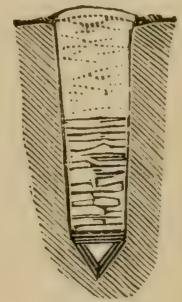

Fig. 41 .

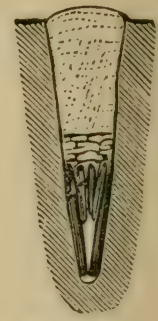

Fig. 4t.

What are known as "French drains" (see fig. 40, 41 and 42) trenches filled with stones, answer admirably, and are cheap besides.

These tremches should be dug across the place where the ice house is to be built, with a grade of descent of at least one quarter of an inch to the foot. They should

(1) This exposure to the sun and air, will not be detrimental, as many suppose, for if the house is jroperly constructed anil the ice sufficiently protected, the heat cannot penetrate it to any great extent, whilst the exposure will serve to absorb vapor and dampness, which are more detrimental than the heat outsi le of the house. 
be two feet.wide (or: more), filled with small stones up to within three inches of the level of the ground, which three inches should be filled with shavings or some other material that will keep the dirt out. The end of the drain should be carried a fair distance from the building.

Tiles or wood may be used for the same purpose, but in this case the drain should terminate by a pipe shaped like a $V$, to form a trap. This to a certain extent prevents the air from entering.

BEST MATERIAL FOR AN ICE HOUSE.

Wood is the cheapest and best material for building an ice house. Its porous character is favorable to free evaporation, and evaporation is the key to the secret of keeping any building dry. The most porous wood is the best. The kinds most in favor are hemlock and the three branches of the pine family, namely spruce and white and yellow pine. The main points aimed at in the selection is their relative durability.

Stone or brick retains the vapors and causes sweating, which melts the ice.

\section{THE BOTTOM OF AN ICE HOUSE.}

The bottom of an ice house should be as dry as possible, and at the same time impervious to heat, air, damp. ness and water, for if through defective drainage, the ice is constantly immersed in water, the waste will be much greater at the bottom of the ice house, from this cause, than at the top from the heat of the sun. It would therefore, hardly be possible to give the subject of drain. age and construction of the bottom too much attention, when houses are first built. 


\section{FOUNDATIONS}

Large houses should stand on a stone foundation, al. though it is the custom with many builders to do away with the wall, and rest the sills directly on the ground. In low places the sills rest on piles. When they rest on the ground, the sills should be of cedar or white pine.

If a stone foundation be laid, it should be of masonry of the best description; it should be carried below the line of frost, and one foot above the surface of the ground. When a stone foundation is laid, the sills may be of the same material as the rest of the building.

\section{THE FLOORING OF AN ICE HOUSE.}

The drain and foundation having been constructed. level the ground inside. If there be any slope, let it be towards the drain. Corer the ground to a depth of at least 10 inches, with a bed of fine gravel, cinders, sharings, tail or sawdust. (We prefer cinders.)

Lay stringers $4 \times 4$ about 3 feet apart, and fill and pack well between stringers with cinders or sawdust. Over these stringers nail 2 inch boards. They should neither be tongued and grooved nor tightly fitted together. This is to allow the water to trickle down between them, and thus escape.

\section{A TIGHT FLOOR.}

When ice houses are built in connection with dairies etc. and it is desirable to utilize the drippings, a tight floor is put in. This can be made of tongued and grooved boards closely fitted together, after the bottom has been prepared in the manner previously described. Asphalt, cement or concrete floors may also be constructed. 
A tight floor should slope from two sides to the middle. A small groove, along the middle of the floor, receives the water, and conducts it to an end of the building from which a pipe carries it to the cold room or dairy. The end of the pipe should be bent in the form of a $\nabla$, so as to prevent the air from entering.

\section{WALLS.}

The best ice houses have three shells, an inside, a middle, and an outside shell. The space between the inside and the middle shells varies, with the size of the ice house. The smaller the house, the greater should be the inner space. The smaller and lower the ice house, the less should be the outer space, or draught cham. ber.

\section{HOW TO PUT UP THE WALLS.}

FOR LARGE HOUSES.

The uprights should consist of stout $8 \times 10$ posts around the outside, at intervals of 12 feet placed on sills $6 \times 10$. On these posts, the frame work and rafters of the roof will rest. Immediately on the inside line of these posts $3 \times 6$ studdings, should be firmly placed at a distance of 3 feet apart. Commencing about 3 inches from the bottom, (so as to leave an open space) nail weather boards on the outside of the posts, (not to the studs) up to the eaves. Commencing close at the bottom, nail to the posts and studding on the inside, tongued and grooved boards. They should be fitted as closely as possible.

Upon the inside of this wall stretch a sheating o1 felt. (1)

(1) Common roofing felt, or better Sackett's sheilting consisting of a layet of cement between two layers of manilla paper. It costs $\frac{1}{2} \mathrm{ct}$. a square. foot. 
Then place against this papered wall studs of $3 \times 8$ at the same distance apart as the first. From stud to stud, stretch another course of manilla sheating, and over this commencing at the bottom, nail tongued and groored boards. They sho lld be joined as closely as possible.

The space between the two interior walls, known as the packing chamber,should be filled (when convenient) (1) with dry saw-dust very-tightly packed. If sawdust cannot be had use dry tan, shavings or chaff.

The outside space, called the draft chamber (fig. 48) which is in this ease about 10 inches, has an opening at the bottom to allow the air to enter and at the top, to allow it to escape. Its purpose is : to prevent the rays of the sun from striking directly on the walls; to protect the walls from rain and to afford better ventilation.

Some of the largest Canadian builders construct their walls in the following simple manner: They place on the sills, uprights 3 or 4 inches by 10 or 12 inches from 3 to 4 feet apart. Orer these they nail rough boards and fill in with saw-dust.

In many cases the draught chamber is dispensed with. When this is done, the space between the walls of the packing chamber should be at least 18 inches.

WALLS FOR SMALL HOUSES.

The walls for these, should be built upon the same plan as for large houses, (smaller timber should be used than for large houses.) The difference is that the space for the packing chamber, should be considerably greater, and that for the draught chamber considerably less. For an ice house 15 feet high, the draught chamber should be from 2 to 5 inches.

(1) When it is not convenient to fill the space, be careful in boarding ep 10 make it as air tight as possible, this is known as a dead air chamber. 
Thus in a small building, the packing chamber should be about 14 inches and the draught chamber five.

\section{ROOF AND VENTILATORS}

A good water-tight roof of reasonable pitch should be placed over the walls. Wrod and shingles are the best materials to use. For those desiring a model roof see fig. 48 with description.

When no air chamber is constructed, two small doors in the gables placed as near to the top of the roof as possible will help to ventilate. These doors should be

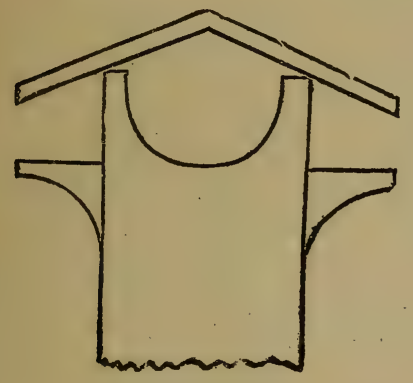

Fig 43 .

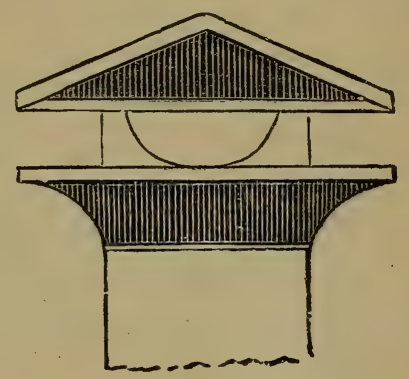

Fig. 44.

opened during cool nights to let out the warm air, which may have accumulated during the day.

One style of ventilator consists of an opening at the ridge pole, running the whole length of the roof. It is covered with a box-shaped cap, open at the extremities. (See fig. 48.)

Another style of ventilator is very simple and effective (see fig. 43 and 44). It consists of 4 hoards out of which a $\mathrm{U}$ shaped piece is cut. These boards are nailed together, and, a roof shaped cover, projecting at least 3 inches, is fixedat the top. Four pieces of wood $2 \times 3$ inches, having the underneath beveled, are nailed to the sides of this 
ventilator. This gires it a better shape, and increase the current.

The roof of the ventilator, should extend well orer the under piece to prevent the rain from entering.

The siz: of box ventilators should be made in proportion to the length and breadth of the building. The smaller the ice-house the larger the ventilator should proportionately be.

For an ice house $10 \times 10 \mathrm{ft}$., the ventilator should be 4 square inches to the square foot. Thus, it should have a surface of $20 \times 20$ inches.

For an ice house of $20 \times 20$ feet, the ventilator should be $3 \frac{1}{4}$ square inches to the square foot. This would give a ventilator of $36 \times 36$ inches.

For an ice house $50 \times 60$ the ventilator should be $1 \frac{2}{5}$ square inches to the square foot of surface. This would give a ventilator of about $36 \times 120$ inches.

If a square box ventilator is used the sides should be of lattice, like window blinds.

\section{A LOFT FLOOR.}

In good ice houses, a loft floor is generally made. It is more necessary in small ice houses then in large ones.

This floor should be covered with saw dust, hay or straw to the depth of from 10 to 12 inches.

If the house is to be frequently opened, lengthwise, along the middle of the floor, an opening should be left for ventilation. Its extremities should be about $2 \frac{1}{2}$ feet from the gables. The width will depend on the width of the ice house. It is a safe rule to allow 3 inches for every foot in the width of the building.

For instance an ice house $12 \times 10$ feet inside measure; would have an opening 3 feet wide. Lengthwise on 
each side of the opening is fixed, with good stout well varnished hinges, a trap. When one of these traps is closed, one half of the opening is covered. When the two are closed, the whole is covered.

To the upper side of these traps, is fastened a stout rope, which is passed through a short piece of tube (1) rumning through the floor, for that purpose. By this

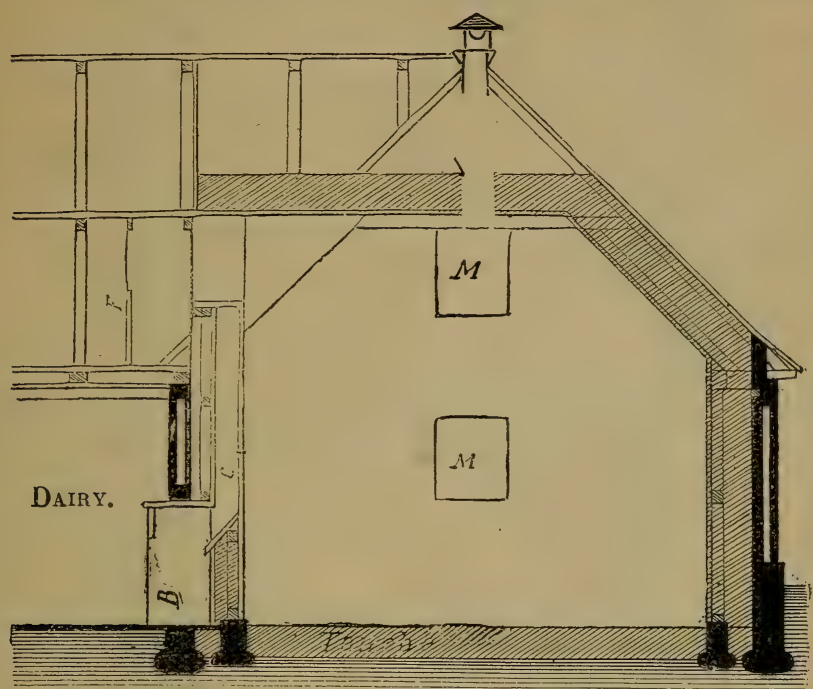

Fig. 45.-Ice house and d.iry. $-M M$, Openings for fill.ng the house $B$, Ice box. $C$, Shaft. $F$, Entrance.

means the trap can be raised or lowered at will from below. Thus any desired degree of rentilation is obtained.

At the back of these traps, there should be fixed to the floor a piece of wood, sufficiently high to keep the trap in such a position, that it will close by its own weight, when the rope is loosened.

(1) A tube is used to prevent the dunnage from falling through the floor. 
If the homse is not to be opened herpuenty or in sinall

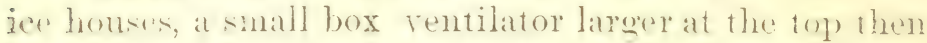
at the hentom is suffieient. It shomld be made to project

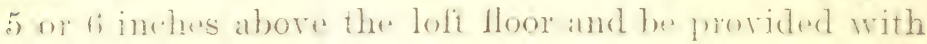
a cover.

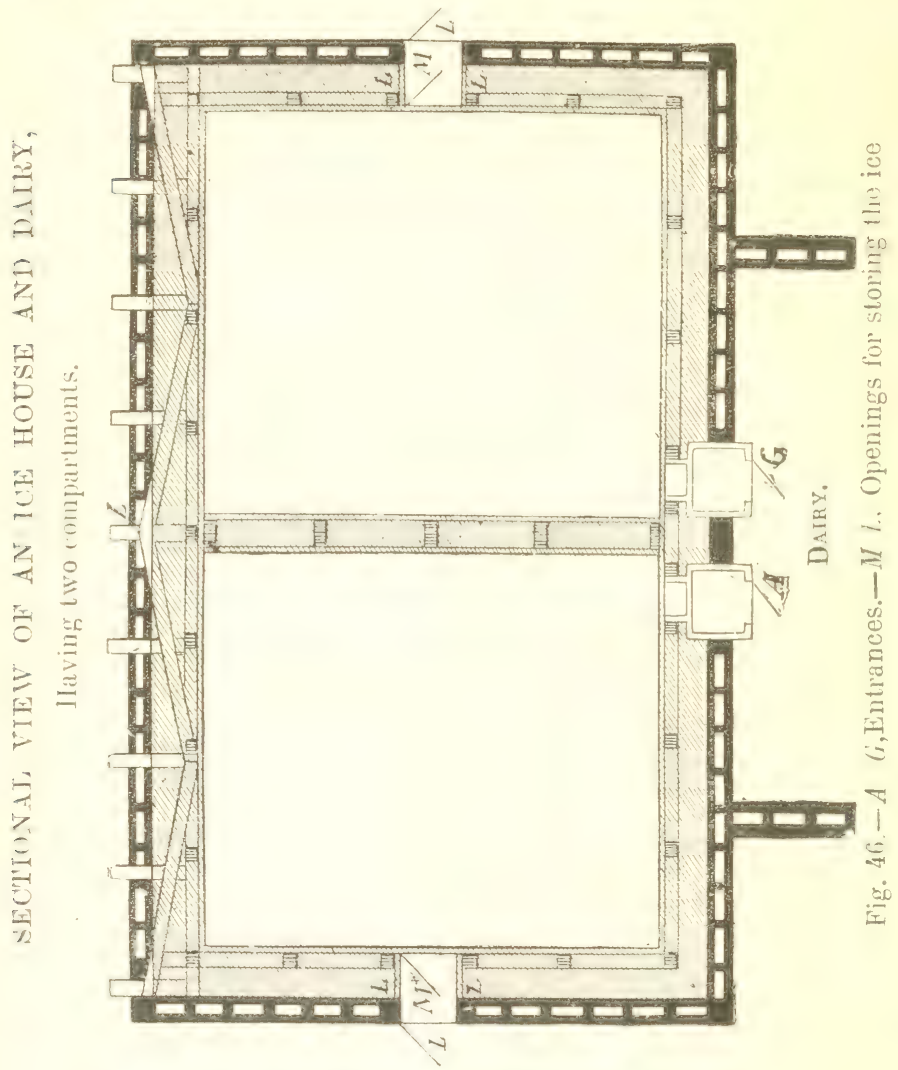

Where there is a domble root an in fig. th the air current

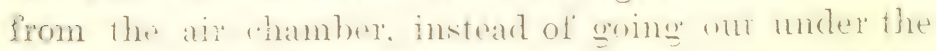

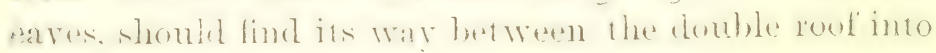
the ventilator at the to. 
In the case of a single roof, the air from the draught chamber should go out under the eaves.

In fig. 45 we have a loft floor differently constructed. In this case it is above the eaves, and offers more store room. It is laid on the collar beams. That part of the roof which extends from the eaves to the collar beam is provided with an outsile shell filled with dunnage. The space filled with saw-dust, is of the same thickness as the walls. In the centre of the loft floor is an opening for ventilation. (See fig. 45.)

THE DIVISION OF ICE H USES.

Large ice houses should be divided into two or four compartments according to the size (see fig. 45.) These divisions offer the double advantage of preventing draughts of warm air from spreading all over the house, and also of removing the insolating material from a section when necessary.

A house 50 feet long should be divided into two sections, and 100 feet long into four sections. The division wall should be doublè and filled with saw'dust.

\section{OPENINGS.}

Openings in the building for the deposit and removal of ice should be as few as possible. Too many of them weaken the structure whilst they afford additional facilities for the entrance of warm air and moisture.

\section{Large houses.}

In large ice houses one opening 4 feet wide, extending from the top to the bottom of the building should be made. This should be arranged so as to open in sections, 


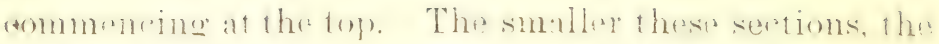

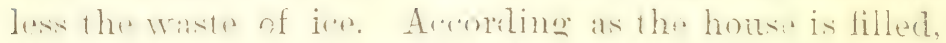

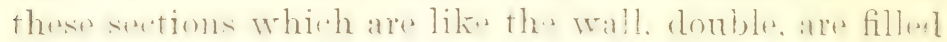
in with saw dust.

\section{Simall houses.}

For smoll housesan op 'ming, the lop ol whith should bes on a lerel with the lotifloor. and the bottom as tar ats
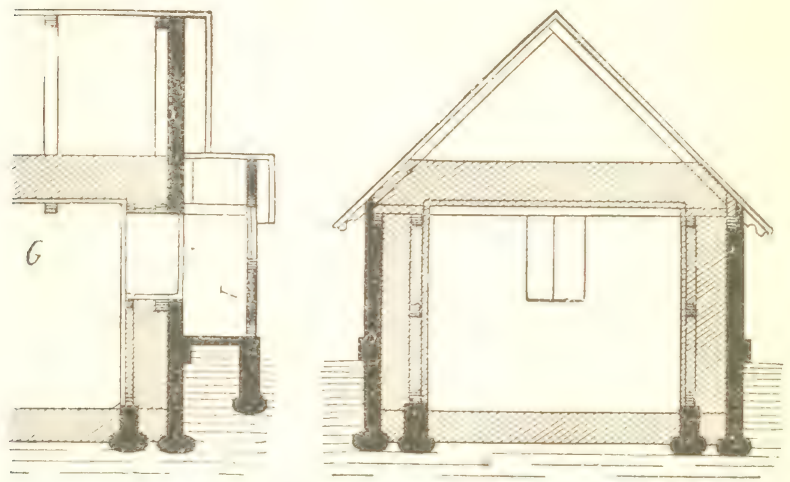

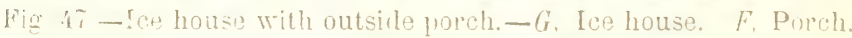

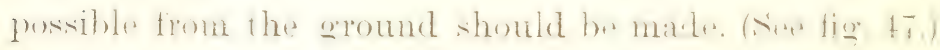
It shondel be moviderl with denble dents. When the

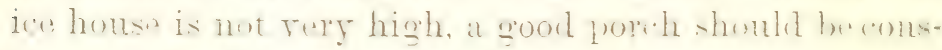
trueted. (See $F$, fig. 47. and $D$, fig. ji.)

Thus with the construction of a poreh as shown in fig. 47 and 51 , it is necessary to open three doors before entering the ice house. The first one is fixed on the inner ader of the opening made in the wall of the ice

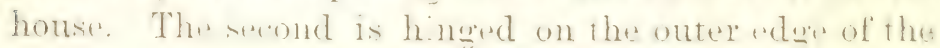

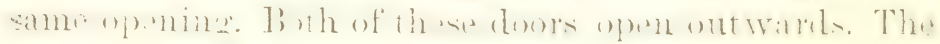
third one closes the porch. 


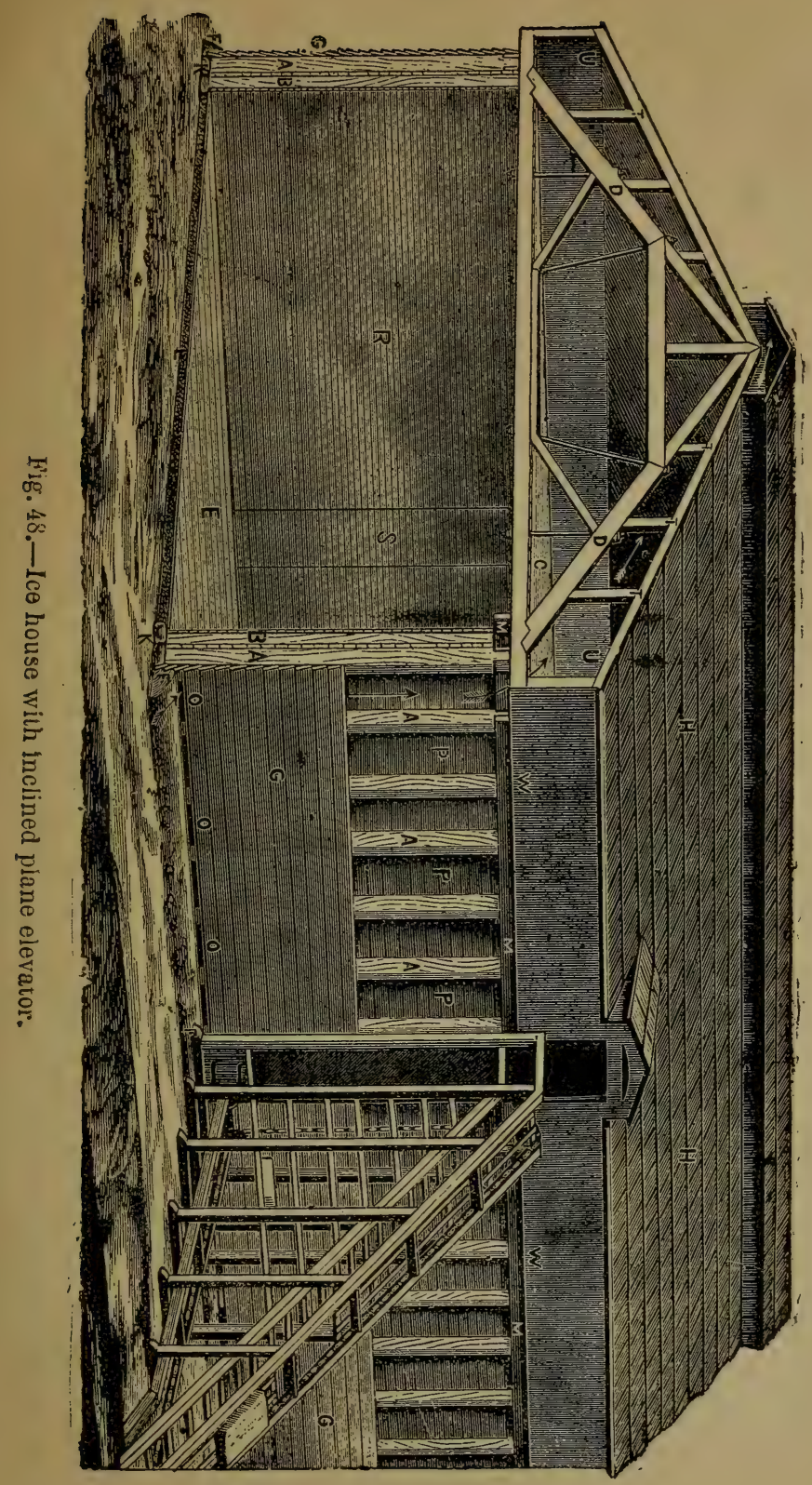


ICE IYOTSEA WTTH INCIINED PHAYED ETEVATORA.

On page 113 we give a cut of an ice house, with in. clined plane elerator.

A rupes nis the mulle I space of the outsile wall; B the filled sprace

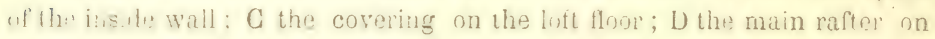
which the double roof bonrling is placed; E the floor of the ic house; F in emiankment of lint aromi the sill of the house, one foot ab), ve the

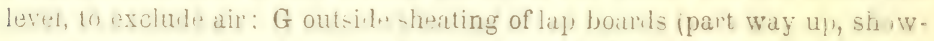
ing the miftlle boarding $P_{1}$ : II shingle roof: I Ventilator running the luighth of the peak of the roof, with opening: In stone foundation: $L$ a lill ny of the inche of charcoal or sibwlust unler the floor; M flatus placel edgewise on thr outsile ureright to allow the air to pass freely liom the botcom of the outsile wall of hruse to the ventiator at peak of the rof, and grive alditional slength: () optnings between each upright to almit coul nir at bottom and irife out the wisn; P midtle? sheating of gronved or worked boards: R upen end, showing insilw sheathing; $\mathrm{S}$ door way

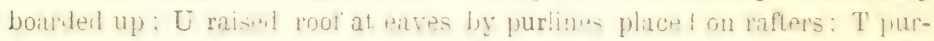
lines placed on rafters: W projection of roof, to prevent rata heating against sibles of house. Arrows shuw the current of arr frassing from openings at the buttom through untilled space A to rentiator at peak of poof, is

We give below a description with sut of the ice house, of Mr. W, G. Walton of Hamilton, whith is one of the best in the Dominion.

It stands at the water edge of Burlington bay, near G. T. R. Denot in th. ity of Hamilton, with siding from main line of $G$. T. R., for shipping purposes

It is $120: 100 \times 41 \mathrm{ft}$. high and has a storing rapa city of about 12,1000 tons. It is divided into four compartaents, and providel with a stam werator and gallerin, extending the whole length and huight ontside of the building.

The werator is driven by a 12 horse power engine.

For tilling this house a field of from $\frac{1}{4}$ to $\frac{3}{4}$ of a mile

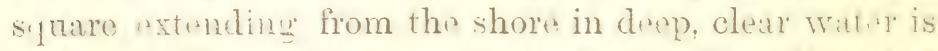
at hanl. The ice is plowed into block: $22 \times 30$ inchess

(1) From the lce Journal, Philalelphia 
and towed down to the elevator by horses in large rafts of 500 to 1000 blocks each, through a channel cut in the ice. It is then broken off, in single blocks, caught and carried up by the elevator.

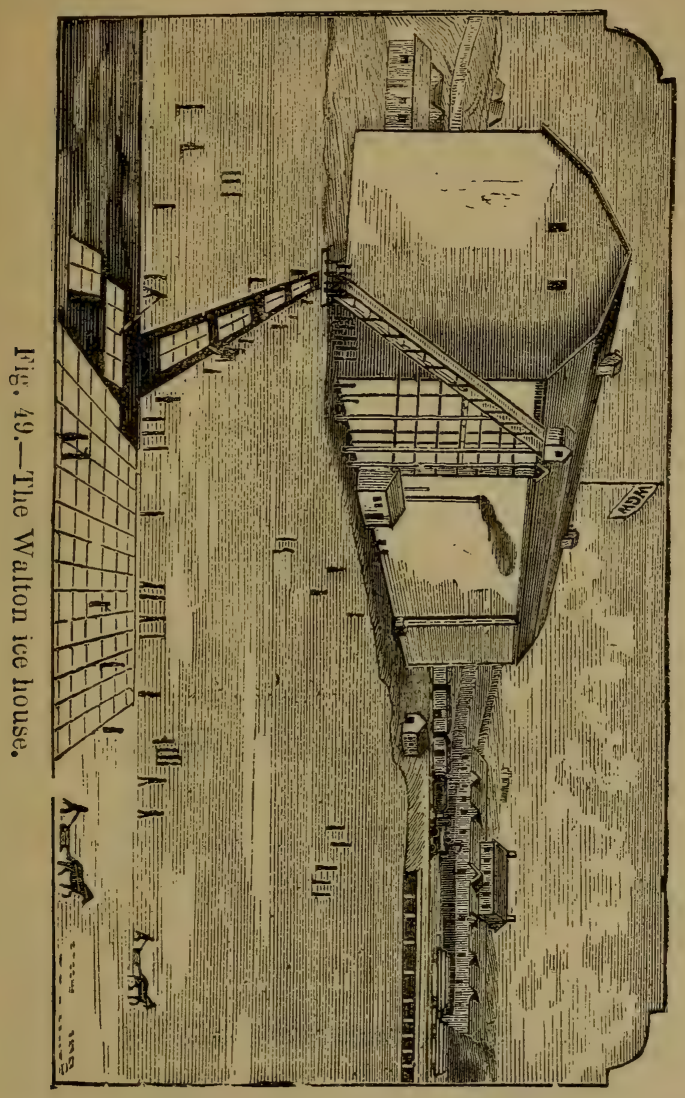

The elevator, galleries, and skids are so arranged tha? the ice is elevated to any gallery desired, and distributed to any room, and to any part of each room, without being handled until it is placed in position by the men 
Cars can tie loaded directly from the ice field, by the elorator and an?leries. Thus from one to two hundred tons of toe per hour, can be stored, or loaded ready to ship when disired. The house is also provided with two sets of automatie gig's for lowering the ice into cars or wagons. (1)

\section{IXCLIALD PLAYES. ELETATORS, SKIDS ADD HUINTAG TUSGO.}

\section{ETETATORS}

The mle is to mse inclined planes with elerntors (sec

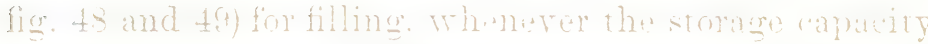

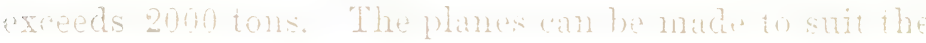

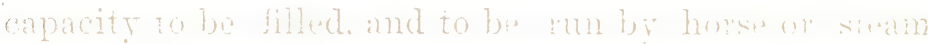

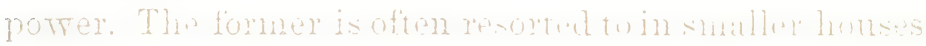
wepeially in cold climates, where the is ample tom tor har testing:

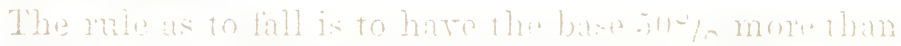

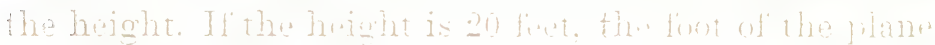

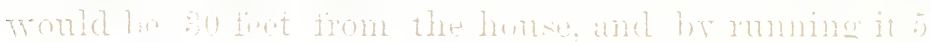

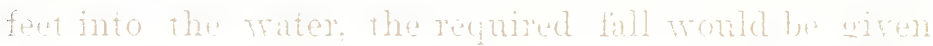

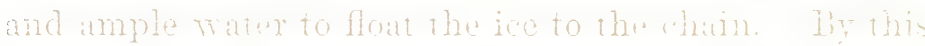
means, sereral hundredtoms of ice can be lifted 30 find it an hour:

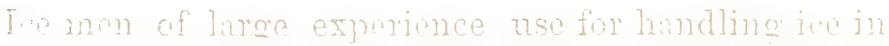
warce ice homses opmetally comstrueted skick or mus for moring in during the sumer and for loading it on wragons, cars or ships.

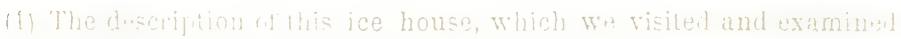
"mafully, Was hindig lunished by Mr. W. G. Walton. 
The skids may run in any direction in the ice house; so that the furthest blocks from the outside opening: may be run along the skids as well as those close to it. The ice can be lowered in self acting baskets or gigs, and emptied on the skids, which are so arranged as to reach the bottom of a car or the hold of a ship. By this means the ice is moved and loaded by its own weight, without any handling.

This method effects a great saving of time and labor, and reduces the breakage of the ice.

\section{HOISTING TONGS.}

In smaller ice houses, hoisting tongs fixed to a rope and pulley, are used for hoisting and lowering the ice. The pulley is strongly fixed over the opening of the ice house.

They can be worked by a horse.

DAIRY ICE HOUSES.

For convenience, of late years ice houses have been built close against dairies or creameries in order to utilize them for cold storage. In this case, the building should be put up towards the East or South East of the dairy, as the morning sun will absorb the dampness of the air.

Ice houses for dairy purposes are constructed on the same plan as those already described. The only things calling for remark are.

1st. The manner of entering.

$2 d$. 'The using of the meltage from the ice.

$3 d$. The manuer of utilizing the ice for cold storage. 


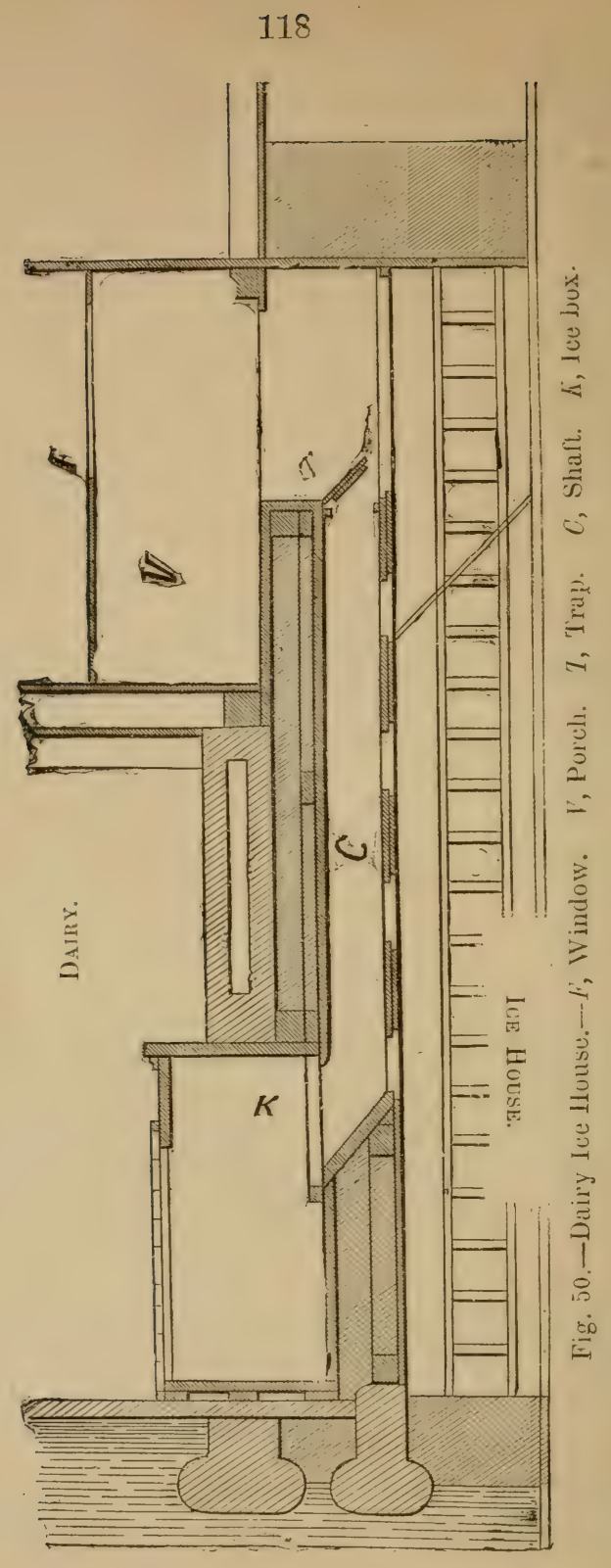


ENTRANCE OF DAIRY ICE HOUSES.

When ice houses are built close against the dairy or creamery, the entrance may be made in the upper. part, by building in the upper story of the dairy a porch joined to a passage opening directly into the ice house. (See fig. 50.)

It will thus be necessary to open two doors before entering the ice house proper. A window in the porch,

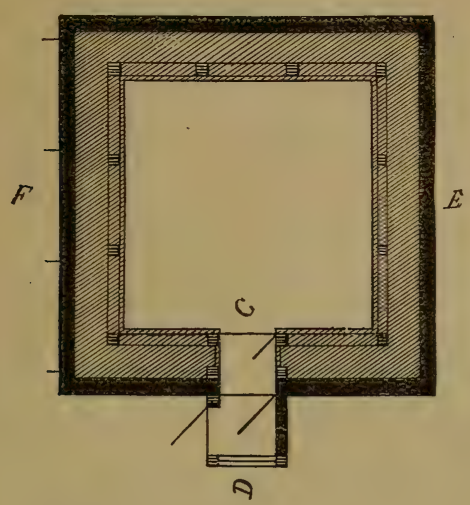

Fig. 51.-Ice house with porch.

will, when the doors are opened, allow the light to penetrate into the interior.

When the ice house is high, it is convenient to build directly under the opening, between the wall of the ice house, and that of the dairy, a shaft by means of which the ice may be thrown into a box, placed to catch it inside the dairy. (See fig. 50.)

The bottom of the shaft is covered with an iron plate, to protect it against the blows of the blocks of ice. The shaft is closed by means of a trap door. (See fig. 50.)

Opposite the shaft, and placed one above the other, 
in the walls of the house, are openings through which the ice may be taken out at any height, as the quantity diminishes in the ice-house. ( See fig. 50.)

In smaller ice houses, or.ice houses completely isolated, an outside porch may be built. (See D. C. fig. 51.)

\section{MELTAGE.}

In the chapter on floors, we have already described the method of utilizing the meltage from the ice in the dairy.

\section{THE CONSTRUCTION OF COLD STORE ROOMS AND FRLEZERS.}

COLD STORE ROOMS.

There are many methods of constructing cold store rooms. We shall deseribe a few of the best. The information here given has been derived from some of the largest users of cold storage in Montreal and elsewhere, as well as from the best builders and inventors.

All cold store rooms are built on the same principle.

The differences are differences of detail. This principle consists in placing the ice overhead, or alon! side of the building ; in some cases in placing it both along side and overhead.

Openings are then made either in the ceiling or sides, or both, to create an air current. They are arranged in such a manner that any warm air, which enters the apartment, immediately ascends to the cooling room above, where it is cooled and from which it returns in the shape of cold air.

We give below the description of an unpatented cold store room. 
The cold store room, for an ordinary size creamery, should be from about 12 to 15 feet square, and two stories high. The lower chamber should not exceed 7 feet in height. The top or ice chamber may be of the same length and breadth, but a little higher. In the case of a room $12 \times 12$ it should be about 8 feet high. Where economy is not a prime consideration, the ice chamber may with advantage be made higher.

The walls of such a building are like those of an ordinary ice house, but somewhat stronger to stand the pressure.

\section{MEANS OF PRODUCING THE AIR CURRENTS.}

In the ceiling of the cold store room, there should be, at right angles with the beams, two openings. When possible these openings should be, one on the side nearest to the door, and the other on the opposite side. One of these openings is called the hot air flue, the other the cold air fue. In our descripuon, the one nearest the door is the hor air fue. They sbouid be from 5 to 12 inches wide, according to the size of the room, and run the length of the building. They should be prorided with traps.

Both these traps should be hinged to the sides of their openings farthest from the walls. The one nearest to the door opens upward in the flue, the other one downward into the room, and when open is suspended from the ceiling. Along the split between the hinges of this latter on the lower side, nail a narrow strip of soft leather listing or cloth. This is to prevent the warm air rrom ascending between the trap and the ceiling into the coid air flue. These traps are used to regulate the temperature in the cold store room. They should be.provided with cords running through hooks, by 
means of which, they can he closid or openod as muib or as little as is necessary. (1)

It will be asy to muderotand, how the traps are arranwed. when it is remembered that to elose the on : in nhe hot an ilne, it is neassury to let go the rope, and to clowe the other it is necessary to pull on the roper.

The opming nenest to the deor is male to allow the warm air to aseend.

(1) the niprer thor, on the inmer ados of the warm wir flut. sonstru.t a double wall. whis holow spane of about 6 inche, whin shouhl be hlled wih saw tust. The woll should bu carried to whin 7 or 9 in ins of the tuy of the ice whmbr. If the ice is 12 teet high, the space may be increased to about a foot.

Ruming parallel with the pousul will, loy on the lloor, at 15 inches apret, a saries of stringers $3 \mathrm{in}$ ches thick wne of decreasing hight. Tha lighest, whe h should the sineher, is pland along sin of the parint wall. The lowest, which nerer should be lese thun 3 inches, is placed along the imer side of the cold nir Alue, and wilnin a foot of the edge. These stringers

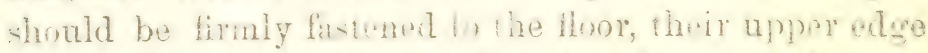
should be b.vellest so that il a board was laid upon then it would form an in ined plane. Fill in the space between the stringers with saw-dust.

Oror the stringers lay a flooring of boarls. We now have an inclined 11 m., the highest part of which is against. the wam an lint, ant th lowest point of which is near the edge of the cold air flue.

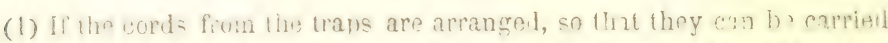
to the millthe of store rocm, the circulation can be incereased and the room

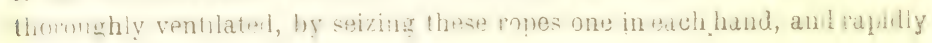
opening and closing the traps in succession. 
Cover this with sheets of zinc, thus producing a water tight floor. The edges of the zinc close to the walls should be turned up about 5 inches. The end nearest to the cold air thue should form a spout. From this spout a pipe is run to carry off the water.

Underneath where the sheets of zinc meet, a slat $1 \times 2$ inches is placed. The zinc is fastened to this and soldered. Upon this zinc floor, lay another series of stringers at right angles to the wall, cut in the shape of inclined planes; they should be 3 inches thick and placed 15 mches apart. The larger end (which should be 8 inches high) should be placed farthest from the packed wall, the smuller (which should be 3 or 4 inches high) touching it.

Across these, lay $3 \times 4$ inch stringers about 3 inches apart. On this bed of stringers, pile the ice.

There is now a vacant space over the cold air flue. This space must be arranged so as to allow the ice to be piled above, without closing it up completely, and without allowing the meltage to drop into the store room below. This is done in the following manner.

Upon the beams, which have been uncovered by the opening made in the floor, place on end, ag'ainst the wall, pieces of wood $3 \times 4$ inches and about 14 inches high. Resting on the top of these pieces, and also on the inclined planes, which come directly orer the zinc, place on edge pieces of plank 3 inches thick 15 inches high at one end and $14 \frac{3}{ \pm}$ inches at the other, and 30 inches long, or of less length according to the size of the opening in the floor.

Cover the top of this frame work with 3 inch planks, over which sheathe with zinc; the edges of this zinc 
should project about 3 inches, so as to allow the meltage to drop into the spout formed by the larger zinc.

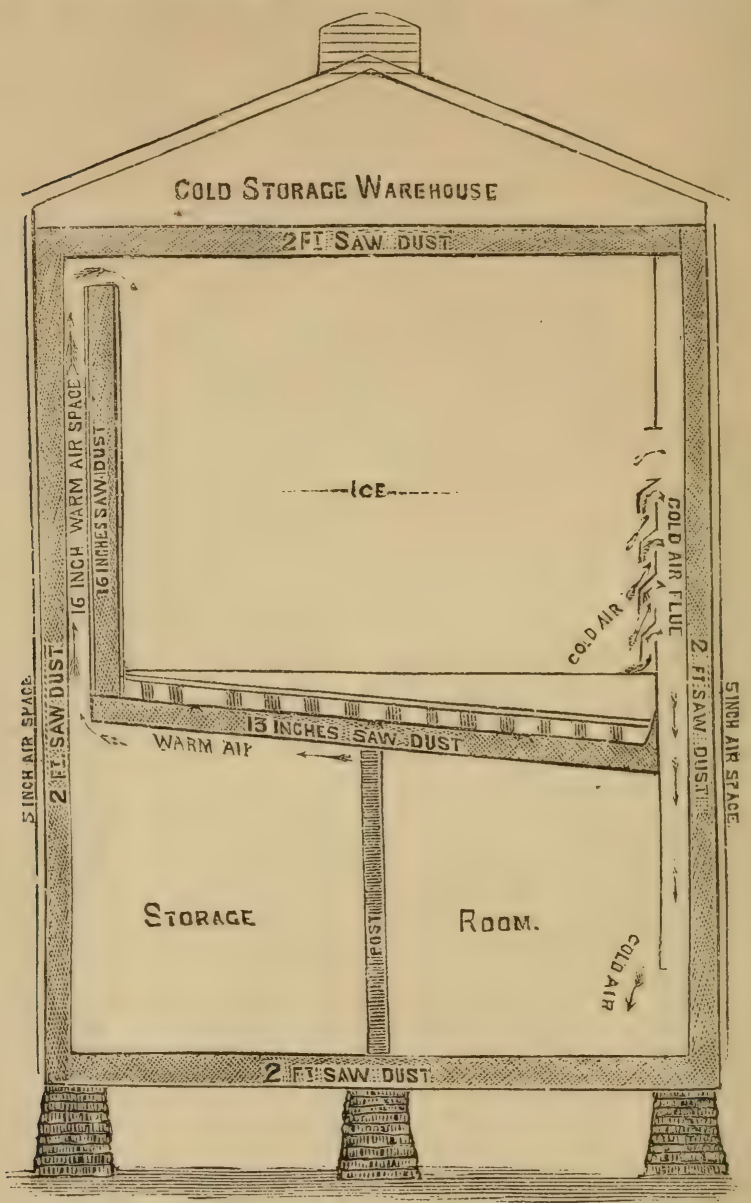

Fig. 52.

Cut No 52 represents a cold store room on another plan. In this the floor of the ice chamber and the ceiling of the store room are both inclined. This is an ad- 
vantage. The warm air always seeks the highest part of the room. It is therefore evident, that it will grar.ually find its way to the warm air flue.

On the other hand, the cold air flue is continued to within a few feet of the floor of the store room. This continuation prevents the formation of a double current in the cold air flue, and helps to cause a complete circulation. By looking at the figure it will be seen that the cold air flue is carried up to the ceiling. Openings in the side of it allow the cold air to descend. A glance at the figure will make clear the position of the inclined plane stringers, which are placed at right angles to the packed wall, 3 inches apart and serve to form a level surface upon which the ice is piled. Without this precaution much of the weight of the ice would come upon the partition of the cold air flue.

In building a floor, such as is seen in figure 52, the beams should be put in as in an ordinary building. We have already described on pages 122 and 123 how the slant is obtained.

When the room intended for cold storage is built against the ice house, two openings are made through the walls of the latter, one close to the floor, and the other close to the ceiling of the store room. By this means, cold air is constantly pouring into the store room. The openings are provided with sliding covers by which the current can be increased or diminished at will, thus regulating the temperature.

When it is desired to build a cold store room withour having the ice house over head, and without making openings in the sides of the ice house, proceed in the following manner:

Build the room for cold storage as close as possible to 


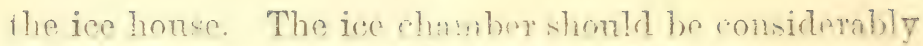
smaller than the room to be cooled. Of conrse, the size depenuls on the temperature reguind in the room. For a temprature of ahout $55^{\circ}$ Fahr, the size of the ices chamber shonld be about $\frac{1}{10}$ of the size of the room to be conded, but this ice chamber will have to be filled every 10 or 15 days.

To cool a rom $12 \times 12,7$ feet high, the ice chumber would be a box whose length breadth and height, would bes is fort. It would contain 12.5 abic fint of ice. This would tak ahout $2 \frac{7}{2}$ tons of 1 ce erery 10 or 15 days, Th. ice chamber should be settled in the same manner as in the store rooms alreary described.

The meltag from the ice may be utilized as a cooling agent for different purposes.

Mr . Tos laril of Montreal is the patentin of an excellon systrm of cold striag and freezers. If. his alyady constructed a large number of these for butchers, produce dealers, dairy-men and others.

In his system the ceiling is sloped as in fig. 52. Thr re are two cold air flues situatnd, one at each end of the building, and one hot air fite at one sille. The partiinons of the cold air flues are carrind dorn a certain distance below the ceiling into the store room.

The ice chamber is provided with a zine corered lloor slichty in lined. At the inner edges of the rold air Hues. an open frame work runs up to the ceiling. This prerents the ice from dropping into these openings, and allow the air to cineulate fredy. This system is very effective.

FREFZFRS.

Freagers are construted in the following manner: The room should be iow, and the smaller the better. 
The walls should be well built and thick. It should be provided with double doors and an ante-room. The doors should be provided with weather strips.

Along the ceiling; on at least three sides, make an opening. Above this opening, in the ice chamber, fit a water tight trough, from the bottom of which, at intervals, pipes should be run into the chamber below. The diameter of these pipes should be equal to that of an ordinary stove pipe. The lower ends of these pipes should be conical in form and come close to the floor. They should be connected at their lower extremity with an outlet pipe, to carry off the meltage from the ice.

The greater the degree of refrigeration required, the greater should be the number of these pipes, and in some cases it is necessary to run a certain number from the midle of the ceiling, as well as those we have already described around the walls. The central ones may be, when necessary, much larger and if oval shaped are more effective.

The upper chamber should be as low as possible (the lower the better). Into the troughs, which should be provided with packed covers, as well as packed sides, the ice is thrown, after having been broken quite fine and mixed with salt. The quantity of salt is from 8 to 10 per cent. of the quantity of ice.

\section{CHEAP ICE HOUSES.}

A family ice house need not be an expensive structure. It may be built cheaply, and serve its object excellently. A building of 12 feet square and 9 feet high is sufficient for the wants of the most exacting family.

It may be a frame building entirely above the surface 
of the ground (better still if supported on posts elevated a few inches, to be certain of good drainage, built of joists 2 or 3 inches, with an outer boarding, having inside another series of uprights, also boarded, from 6 to 10 inches removed from the outer shell, and a solid floor of plank. Fill the space between the two walls with tan bark, saw dust, swamp moss, etc.; put on a roof of good pitch, and the ice house is complete.

A drain for water should be made from the floor, and the pitch of the roof filled with straw, hay or similar dry porous material. On the roof should be a rentilator, the top defended from the rain. The ice shorld be packed in one solid mass, the sides not reaching the inmer walls of the building, but allowing a space of from 12 to 6 inches all round.

The top of the ice sinould be covered with straw, and the doors should be like the sides of the building, or double doors should be made, one in the outer and the other in the inner wall.

Two workmen, if not practical carpenters, can put up such a building in one or at most two days. It will prove a useful adjunct to the farm and dairy. It is very useful as a refrigerator on a large scale for preserving food.

It costs but a little to build an ice house, that will keep ice the year round, where practical utility only is aimed at, and not elegance of structure.

A writer on this subject, thus tells how he constructed an ice house. I set posts in the ground so as to make a house 12 feet square (three posts on each side), then I boarded it up 8 feet high on the outside. I hen dug out the surface earth 6 inches deep, and filled in with saw dust, one fout deep, making it 6 inches above the level of the earth. 
I packed the ice carefully, 9 feet square and 6 fect high, leaving a space of 18 inches between the ice and boards, which I closely packed with sawdust. I placed the same thickness of sawdust orer the ice. I have a board roof over this ice house, the space abore the saw dust is left open so that the air can circulate through. The result is that we have used ice daily and have plenty yet. As to the cost, four men with one team cut, hauled and packed the ice, and filled in the sawdust in less than two days. We had to hanl the ice $\frac{1}{2}$ a mile.(1)

\section{KEEPING ICE IN BARNS, SHEDS OR IN STACKS.}

\section{IN BARNS OR SHEDS.}

Ice will keep in a harn or a shed, when properly packed. In the first place skids, small stones and sawdust are laid down for foundation and drainage.

The ice is piled in a bed of snow to prevent the air from reaching it. It is then surrounded and covered with 18 inches of well packed sawdust, or three feet of hay or straw.

\section{IN STACKS.}

Construct a pen near a pond, or a stream, where the ice is to be gathered. If such a site is not to be had choose a convenient spot outside of droppings from roofs, always making provision for drainage.

The pen may be made of rails 12 feet long or of any desired length. The larger the pen, the better the ice will keep. Lay up two rails upon each of the four sides, make the bottom level, and cover it a foot or more with sawdust, tan or straw etc.

(1) Youman's Dictionary of every-day wants. 
C'ut the cakes of ice in the usual manner and pack them closely, filling the interstices with pound.d ice. Pack the outside with a font of straw, saw-dust or other material, and put up the fence as the pile risis. The pile can be conveniently made from 8 to 12 feet high.

Cover the ice with at least 18 inches of saw-dust, or two feet of straw or hay trodden down closely, make a roof of boards, or slabs, slinting to the North, sufficiently steep to shed water, and fasten with a fiew nails.

\section{AN ICE BOX.}

In connection with such a start, a cheap ice hox made with double sides, and packed with sawdust will be wanted. The ice chamber should be about 2 feet long, 2 feet deep and 18 inches wide. This will hold a single cake of ice weighing one hundred pounds, or more and leave room on the top for cold storage.

If the stack is not disturbed more than once or twice a week, it will probably supply the family through the summer with an abundance of ice.

As the stack diminishes, are nutust be taken to see that it is kept closely packed.

\section{THE OPENING OF AN ICE FIELD.}

YOR LARGE ICE HOUSES.

On rumning water, cutting a hole in the ice and dump. ing the snow into it, is a very good plan.

On still, shallow water it is impracticable as the hole will soon fill up with the sinking of the snow to the bottom If banked up on the field it may, in some places, sink the ice, and let the water on 
When the snow is loose, it can often be got rid of, by rumning a $V$ scraper or snow plough, thus throwing the snow into the water. But this method is only available, where there is only one elevator to feed. In very large ice houses it is too slow.

A goud way, to dispose of this greatest of nuisances, is to run it ashore in scoops made for this purpose.

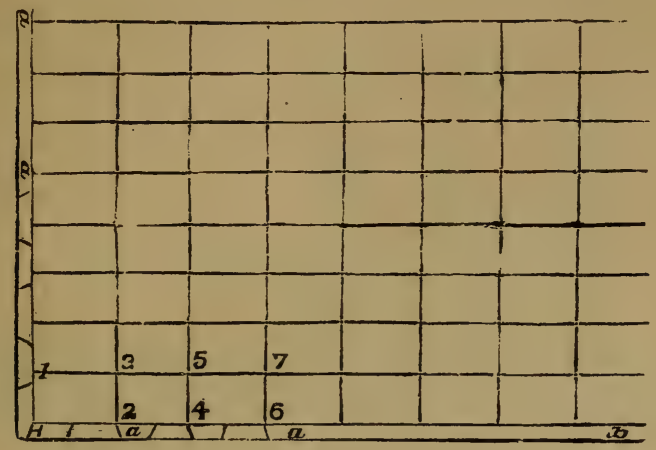

Fig. 53.- Ice field marked in blocks.

The field is marked with rery ingenious ice markers driven by horses. It is then furrowed to a certain depth, with specially constructed ice cutters called ploughs,also driven by horses.

FOR SMALL ICÉ HOUSES.

Having chosen a place where the ice is clear and sound clear off the snow. Then with a plank, 12 feet long and 10 inches wide, to serve as a ruler and a chisel, mark off the field something like a checker board. Making the blocks 20 inches long, by 40 wide. (See fig. 53.) Enough should be marked at a time for a day's work.

Having made a hole in a corner with an axe, sufficiently large to pass a saw, saw one block, push it 


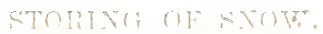

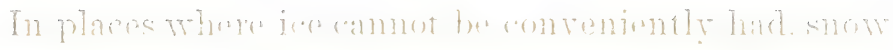

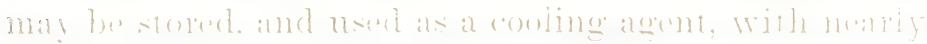

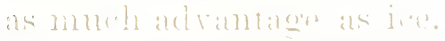

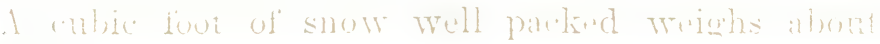
tis ilis.

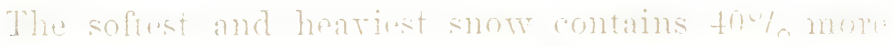

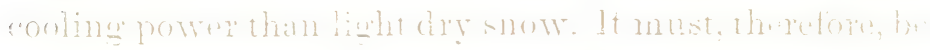

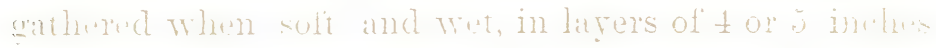

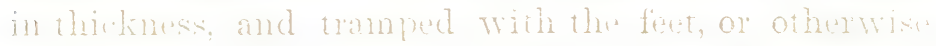

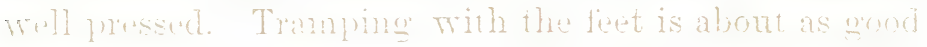

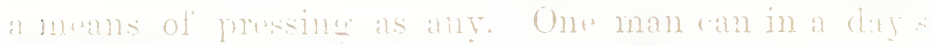

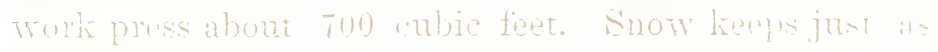
$[1+1]$ as ire.

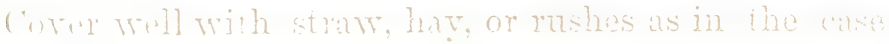

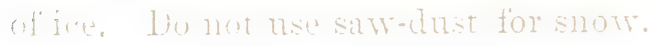

\section{(AFNERAL REMARKS OX JCE HUETES.}

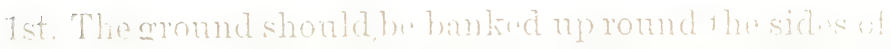

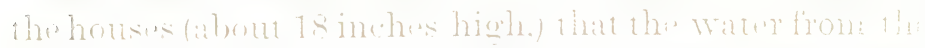

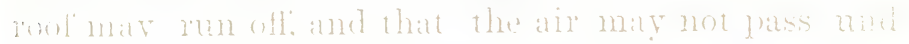

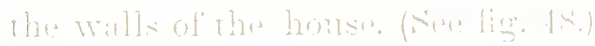

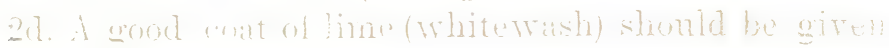

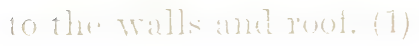

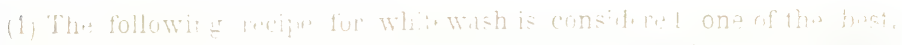

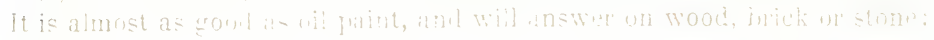

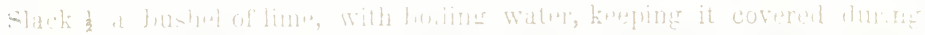

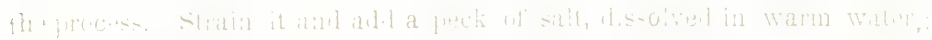

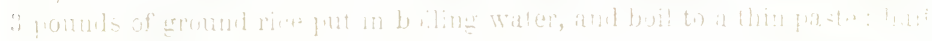

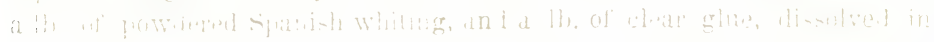

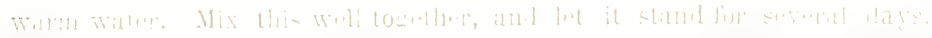

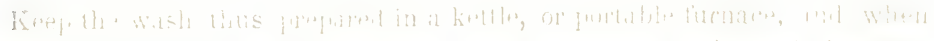

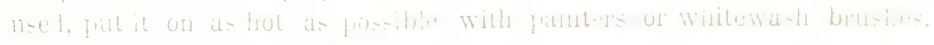


3d. See that the ice is kept air tight as much as possible and to effect this, close up any chinks or crannies in the walls or floor, and keep the covering on the ice and floor of the loft.

4 th. If the house is not to be opened until the end of the season. dispense with ventilation in the ice chamber $y$ closing up the aperture in the loft floor, and keep e room close.

5 th. If the house is opened frequently, supply ine ice chamber with ventilation, to carry off the moisture produced by the warm air admitted, when it is opened. 6 th. Go over the house carefully from time to time, and see that every thing is right inside, and check anything that may be amiss.

\section{Tre END.}




\section{LATEST IMPROVED}
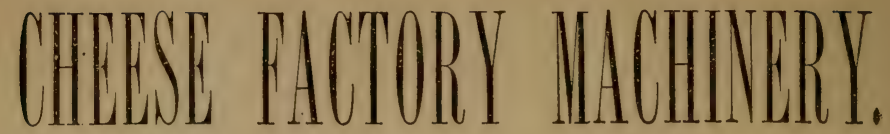

Any appliance which improves the quality and quantity of the VERY important product of our country, "CHEESE," should be adopted by all who wish to progress and keep pace with this age of ad ancement.

The following articles for use in the handling of milk by the Dairyman and manufacture of Cheese by the Factoryman, are offered to the Public as an advance on all previous articles user for the purpose, and a trial of same is solicited.

\section{MACPHERSON'S PATENT MILK COOLER, FRATOR AND STRAINER}

Will reduce the temperature of FRESH WARM milk twenty to forty degrees-thoroughly strain-and at the same time thoroughly air the milk, which is one of the most important factors for preserving the milk sweet and pure for delivery at the Cheese Factory or to families in the city, and at the same time put the milk into the milk can. This is all done by one operation, without labour or attention.

City millimen are specially asked to give it a trial.

\section{MACPHERSON'S PATENT CURD MILL.}

A machine taking the precedence of all others, LIGHT RUNNING. RAPIUITY AND QUALITY OF WORK DONE, all commends itself for approval by practical Cheese Makers.

\section{MACPHERSON'S PATENT CURD AND MILK STIRRER.}

A very valuable implement used in the manufacture of cheese for stirring the milk in the cheese vat and curd while heating. Will increase the quantity of curd from o.e to three per cent., and give a much better quality. A saving of hundreds of dollars has been effected by its use in one factory.

A trial of these articles is solicited, and a sample machine will be sent (on trial) to any part of the country by applying to

\section{M. MACPHERSON,}

Proprietor of Allan Grove Cheese Combination, LANCIASTER, ONTARIO. 


\section{TABLE OF CONTENTS.}

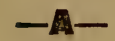

PAGES

A hlborn Milk Heater ...................................................... 42

Analysis of the Butter Milk............................................. 60

Analysis of the Butter ................................................... 60

Analysis of the Skim Milk ................................................ 60

Advantages of the Shallow P $:$ S System ................................ 63

"، " Deep Setting ................................................. 65

" " $\quad$ Deep Setting in Ice....................................... 66

" " $\quad$ " the Cream Gathering System ............................. 69

" " Churning the Whole-Milk .............................. 71

" " the Centrifugal System .................................. 71

Advice to intending purchasers of Centrifugal Milk Separators....... 79

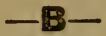

Burmeinster \& Wain Milk Separator .................................. 24

" " " " Capacity and Speed ................ 25

" . " " " " "

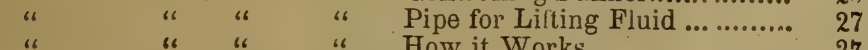

." " " " "

Best Material for an Ice-House ..................... 29

Bottom of an Ice-House ................................................... 103

Cream .................................................................... $\quad 5$

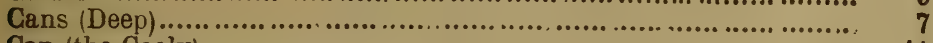

Can (the Cooly) .............................................................. 14

Creamers of Different Description.......................................... 13

" " " " The Hardin ............................... 13-14

" " " " The Cooly .................................. 15

" " . " " The Ferguson Bureau ..................... 15

" " " " " The Little Gem ..........................15-16

" " " " The Home .............................. 17

" " " " The Kellog................................... 16

Cream Gathering System (The) ............................................ 18

Gream Gathering or Fairlamb can ...................................... 18

Gream Cooler (Fjord's) ..................................................... 44

Centrifugal force (Definition of the) ...................................... 21

Controlling Funnel (Fjords.) ................................................. $\quad 26$

Controller for Testing Milk (Fjord's) ................................... 46 


\section{$-6$}

PAGES.

Comparison of the Cooly with other Systems .........................49-50

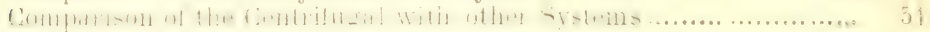

Concluding remarks on the dillirent Systems......................... 63

Cabinst Creamers. Vats, Pans etc................................ 13-69

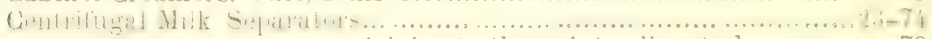

\begin{tabular}{|c|c|c|c|}
\hline “ & .. & "6 & Alvice to those intending to buy......... \\
\hline “ & "6 & " & Points of a good ................ \\
\hline " & 66 & “ & Defects of $\ldots . . . . . . . . . .$. \\
\hline " & "6 & "6 & Powver requirad to rlrive... \\
\hline « & " & 6 & Things to be remembered in using... \\
\hline « & « & " & dlle: of ditfirent \\
\hline
\end{tabular}

Capacity of Milk Separators.........................................

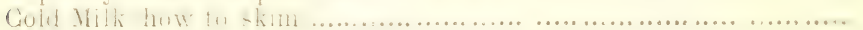

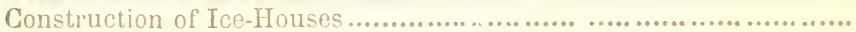

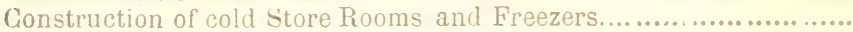

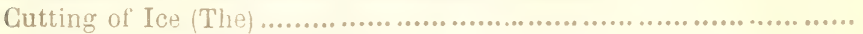

Cost of Cutting and Storing Ice........................................ 133

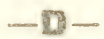

I), n., Cins

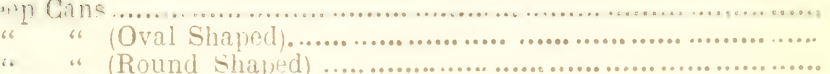

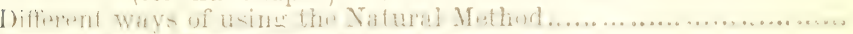

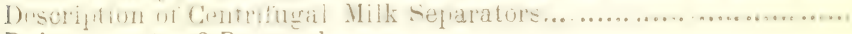

Dairy experts of Denmark..............................................

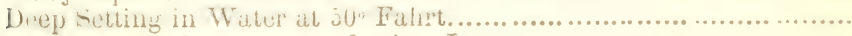

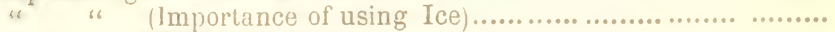

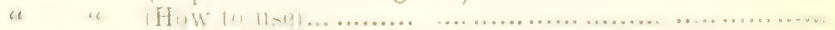

Disadvantages of the Shallow Pan System...............................

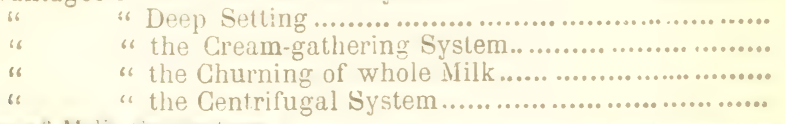

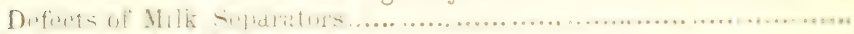

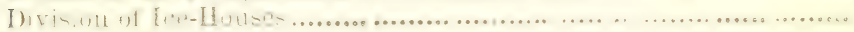

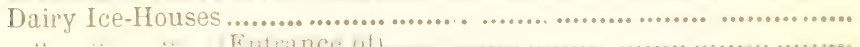

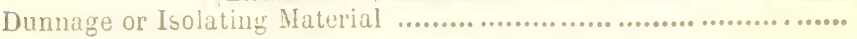

Elevators for Ice-Houses ..................................................

Entrance of Dairy Ice-Houses ....................................... 119

Effects of the heating of milk on the quitity of the Butber. ........... 3? - an

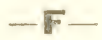

Ferguson Bureau Creamer....

Fatilituh Mll! Giln... 
Ice Houses and their construction

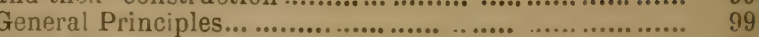

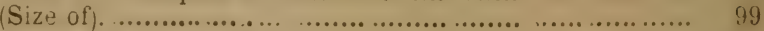

Site and drainage of ............................................. 102

Best material for ............................................. 103

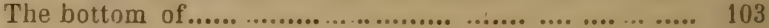

Foundations of ............................................ 104

Flooring of ........................................... 104

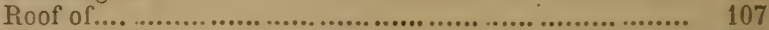

Ventilatorsof.................................................. 107

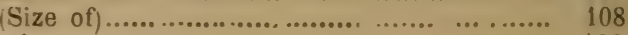

Loft Floors of .................................................... 108

Division of ...................................................... 111

Openings of ................................................. 111

With inclined planed elevators ................... $113-114-115$

" " " $\quad$ For the Dairy ............................................... 117

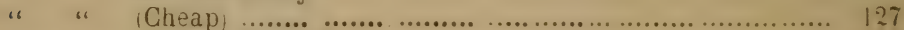

" .. General Remarks on .................................... 134

Inclined planed elevators............................................ 116

Ice kept in Barns, Sheds or Stasks ................................ 129

Ice-Box............................................................ 130

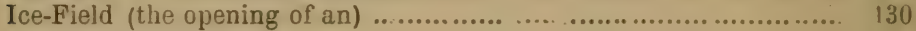

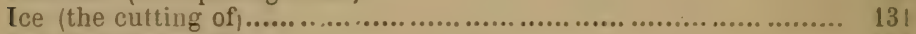

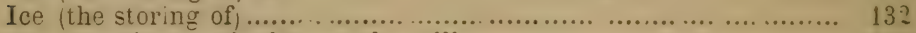

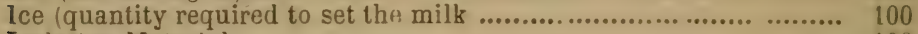

Isolating Material ..... ............................................... 133

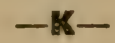

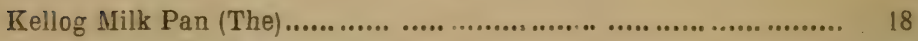

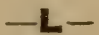

Little Gem Greamer ................................................. 15-16

Laval Milk Separator (De) ..... . .................................. 30

Lefeldt Milk Separator............................................... 33-34-35

Loss of butter from heavy Milk, set in deep cans ....................... 5 i

Loss of butter from cooled or transported Milk ..................... 57

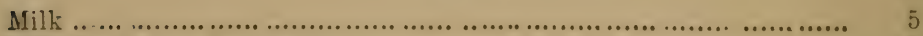

Milk, heavy, its causes ...................... ….....................

Milk. Whole ............................................................

" When it should be set...................................................... 6-21

". Vessels .................................................................... 7

"Ves $s$ els (how made) ...................................................... 8

“. Pan. The Marquis ............................................... 17

" " The Kellog................................................. 16

“ ، The Fairlamb ......................................... 18 
Milk Heater (Ahlborn's) $.42-43$

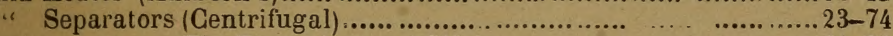

" " The Burmeinster \& Wain.............................. 24-25

" " De Laval............................................30-31

" " The Lefeldt................................... $33-34-35$

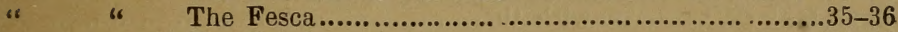

" " The Nakskov .............................................

" " The Henrich Petersen Shale Machine,..... .....38-39-40

" " The Herman Pape Machine ...........................40-41

Methods of skimming Milk ............................................. 6

Methods, the Natural used in different ways ..................... 21

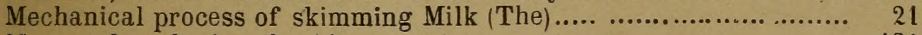

Means of producing the Air currents............................... 121

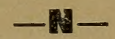

Nakskov Milk Separator ......................................... 36-37

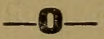

Openings of Ice-Houses......................................... 111

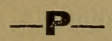

Proportion of Butter fat in whole Milk ............................. 6

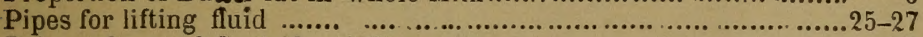

Points of a good Centrifugal Separator........................... $\quad 79$

Power required to drive Milk Separators............................... 80

Power required to drive the Burmeinster \& Wain \& De Laval Milk Separators

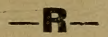

Requisites of the Natural Method .................................... 7

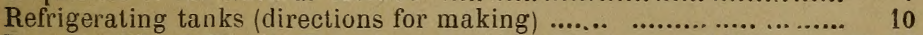

Results of Prof. Fjord's Experiments on the Skimming of Milk........53-59

Remarks on the different Systems.................................. 63

Remarks on the use of Animal power required in running Centrifugal

Milk Separators................................................... 81

Roof of an Ice-House.................................................. 107

Remarks on Ice-Houses ........................................... 134

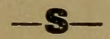

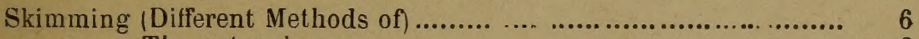

" The natural process....................................... 6

" The First and Last Contents of the Burmeinster \& Wain Milk Separator.......................................28-29

Shallow pans..................................................... $7-63$ 



\section{LIBRARY OF CONGRESS}

||||||||||||| |||||||||||||||||||||||||||||||||

|||||||||||||||||||||||||||||||||||||||||||||||||||||

00008910133 